\title{
Energy and Emissions Saving Potential of Additive Manufacturing: The Case of Lightweight Aircraft Components
}

\author{
Runze Huang ${ }^{1}$, Matthew Riddle ${ }^{2}$, Diane Graziano ${ }^{3}$, Joshua Warren ${ }^{4}$, Sujit Das ${ }^{4}$, Sachin Nimbalkar ${ }^{4}$, Joe Cresko $^{5}$, and \\ Eric Masanet ${ }^{1} *$ \\ 1. McCormick School of Engineering and Applied Science, Northwestern University, 2145 Sheridan Road, Evanston, \\ Illinois, USA \\ 2. Energy Systems Division, Argonne National Laboratory, 9700 South Cass Avenue, Argonne, Illinois, USA 60439 \\ 3. Global Security Sciences Division, Argonne National Laboratory, 9700 South Cass Avenue, Argonne, Illinois USA \\ 60439 \\ 4. Oak Ridge National Laboratory, 1 Bethel Valley Road, Oak Ridge, Tennessee, 37831 \\ 5. Advanced Manufacturing Office, United States Department of Energy, 1000 Independence Avenue, SW, \\ Washington, DC, USA 20585 \\ * Corresponding author. Tel: +1 847467 2806; email: eric.masanet@northwestern.edu
}

\begin{abstract}
Additive manufacturing (AM) holds great potential for improving materials efficiency, reducing life-cycle impacts, and enabling greater engineering functionality compared to conventional manufacturing (CM), and AM has been increasingly adopted by aircraft component manufacturers for lightweight, costeffective designs. This study estimates the net changes in life-cycle primary energy and greenhouse gas emissions associated with AM technologies for lightweight metallic aircraft components through the year 2050, to shed light on the environmental benefits of a shift from CM to AM processes in the U.S. aircraft industry. A systems modeling framework is presented, with integrates engineering criteria, lifecycle environmental data, aircraft fleet stock and fuel use models under different AM adoption scenarios. Estimated fleet-wide life-cycle primary energy savings at most reach 70-173 million GJ/year in 2050, with cumulative savings of 1.2-2.8 billion GJ. Associated cumulative GHG emission reductions were estimated at 92.1-215.0 million metric tons. In addition, thousands of tons of aluminum, titanium and nickel alloys could be potentially saved per year in 2050 . The results indicate a significant role of AM technologies in helping society meet its long-term energy use and GHG emissions reduction goals, and highlight barriers and opportunities for AM adoption for the aircraft industry.
\end{abstract}

Keywords: additive manufacturing, life cycle assessment, lightweight aircraft, energy saving, greenhouse gas emissions 


\title{
Energy and Emissions Saving Potential of Additive Manufacturing: The Case of Lightweight Aircraft Components
}

\author{
Runze Huang ${ }^{1}$, Matthew Riddle ${ }^{2}$, Diane Graziano ${ }^{3}$, Joshua Warren ${ }^{4}$, Sujit Das ${ }^{4}$, Sachin Nimbalkar ${ }^{4}$, Joe Cresko ${ }^{5}$, and \\ Eric Masanet ${ }^{1}$. \\ 1. McCormick School of Engineering and Applied Science, Northwestern University, 2145 Sheridan Road, Evanston, \\ Illinois, USA \\ 2. Energy Systems Division, Argonne National Laboratory, 9700 South Cass Avenue, Argonne, Illinois, USA 60439 \\ 3. Global Security Sciences Division, Argonne National Laboratory, 9700 South Cass Avenue, Argonne, Illinois USA \\ 60439 \\ 4. Oak Ridge National Laboratory, 1 Bethel Valley Road, Oak Ridge, Tennessee, 37831 \\ 5. Advanced Manufacturing Office, United States Department of Energy, 1000 Independence Avenue, SW, \\ Washington, DC, USA 20585 \\ * Corresponding author. Tel: +1 847467 2806; email: eric.masanet@northwestern.edu
}

\section{Highlights}

- We estimate the energy and GHG saving potentials of AM lightweight aircraft parts

- Model includes adoption estimation, LCl, fleet stock and scenarios through 2050

- Total fleet-wide life-cycle primary energy savings potentials is 1.2-2.8 billing GJ

- Associated cumulative emission reduction potentials of $\mathrm{CO}^{2}$ is $93-217$ million tons

- Thousands tones of $\mathrm{Al}, \mathrm{Ti}$ and $\mathrm{Ni}$ alloys could be saved per year in 2050 


\title{
Energy and Emissions Saving Potential of Additive Manufacturing: The Case of Lightweight Aircraft Components
}

\author{
Runze Huang ${ }^{1}$, Matthew Riddle ${ }^{2}$, Diane Graziano ${ }^{3}$, Joshua Warren ${ }^{4}$, Sujit Das ${ }^{4}$, Sachin Nimbalkar ${ }^{4}$, Joe Cresko ${ }^{5}$, and \\ Eric Masanet ${ }^{1}{ }^{*}$ \\ 1. McCormick School of Engineering and Applied Science, Northwestern University, 2145 Sheridan Road, Evanston, \\ Illinois, USA \\ 2. Energy Systems Division, Argonne National Laboratory, 9700 South Cass Avenue, Argonne, Illinois, USA 60439 \\ 3. Global Security Sciences Division, Argonne National Laboratory, 9700 South Cass Avenue, Argonne, Illinois USA \\ 60439 \\ 4. Oak Ridge National Laboratory, 1 Bethel Valley Road, Oak Ridge, Tennessee, 37831 \\ 5. Advanced Manufacturing Office, United States Department of Energy, 1000 Independence Avenue, SW, \\ Washington, DC, USA 20585 \\ *Corresponding author. Tel: +1 847467 2806; email: eric.masanet@northwestern.edu
}

\begin{abstract}
Additive manufacturing (AM) holds great potential for improving materials efficiency, reducing life-cycle impacts, and enabling greater engineering functionality compared to conventional manufacturing (CM), and $\mathrm{AM}$ has been increasingly adopted by aircraft component manufacturers for lightweight, costeffective designs. This study estimates the net changes in life-cycle primary energy and greenhouse gas emissions associated with AM technologies for lightweight metallic aircraft components through the year 2050, to shed light on the environmental benefits of a shift from CM to AM processes in the U.S. aircraft industry. A systems modeling framework is presented, with integrates engineering criteria, lifecycle environmental data, aircraft fleet stock and fuel use models under different AM adoption scenarios. Estimated fleet-wide life-cycle primary energy savings at most reach 70-173 million GJ/year in 2050, with cumulative savings of 1.2-2.8 billion GJ. Associated cumulative GHG emission reductions were estimated at 92.1-215.0 million metric tons. In addition, thousands of tons of aluminum, titanium and nickel alloys could be potentially saved per year in 2050. The results indicate a significant role of AM technologies in helping society meet its long-term energy use and GHG emissions reduction goals, and highlight barriers and opportunities for AM adoption for the aircraft industry.
\end{abstract}

Keywords: additive manufacturing, life cycle assessment, lightweight aircraft, energy saving, greenhouse gas emissions 


\section{Introduction}

Additive manufacturing (AM) has been defined as "the process of joining materials to make objects from three-dimensional model data, usually layer upon layer"[1]. After many years of development, AM has evolved from applications mostly limited to rapid prototyping of polymeric objects to commercial production of both polymeric and metallic components in a number of different industries[2-4]. Early adopters include the aerospace, medical, and automotive industries, which use a variety of different polymers and metals for AM components, the latter of which include steel, aluminum, nickel, and titanium alloys[5, 6].

Compared to conventional manufacturing (CM) processes such as thermoforming, injection molding, and blow molding (for polymeric components) and casting, forging, machining, and finishing (for metallic components), AM holds at least three promising advantages. First, AM enables designs with novel geometries that would be difficult or impossible to achieve using CM processes[4, 7], which can improve a component's engineering performance. Second, AM can reduce the "cradle-to-gate" environmental footprints of component manufacturing through avoidance of the tools, dies, and materials scrap associated with CM processes $[8,9]$. Third, novel geometries enabled by AM technologies can also lead to performance and environmental benefits in a component's product application[2, 4]. For example, the aircraft industry has adopted a number of different AM components for reducing aircraft mass-including flight deck monitor arms, seat buckles, and various hinges and brackets - which can lead to greater aircraft fuel efficiency [10-13].

This study quantifies the life-cycle energy and greenhouse gas (GHG) emissions savings potential of AM technologies for metallic aircraft components in the United States. As an early adopter of metallic AM components, the aircraft industry provides a compelling case study of the life-cycle environmental savings potential of AM technologies. Firstly, lighter weight aircraft are a critical strategy for reducing societal energy use and GHG emissions [10]. Aviation is currently the second largest consumer of transport fuels globally [14]. In 2009, the world's aircraft consumed 250 million tons of oil equivalents and comprised $12 \%$ and $9 \%$ of global transport sector energy use and GHG emissions, respectively[14, 15]. Furthermore, global aircraft fuel use is projected to triple by 2050 due to rapid economic growth and increasing globalization - a growth rate that is faster than any other transportation mode, including automobiles $[16,17]$. In the US, air travel's share of transportation sector energy use is $9.4 \%$, though projected growth rates are slower [18].

Secondly, the cradle-to-gate materials mass requirements for metallic AM components promise to be far lower than those for CM processes. Presently, the so-called "buy-to-fly" ratio-the mass of raw material needed per unit mass of finished component-ranges from 12:1 to 25:1 for aircraft components made of aluminum and titanium alloys using CM processes[11, 19]. These high buy-to-fly ratios result in substantial amounts of materials scrap in the cradle-to-gate manufacturing system[19, 20], which leads to high manufacturing costs and large energy and environmental emissions footprints. For these reasons, a growing number of aircraft industry companies such as Airbus, Boeing, and General Electric are beginning to develop, test, and deploy AM components[10, 12, 13, 21-23]. 
Table 1: Quantitative literature on AM processes and applications

Studies that quantify the life-cycle energy use and GHG emissions implications of AM components are currently scarce. Table 1 summarizes the existing literature, from which several observations can be made. First, most studies focus only on the direct energy intensity of AM processes without comparisons to the energy and material requirements of the $\mathrm{CM}$ processes that are replaced. Second, most studies have considered polymeric AM technologies, due to their maturity, low cost, and widespread availability. Third, energy intensity estimates for AM processes vary widely across studies, primarily due to different material selections, component geometries, and data collection methods, which preclude direct comparisons of study results. Fourth, none of the studies considered application performance improvements due to changes in component geometries or, by extension, the environmental implications of such performance improvements.

\begin{tabular}{|c|c|c|c|c|c|c|c|}
\hline Study & $\begin{array}{c}\text { AM } \\
\text { Technology }\end{array}$ & Material(s) & $\begin{array}{c}\text { Raw } \\
\text { materials } \\
\text { energy use }\end{array}$ & $\begin{array}{l}\text { Manufacturing } \\
\text { energy use }\end{array}$ & $\begin{array}{c}\text { Comparison } \\
\text { to } \mathrm{CM} \\
\text { processes }\end{array}$ & $\begin{array}{l}\text { Application } \\
\text { market } \\
\text { implications }\end{array}$ & Method \\
\hline \multirow[t]{3}{*}{$\begin{array}{l}\text { Luo et al } \\
1999[27]\end{array}$} & SLA & $\begin{array}{l}\text { Liquid } \\
\text { photopolymer }\end{array}$ & & $74.52-148.97 \mathrm{MJ} / \mathrm{kg}$ & No & No & \multirow[t]{3}{*}{$\begin{array}{l}\text { Data is not empirically measured and eco- } \\
\text { indicator is used }\end{array}$} \\
\hline & SLS & $\begin{array}{c}\text { Polymer, Nylon, } \\
\text { Polyamide, } \\
\text { Polycarbonate }\end{array}$ & & $\begin{array}{c}107.39-144.32 \\
\mathrm{MJ} / \mathrm{kg}\end{array}$ & No & No & \\
\hline & FDM & ABS & & $\begin{array}{c}83.09-1247.04 \\
\mathrm{MJ} / \mathrm{kg}\end{array}$ & No & No & \\
\hline $\begin{array}{l}\text { Morrow et al } \\
2005[8]\end{array}$ & DMD & H13 tool steel & $35 \mathrm{MJ} /$ part & $3000 \mathrm{MJ} /$ part & Yes & No & $\begin{array}{l}\text { Experiment and energy estimation are } \\
\text { used. Tooling life cycle case studies of large } \\
\text { solid-to-cavity ratio, small solid-to-cavity } \\
\text { ratio and remanufacturing are used } \\
\text { compared to CNC machining }\end{array}$ \\
\hline \multirow{3}{*}{$\begin{array}{l}\text { Mognol et al } \\
2006[28]\end{array}$} & 3DPrinting & / & & 7.56-13.68 MJ/part & No & No & \multirow{3}{*}{$\begin{array}{c}\text { Experiment with part in various } \\
\text { orientations }\end{array}$} \\
\hline & FDM & / & & $1.80-4.50 \mathrm{MJ} /$ part & No & No & \\
\hline & DMLS & / & & $\begin{array}{c}115.20-201.60 \\
\mathrm{MJ} / \text { part }\end{array}$ & No & No & \\
\hline $\begin{array}{c}\text { Screenivasan } \\
\text { and Bourell } \\
2010[29]\end{array}$ & SLS & Nylon 12 & & $52.20 \mathrm{MJ} / \mathrm{kg}$ & No & No & Empirical data is not reported \\
\hline \multirow{2}{*}{$\begin{array}{l}\text { Kellens et al } \\
2010[30]\end{array}$} & SLS & Polymer & & $36.1 \mathrm{kWh} / \mathrm{kg}$ & No & No & \multirow{2}{*}{$\begin{array}{l}\text { Full build experiment and life cycle analysis } \\
\text { are conducted }\end{array}$} \\
\hline & SLM & $\begin{array}{c}\text { Stainless steel } \\
316 \mathrm{~L}\end{array}$ & & $26.9 \mathrm{kWh} / \mathrm{kg}$ & No & No & \\
\hline \multirow[t]{2}{*}{$\begin{array}{l}\text { Baumers et al. } \\
\text { 2010[31] }\end{array}$} & SLM & $\begin{array}{l}\text { Stainless steel } \\
316 \mathrm{~L}\end{array}$ & & $\begin{array}{l}111.60-139.50 \\
\mathrm{MJ} / \mathrm{kg}\end{array}$ & No & No & \multirow[t]{2}{*}{$\begin{array}{l}\text { Both single part and full build experiments } \\
\text { are conducted }\end{array}$} \\
\hline & EBM & Ti6Al4V & & $61.20-176.67 \mathrm{MJ} / \mathrm{kg}$ & No & No & \\
\hline
\end{tabular}

Despite its growing use, AM has limitations that currently preclude its application to many components and products. The throughput of AM processes is presently low, which makes AM technologies less surface roughness also present barriers in applications that require high dimensional precision, surface quality, and fatigue resistance[2, 4, 5]. Given the intense focus on improving AM technologies in the industrial and scientific communities, however, it is likely that these obstacles can be overcome in the next 5-20 years[24]. Despite these limitations, the aircraft industry has moved forward with AM
technologies by strategically focusing on applications to basic interior parts in non-critical applications next 5-20 years[24]. Despite these limitations, the aircraft industry has moved forward with AM
technologies by strategically focusing on applications to basic interior parts in non-critical applications $[25,26]$. suitable for high-volume production [3]. Issues with geometric repeatability, residual stresses, and high $[25,26]$. 


\begin{tabular}{|c|c|c|c|c|c|c|c|}
\hline Baumers et al. & SLS & Nylon 12 & & $56.75 \mathrm{kWh} / \mathrm{kg}$ & No & No & \multirow{7}{*}{$\begin{array}{l}\text { Both single part and full build experiments } \\
\text { are conducted }\end{array}$} \\
\hline $2011 a[32]$ & SLS & Nylon 12 & & $66.02 \mathrm{kWh} / \mathrm{kg}$ & No & No & \\
\hline \multirow[t]{5}{*}{$\begin{array}{l}\text { Baumers et al } \\
\text { 2011b[33] }\end{array}$} & SLM & $\begin{array}{l}\text { Stainless steel } \\
316 \mathrm{~L}\end{array}$ & & $83-106 \mathrm{MJ} / \mathrm{kg}$ & No & No & \\
\hline & SLM & $\begin{array}{l}\text { Stainless steel } \\
\text { 316L }\end{array}$ & & $423-588 \mathrm{MJ} / \mathrm{kg}$ & No & No & \\
\hline & DMLS & $\begin{array}{c}\text { Stainless steel } \\
17-4 \mathrm{PH}\end{array}$ & & $241-339 \mathrm{MJ} / \mathrm{kg}$ & No & No & \\
\hline & SLS & PA 12 & & $107-4849 \mathrm{MJ} / \mathrm{kg}$ & No & No & \\
\hline & FDM & Polycarbonate & & 519-636 MJ/kg & No & No & \\
\hline $\begin{array}{l}\text { Baumers et al. } \\
2013[34]\end{array}$ & DMLS & $\begin{array}{l}\text { Used stainless } \\
\text { steel } 17-4 \mathrm{PH}\end{array}$ & & $280 \mathrm{MJ} / \mathrm{kg}$ & No & No & $\begin{array}{l}\text { Experiment is included to test the energy } \\
\text { and cost consumption model. }\end{array}$ \\
\hline $\begin{array}{l}\text { Telenko and } \\
\text { Seepersad } \\
2012[35]\end{array}$ & SLS & Nylon & $116 \mathrm{MJ} / \mathrm{kg}$ & $130 \mathrm{MJ} / \mathrm{kg}$ & Yes & No & $\begin{array}{l}\text { Experiment and LCA are included. Case } \\
\text { study of paintball gun handle is used to } \\
\text { compare to injection molding }\end{array}$ \\
\hline $\begin{array}{l}\text { Wilson et al } \\
2013[37]\end{array}$ & LENS & NiCr20Co18Ti I & $335 \mathrm{MJ} / \mathrm{kg}$ & $1052 \mathrm{MJ} / \mathrm{kg}$ & Yes. & No & $\begin{array}{c}\text { Experiment and LCA are included. } \\
\text { Remanufacturing of turbine blade is used } \\
\text { as a case study compared to } 2 \text { arc welding } \\
\text { processes (GTAW, PTA) in repairing and } \\
\text { casting a new blades }\end{array}$ \\
\hline
\end{tabular}

This study helps fill this quantitative knowledge gap for the case of selected AM components in the U.S. aircraft fleet. The analysis considers AM technologies for selected steel, aluminum, nickel, and titanium alloy components and compares their cradle-to-gate energy and GHG emission footprints to the case of $\mathrm{CM}$ technologies for those same components in an analytically consistent manner. Potential aircraft fuel use reductions due to these lighter weight AM components are estimated over the period 2014-2050 at various rates of market adoption as existing aircraft are upgraded and new aircraft are added to the fleet. As such, the analysis considers the life-cycle energy and GHG emissions implications of AM technologies for a critical global industry over a plausible adoption period. Such analyses are important for assessing the role of AM technologies in helping society meet its long-term energy use and GHG emissions reduction goals, as well as for highlighting opportunities for manufacturing technology adoption that can lead to broader societal benefits.

\section{Methodology}

The analysis framework employed in this study consisted of five major steps. First, several aircraft systems were identified as candidates for near-term adoption of AM components based on a structured selection process that considered geometric, load, and application suitability. Second, the replaceable mass for different metal alloys within each selected component system was estimated using aircraft materials composition data and AM case studies from the industry. Third, a cradle to gate manufacturing life-cycle inventory ( $\mathrm{LCl}$ ) model was developed to estimate energy and GHG emissions reductions associated with replacing existing CM components with lighter weight AM components within the selected systems. Fourth, a temporal adoption model was developed to estimate the penetrations of different AM components as fleet upgrades and additions occur through the year 2050. Fifth, an aircraft fuel use model was applied to estimate the potential energy and GHG emission savings associated with lighter weight aircraft due to AM component adoption. Together, these steps facilitated 
an integrated analysis of net changes in primary energy use and GHG emissions within the U.S. manufacturing and air transport sectors attributable to the adoption of AM components over the next 36 years. Each step is summarized in the remainder of this section. Further details on the approaches, data sources, and calculations for all steps are provided in the Supplementary Information (SI).

\subsection{Aircraft component selection}

This study adopted major aircraft component system definitions developed by Kroo et al [38], which identified 17 major component systems within typical commercial passenger aircraft models and as well as the contributions of each system to total aircraft mass. Given the infeasibility of analyzing the thousands of aircraft components, this study focused on identifying systems that represent the most feasible application opportunities for lightweight AM components in the near term (i.e., within 5-20 years). Feasible applications were defined as those that met specific criteria for load profile, geometric complexity, geometric volume, materials, and other factors as described below.

Feasibility for near-term adoption of lightweight AM components was determined in three steps. First, systems consisting primarily of metallic component assemblies were selected for further analysis based on available aircraft materials data [38-40]. Excluded were component systems such as flight controls, instruments, and electrical systems whose materials complexity precludes near-term AM adoption and component systems that comprise less than $2 \%$ of total aircraft mass. Second, the total mass of each selected system was decomposed into three component categories [39, 41, 42]: (1) structural, which refers to components whose primary purpose is to maintain aircraft geometries and bear major system loads (e.g., wing components); (2) functional, which refers to components whose primary purpose is to provide flight functions (e.g., seats); and (3) auxiliary, which refers to all non-structural and nonfunctional components (as defined above) that are also small geometric volume components (e.g., brackets, hinges, and clips). Third, the load profile, geometric complexity, and geometric volume attributes of each component category were assessed based on available aircraft component data [39, $41,43,44]$. Qualitative ratings of high, medium, and low were assigned for each attribute to identify component categories with non-critical load profiles, complex geometries, and small to medium geometric volumes as the most likely for near-term AM adoption [3, 11]. Table 2 summarizes the results of the component selection process, in which the component systems and categories for further analysis are indicated in bold typeface based on their final feasibility score. Further details on all data sources and assumptions are provided in Section 2.1 of the SI. 
Table 2: Aircraft component systems attribute ratings

\begin{tabular}{|c|c|c|c|c|c|c|}
\hline Component systems & $\begin{array}{l}\text { Component } \\
\text { category }\end{array}$ & $\begin{array}{l}\text { Mass } \\
\text { fraction }\end{array}$ & Load rating & $\begin{array}{l}\text { Shape } \\
\text { complexity rating }\end{array}$ & $\begin{array}{l}\text { Geometric } \\
\text { volume rating }\end{array}$ & $\begin{array}{l}\text { Feasibility } \\
\text { evaluation } \\
\text { score* }\end{array}$ \\
\hline \multirow[t]{3}{*}{ Wing systems } & & 0.24 & & & & \\
\hline & Structural & 0.95 & High & Medium & High & 4 \\
\hline & Auxiliary & 0.05 & High & Low & Low & 5 \\
\hline \multirow[t]{3}{*}{ Body systems } & & 0.19 & & & & \\
\hline & Structural & 0.95 & High & Medium & High & 4 \\
\hline & Auxiliary & 0.05 & Medium & Low & Low & 6 \\
\hline \multirow[t]{4}{*}{ Furnish \& equip systems } & & 0.13 & & & & \\
\hline & Structural & 0.36 & Low-Medium & Medium & Low-Medium & 7 \\
\hline & Functional & 0.57 & Low & Medium & Medium & 7 \\
\hline & Auxiliary & 0.07 & Low & Low & Low & 7 \\
\hline \multirow[t]{4}{*}{ Engine } & & 0.12 & & & & \\
\hline & Structural & 0.17 & High & Medium & High & 4 \\
\hline & Functional & 0.77 & High & High & Medium-High & 5.5 \\
\hline & Auxiliary & 0.06 & Medium-High & Low & Low & 5.5 \\
\hline \multirow[t]{3}{*}{ Alighting gear systems } & & 0.09 & & & & \\
\hline & Structural & 0.95 & High & Medium & High & 4 \\
\hline & Auxiliary & 0.05 & High & Low & Low & 5 \\
\hline \multirow[t]{3}{*}{ Tail systems } & & 0.04 & & & & \\
\hline & Structural & 0.95 & High & Medium & High & 4 \\
\hline & Auxiliary & 0.05 & High & Low & Low & 5 \\
\hline \multirow[t]{2}{*}{ Propulsion systems } & & 0.04 & & & & \\
\hline & Functional & 1.00 & High & High & Medium & 6 \\
\hline \multirow[t]{3}{*}{ Nacelle systems } & & 0.04 & & & & \\
\hline & Structure & 0.95 & High & Medium & High & 4 \\
\hline & Auxiliary & 0.05 & Low-Medium & Low & Low & 6.5 \\
\hline
\end{tabular}

* To determine feasibility scores, numerical values of 1, 2, and 3 were assigned to ratings of high, medium, and low, respectively, for load and geometric volume. Numerical values of 3, 2, and 1 were assigned to ratings of high, medium, and low, respectively, for shape complexity. Component categories with feasibility scores greater than 5 (bolded in this table) were deemed most likely for near-term adoption of AM components.

\subsection{Replaceable mass}

For those component systems and categories that were deemed most likely for near-term AM adoption, the next step was to quantify their metal alloy composition and the mass fractions of each metal alloy that might be replaced by AM components. Establishing the materials composition was necessary to estimate the AM replacement potential within each component category and to identify the CM and AM process technologies applicable to manufacturing replaceable components, as discussed further in Section 2.3. Table 3 summarizes this study's estimates of the replaceable mass of aluminum (Al), titanium (Ti), nickel ( $\mathrm{Ni})$, and steel alloys within each selected component category. The data in Table 3 were derived by first estimating the total mass of each metal alloy within each component system based on available aircraft materials composition data $[39,40,45]$. Next, the mass fractions of each metal alloy that could be replaceable by AM components were estimated based on published AM case studies and industry targets[13, 23, 46], using low and high estimates from the literature to form credible bounds on the mass replacement potentials. Finally, the replaceable mass ranges were calculated by assuming an average aircraft empty operating mass of 40,622 kg for a 142 seat commercial plane, based 
on empty mass, passenger seats, and passenger miles data for the U.S. aircraft fleet $[47,48]$. In total, it was estimated that $9-17 \%$ of total typical aircraft mass may be replaceable by AM components in the near term, with 4-5\% attributable to a replacement of Al alloy components, 2-5\% attributable to replacement of $\mathrm{Ni}$ alloy components, 3-6\% attributable to replacement of $\mathrm{Ti}$ alloy components, and 0.4$1 \%$ attributable to steel alloy components. Further details on all data sources and assumptions are provided in Sections 2.2 and 2.3 of the SI.

Table 3: Replaceable mass by metal alloy, component system, and component category

\begin{tabular}{|c|c|c|c|c|c|}
\hline \multirow[b]{2}{*}{ Component system } & \multirow[b]{2}{*}{ Category } & \multicolumn{4}{|c|}{ Replaceable mass in average aircraft $(\mathrm{kg})^{*}$} \\
\hline & & Al alloy & Ti alloy & Ni alloy & Steel \\
\hline Body systems & Auxiliary & $80-200$ & & & \\
\hline \multirow[t]{2}{*}{ Furnishings and equipment } & Structural & $70-130$ & & & \\
\hline & Functional & $1450-1930$ & & & \\
\hline \multirow[t]{2}{*}{ Engine } & Functional & & $680-1350$ & $940-1880$ & $100-190$ \\
\hline & Auxiliary & & $50-90$ & $50-90$ & $50-90$ \\
\hline Propulsion systems & Functional & & $330-810$ & & \\
\hline \multirow[t]{2}{*}{ Nacelle Systems } & Auxiliary & & $20-40$ & & \\
\hline & Total & $1590-2260$ & $1070-2290$ & $980-1960$ & $140-280$ \\
\hline
\end{tabular}

* Based on an average aircraft empty operating mass of 40,622 $\mathrm{kg}[47,48]$

\subsection{Component manufacturing energy and emissions analysis}

The replaceable mass estimates in Table 3 refer to the total mass of CM components in existing aircraft that might be replaced by AM components in the near term. To estimate net changes in cradle-to-gate manufacturing energy use and GHG emissions associated with a shift from CM to AM processes, this study developed a process-based $\mathrm{LCl}$ model of the cradle-to-gate system depicted in Figure 1 . The system boundary includes the following major process steps for both CM and AM pathways: raw materials production, raw materials distribution, component manufacturing, and component distribution to the aircraft assembly plant. Each process step was modeled based on primary energy use and GHG emissions data for the depicted unit processes obtained from the literature. Raw materials production processes included production of ingots, plates, and powders from different primary and secondary metal production routes [8, 20,49-52]. Open loop recycling of the materials is also considered[50, 53, 54]. Distribution processes included shipment by diesel trucks, cargo ships, rail, and aircraft [51]. Component manufacturing included forging, milling, turning, machining, and casting processes (for CM pathways) and selective laser melting (SLM), direct metal laser sintering (DMLS), and electron beam melting (EBM) processes (for AM pathways) [31, 51, 52, 55-59]. Primary energy and GHG emissions intensities of all processes are summarized in Sections 3.1-3.1 of the SI, including the corresponding data sources and analysis assumptions. High and low energy and GHG emissions intensity values were established for each process in the model for more robust analysis of the differences between $\mathrm{CM}$ and AM pathways. 


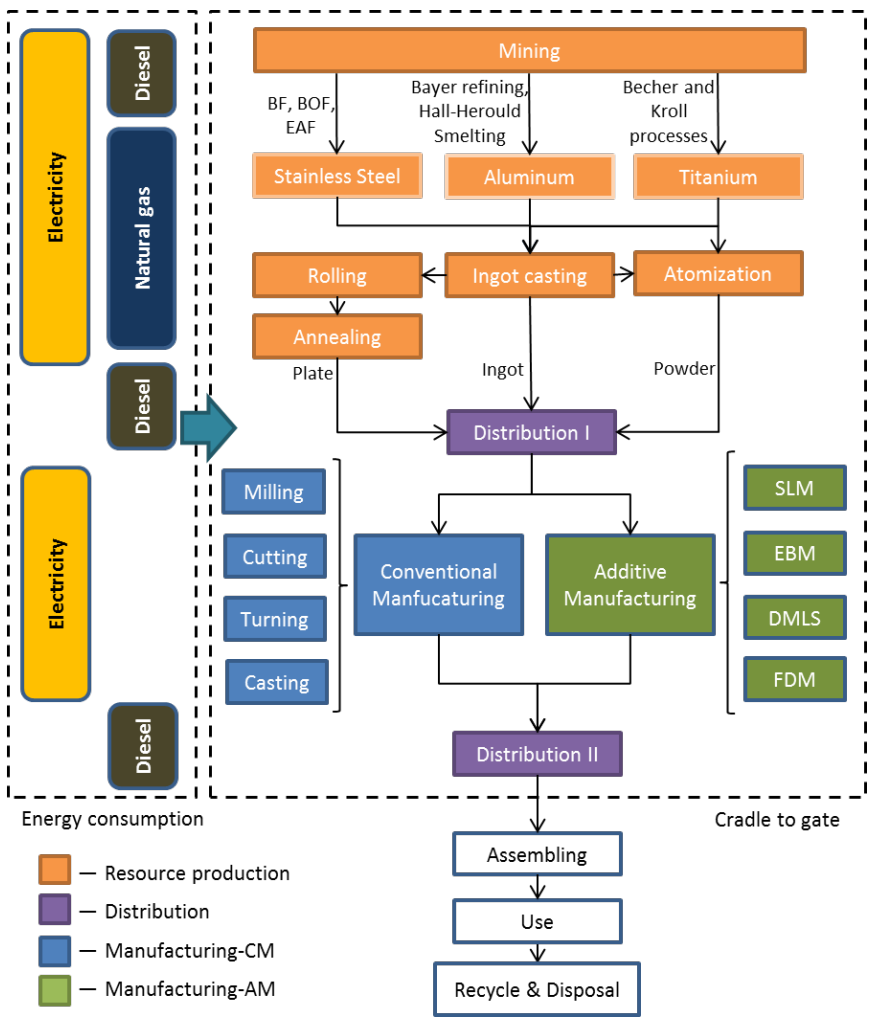

Figure 1: Cradle to gate LCI model system boundary

The model's governing equation for cradle to gate primary energy use for a given component is as follows:

$$
\begin{aligned}
& E_{\text {total }}=E_{\text {materials }}+E_{\text {distribution I }}+E_{\text {manfuacturing }}+E_{\text {distribution II }} \\
& \quad=\epsilon_{\text {materials }} \cdot m_{\text {input }}+\epsilon_{\text {dis I }} \cdot m_{\text {input }}+\epsilon_{m f g} \cdot m_{\text {output }}+\epsilon_{\text {dis II }} \cdot m_{\text {output }}
\end{aligned}
$$

where $m$ represents mass into or out of a process step $(\mathrm{kg}), \epsilon$ represents the primary energy intensity of a process step $(\mathrm{MJ} / \mathrm{kg})$, and $E$ represents the primary energy use of a process step (MJ). The model's governing equation for cradle to gate GHG emissions for a given component is as follows:

$$
\begin{aligned}
& C_{\text {total }}=C_{\text {materials }}+C_{\text {distribution I }}+C_{\text {manfuacturing }}+C_{\text {distribution II }} \\
& =\gamma_{\text {materials }} \cdot m_{\text {input }}+\gamma_{\text {dis I }} \cdot m_{\text {input }}+\gamma_{\text {mfg }} \cdot m_{\text {output }}+\gamma_{\text {dis II }} \cdot m_{\text {output }}
\end{aligned}
$$

where $\gamma$ represents the carbon dioxide equivalent $\left(\mathrm{CO}_{2} \mathrm{e}\right)$ emissions intensity of a process step ( $\mathrm{kg}$ $\mathrm{CO}_{2} \mathrm{e} / \mathrm{kg}$ ), and $\mathrm{C}$ represents the $\mathrm{CO}_{2} \mathrm{e}$ emissions associated with a process step $\left(\mathrm{kg} \mathrm{CO}_{2} \mathrm{e}\right)$. In both equations above, mass inputs and mass outputs are related by the "buy-to-fly" ratio, which is represented by $\alpha$ :

$$
m_{\text {input }}=\alpha \cdot m_{\text {output }}
$$


The average buy-to-fly ratio of aircraft components using subtractive CM pathways (e.g., milling, cutting, and turning) is 8 to 12 , and can sometimes be as high as $30[11,19,59]$. Given the aircraft industry's ongoing efforts to reduce costly materials scrap, this study adopted a conservative average buy-to-fly ratio of 8 for subtractive $\mathrm{CM}$ components. For components manufactured primarily through forming $\mathrm{CM}$ pathways such as casting or forging, this study assumed a buy-fly ratio of 4.5 for final formed components [46], which includes a rough forming process with buy-to-fly ratio of 2 and an additional buy-to-fly ratio of 2.25 for the subtractive finishing operations that follow. In theory AM processes should lead to negligible materials waste [2]. In current practice, however, AM processes exhibit powder loss and require additional finishing to improve component surface quality, which leads to subtractive materials losses. Based on data in the literature $[60,61]$, this study estimated a buy-to-fly ratio of 1.5 for all AM processes.

The cradle-to-gate $\mathrm{LCl}$ model was applied to the replaceable mass quantities in Table 3 using the following steps. First, a literature review was conducted to identify credible, quantitative mass analysis case studies of AM replacements within the selected component systems. In particular, case studies describing the geometric design, material use, component mass, AM technologies, and CM processes replaced were identified[12, 46, 62-64]. The results of this step are summarized in Table 4, which lists the materials, $\mathrm{CM}$ and $\mathrm{AM}$ processes, and component mass reductions achieved through $\mathrm{AM}$ replacement for each case study component.

Table 4: Case study component analysis data $[12,46,62-64]$

\begin{tabular}{|c|c|c|c|c|c|c|}
\hline Case study component & Material & $\begin{array}{l}\text { Original } \\
\text { CM } \\
\text { pathway }\end{array}$ & $\begin{array}{l}\text { AM } \\
\text { technology }\end{array}$ & $\begin{array}{l}\text { Original } \\
\mathrm{CM} \\
\text { component } \\
\text { mass }(\mathrm{kg})\end{array}$ & $\begin{array}{l}\text { Replacement } \\
\text { AM } \\
\text { component } \\
\text { mass }(\mathrm{kg})\end{array}$ & $\begin{array}{l}\text { Mass } \\
\text { reduction } \\
\text { (CM- } \\
\mathrm{AM}) / \mathrm{CM}\end{array}$ \\
\hline Bracket & Ti alloy & Machining & EBM & 1.09 & 0.38 & $65 \%$ \\
\hline Seat buckle & Al alloy & $\begin{array}{l}\text { Forging } \\
\text { and } \\
\text { machining }\end{array}$ & SLM & 0.16 & 0.07 & $55 \%$ \\
\hline Bionic bracket & Ti alloy & Machining & EBM & 0.06 & 0.04 & $35 \%$ \\
\hline $\begin{array}{l}\text { Engine cover door } \\
\text { hinge }\end{array}$ & Ti alloy & $\begin{array}{l}\text { Casting } \\
\text { and } \\
\text { machining }\end{array}$ & DMLS & 0.92 & 0.23 & $65 \%$ \\
\hline Fork Fitting & Al alloy & $\begin{array}{l}\text { Casting } \\
\text { and } \\
\text { machining }\end{array}$ & SLM & 0.8 & 0.4 & $50 \%$ \\
\hline
\end{tabular}

Next, for each case study component, transportation distances and modes were estimated for distribution of raw materials and finished components based on representative distances for aircraft component supply chains as identified in the literature [65]. These estimates are summarized in Section 3.4 of the SI. Third, using the $\mathrm{LCl}$ model, cradle-to-gate primary energy and emissions analyses were conducted for the AM replacement component and the existing $\mathrm{CM}$ component that was replaced in 
each case study. The results of this analysis are partly summarized in Figure 2, which displays the differences in average cradle-to-gate primary energy use between the $\mathrm{CM}$ and $\mathrm{AM}$ pathways for each case study component (left axis), as well the differences in CM and AM process energy intensities (right axis). More detailed analysis results for cradle-to-gate primary energy use and GHG emissions differences for each case study component, including the high and low range estimates for these differences, are summarized in Section 3.4 of the SI.

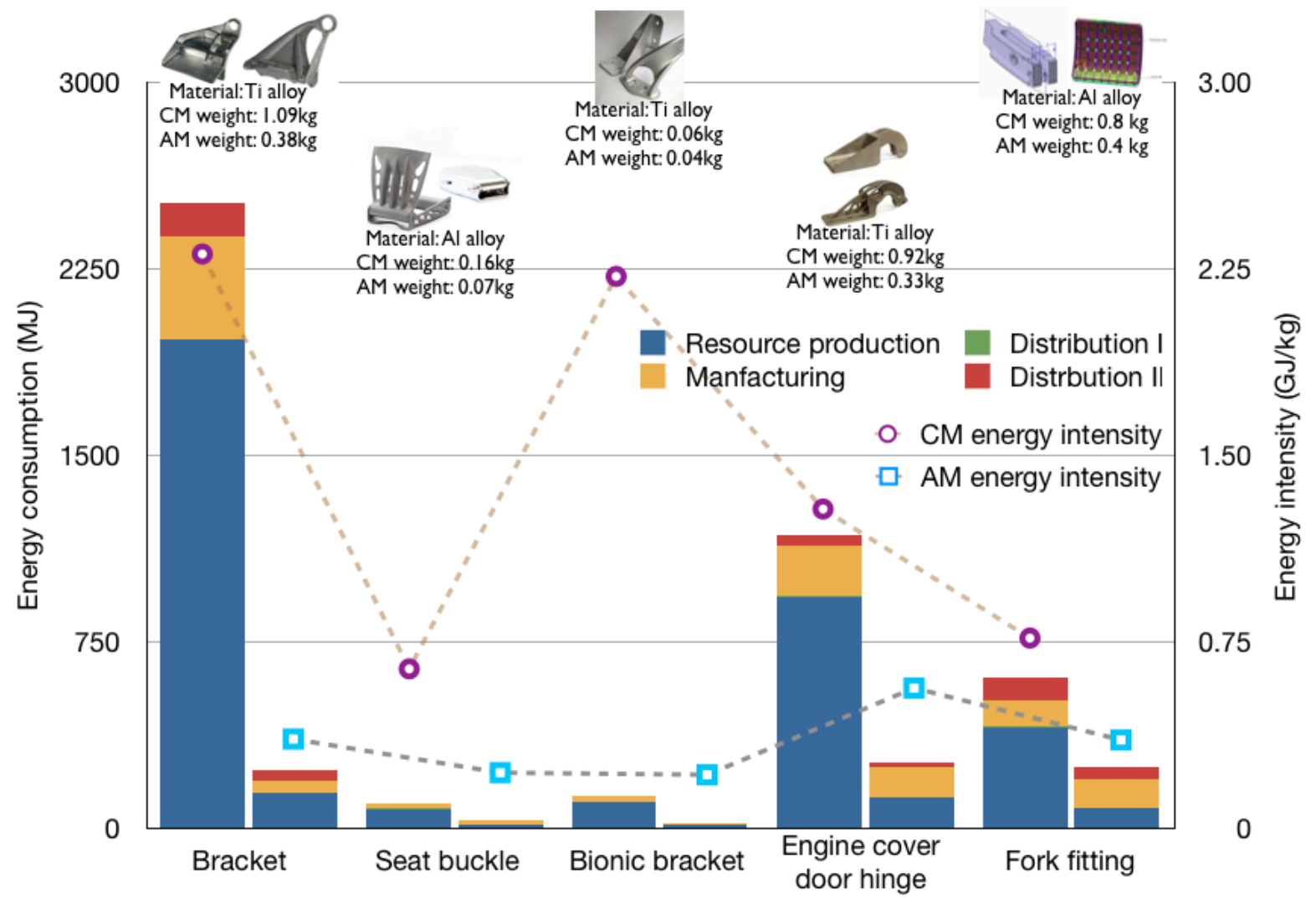

Figure 2: Cradle to gate primary energy results for case study components

The results in Figure 2 highlight the energy saving potential of $A M$ technologies compared to $C M$ technologies. For each case study component, the AM pathway led to significantly lower cradle-to-gate primary energy use compared to the CM pathway, ranging from roughly 2 GJ savings for the bracket to roughly $70 \mathrm{MJ}$ savings for the seat buckle. These energy savings are primarily due to the reductions in resource production energy use attributable to the lower buy-to-fly ratios of AM processes and the reduced mass associated with the AM components' advanced lightweight geometries. Similar reductions were estimated for cradle-to-gate GHG emissions, as summarized in the SI.

Next, the mass reduction data in Table 4 were scaled up to estimate the total mass reduction that would occur within each selected aircraft component system if the full AM replacement potential were realized. Specifically, the results in Table 5 were generated by applying the mass reduction potentials for each case study component (Table 4) to the total replaceable mass ranges for each component system (Table 3 ) in the following manner. First, a representative case study component was assigned to each 
component system and component category in Table 3 on the basis of similar function. Second, the mass reduction potential associated with the representative case study component was multiplied by the replaceable mass ranges for all materials within that same component system and component category. Implicit in this approach is that the mass reductions documented in the case study data for each representative component could be replicated across all replaceable mass within the same component system and category. In total, it was estimated that average aircraft empty mass could be reduced by $4-7 \%$ through the adoption of $A M$ components in the selected systems, with the greatest potential mass reductions attributable to Al alloys (by metal) and furnishing and equipment and engine system components (by component system).

Table 5: Estimated mass reductions by material and component system through AM replacement

\begin{tabular}{|c|c|c|c|c|c|c|c|}
\hline \multirow[b]{2}{*}{$\begin{array}{l}\text { Component } \\
\text { system }\end{array}$} & \multirow[b]{2}{*}{ Category } & \multirow[b]{2}{*}{$\begin{array}{l}\text { Representative } \\
\text { component }\end{array}$} & \multicolumn{5}{|c|}{ Mass reduction in average aircraft $(\mathrm{kg})^{*}$} \\
\hline & & & Al alloy & Ti alloy & Ni alloy & Steel & Total \\
\hline Body systems & Auxiliary & Fork fitting & $40-100$ & & & & $40-100$ \\
\hline \multirow{2}{*}{$\begin{array}{l}\text { Furnishings and } \\
\text { equipment }\end{array}$} & Structural & Bracket & $50-90$ & & & & $50-90$ \\
\hline & Functional & Seat buckle & $790-1060$ & & & & $790-1060$ \\
\hline \multirow[t]{2}{*}{ Engine } & Functional & Bionic bracket & & $240-470$ & $330-660$ & $30-70$ & $600-1200$ \\
\hline & Auxiliary & Bionic bracket & & $20-30$ & $20-30$ & $20-30$ & $50-90$ \\
\hline $\begin{array}{l}\text { Propulsion } \\
\text { systems }\end{array}$ & Functional & Bionic bracket & & $110-290$ & & & $110-290$ \\
\hline \multirow[t]{2}{*}{$\begin{array}{l}\text { Nacelle } \\
\text { Systems }\end{array}$} & Auxiliary & $\begin{array}{l}\text { Engine cover } \\
\text { door hinge }\end{array}$ & & $10-30$ & & & $10-30$ \\
\hline & Total & & $880-1240$ & $380-820$ & $340-690$ & $50-100$ & $1650-2840$ \\
\hline
\end{tabular}

* Based on an average aircraft empty operating mass of $40,622 \mathrm{~kg}[47,48]$

Finally, the $\mathrm{LCl}$ model was used to estimate the total cradle-to-gate reductions in primary energy use and $\mathrm{CO}_{2} \mathrm{e}$ emissions associated with the replacement of $\mathrm{CM}$ components by $\mathrm{AM}$ components when achieving the mass reductions summarized in Table 5. To do so, this study first estimated cradle-to-gate primary energy use of $\mathrm{CM}$ components by multiplying the replaceable mass data in Table 3 by the corresponding cradle-to-gate CM primary energy intensities in the $\mathrm{LCl}$ model for each component category and material (as described in the SI). Second, the mass of the replacement AM components was calculated by subtracting the mass reductions in Table 5 from the replaceable mass in Table 3 for each component category and material. Third, the cradle-to-gate primary energy use of AM components was estimated by multiplying the estimated mass of AM replacements by the cradle-togate AM primary energy intensities in the LCI model (as described in the $\mathrm{SI}$ ). Finally, this study estimated the total cradle-to-gate reductions in primary energy use per aircraft in Table 6 by subtracting the values obtained in the third step from the values obtained in the first step. An identical approach was taken to generate the estimates in Table 7 for cradle-to-gate $\mathrm{CO}_{2}$ e emissions reductions per aircraft. Further details on the $\mathrm{LCl}$ modeling data are provided in Section 3 of the SI. 
Table 6: Aircraft level "cradle to gate" primary energy use reductions

\begin{tabular}{|c|c|c|c|c|c|c|}
\hline \multirow[b]{2}{*}{$\begin{array}{l}\text { Component } \\
\text { system }\end{array}$} & \multirow[b]{2}{*}{ Category } & \multicolumn{5}{|c|}{ Primary energy use reductions (GJ/aircraft)* } \\
\hline & & Al alloy & Ti alloy & Ni alloy & Steel & Total \\
\hline Body systems & Auxiliary & $10-130$ & & & & $10-130$ \\
\hline \multirow{2}{*}{$\begin{array}{l}\text { Furnishings and } \\
\text { equipment }\end{array}$} & Structural & $20-190$ & & & & $20-190$ \\
\hline & Functional & $210-1340$ & & & & $210-1340$ \\
\hline \multirow[t]{2}{*}{ Engine } & Functional & & $1020-3050$ & $720-4090$ & $1-50$ & $1740-7180$ \\
\hline & Auxiliary & & $70-200$ & $40-190$ & $0-60$ & $110-450$ \\
\hline $\begin{array}{l}\text { Propulsion } \\
\text { systems }\end{array}$ & Functional & & $490-1830$ & & & $490-1830$ \\
\hline \multirow[t]{2}{*}{ Nacelle Systems } & Auxiliary & & $10-50$ & & & $10-50$ \\
\hline & Total & $240-1660$ & $1590-5120$ & $760-4280$ & $2-110$ & $2560-11170$ \\
\hline
\end{tabular}

Table 7: Aircraft level "cradle to gate" reductions in $\mathrm{CO}_{2} \mathrm{e}$ emissions

\begin{tabular}{|c|c|c|c|c|c|c|}
\hline \multirow[b]{2}{*}{$\begin{array}{l}\text { Component } \\
\text { system }\end{array}$} & \multirow[b]{2}{*}{ Category } & \multicolumn{5}{|c|}{$\mathrm{CO}_{2} \mathrm{e}$ emissions reductions (metric ton/aircraft)* } \\
\hline & & Al alloy & Ti alloy & Ni alloy & Steel & Total \\
\hline Body systems & Auxiliary & $0-12$ & & & & $0-12$ \\
\hline \multirow{2}{*}{$\begin{array}{l}\text { Furnishings and } \\
\text { equipment }\end{array}$} & Structural & $2-17$ & & & & $2-17$ \\
\hline & Functional & $12-130$ & & & & $12-130$ \\
\hline \multirow[t]{2}{*}{ Engine } & Functional & & $90-270$ & $60-270$ & $1-4$ & $160-540$ \\
\hline & Auxiliary & & $7-17$ & $3-13$ & $0-5$ & $10-35$ \\
\hline $\begin{array}{l}\text { Propulsion } \\
\text { systems }\end{array}$ & Functional & & $45-160$ & & & $45-160$ \\
\hline \multirow[t]{2}{*}{ Nacelle Systems } & Auxiliary & & $2-6$ & & & $2-6$ \\
\hline & Total & $14-160$ & $150-450$ & $70-290$ & $1-10$ & $230-900$ \\
\hline
\end{tabular}

* Based on an average aircraft empty operating mass of 40,622 $\mathrm{kg}[47,48]$

\subsection{U.S. aircraft fleet adoption modeling}

To model the adoption of AM components within the U.S. aircraft fleet over the period 2014-2050, this study first estimated the temporal availability of AM components within each selected component system and category. Table 8 summarizes the assumed availabilities of AM components based on literature information on the pace of AM technology innovation and the specific attributes of each selected component system and category $[24,66]$. Further details on temporal feasibility assumptions are provided in Section 2.4 of the SI.

Table 8: Temporal availability assumptions

\begin{tabular}{lll}
\hline Component system & Component category & Availability \\
\hline Body systems & Auxiliary & 10 years (2024) \\
\hline
\end{tabular}




\begin{tabular}{lll}
\hline Furnishings and equipment systems & Structural & 5-10 years* (2019-2024) \\
Furnishings and equipment systems & Functional & 10 years (2024) \\
Engine & Functional & 20 years (2034) \\
Engine & Auxiliary & 10 years (2024) \\
Propulsion systems & Functional & 20 years (2034) \\
Nacelle systems & Auxiliary & 5 years (2019) \\
\hline
\end{tabular}

*5 years for galley and lavatory, 10 years for floor panel, fasteners and other

Next, this study developed and employed a temporal model of the U.S. commercial aircraft fleet to estimate the penetration of AM replacements under different adoption scenarios and considering their temporal availability. The component penetration model considered the adoption rate and market size for new components.

Once AM replacements become available, their adoption in new component production follows a Bass diffusion curve satisfying the equations[67]:

$$
\begin{aligned}
\frac{f(t)}{1-F(t)} & =p+q F(t) \\
f(t) & =\frac{d F(t)}{d t}
\end{aligned}
$$

Where $F(t)$ is the portion of new component production that uses $\mathrm{AM}, f(t)$ is the rate of new adoption, $p$ is the coefficient of innovation, $q$ is the coefficient of imitation, and $t$ is the number of years from first adoption.

The estimated market for new components considers the size, age, and turnover in the U.S. fleet of active passenger aircraft. Forecasts for the size of the U.S. fleet are based on the U.S. Department of Energy's Annual Energy Outlook (AEO) 2014 forecasts[18]. New components are used in new aircraft, which gradually replace old aircraft as they are retired, and may also replace old components in existing aircraft. Aircraft are retired at rates that depend on the age of the aircraft, based on data from Forsberg[68]. In addition, we assume that one seventh of all interior parts and one tenth of all engine parts in active aircraft are replaced each year. We also consider the case of accelerated adoption when components are replaced ahead of schedule in order to realize the energy savings benefits of lightweighting. Details on the component penetration model and assumptions are in section 5.1 of the SI.

Three scenarios are considered for the adoption of AM parts in aircraft, which are summarized in Table 9. They differ both in the diffusion parameters that are used, and in the conditions under which retrofits are performed. The values for the technology diffusion parameters in each scenario are based on a range of diffusion rates that have been found in other studies of technologies used in aircraft and related industries [69-71] as described in section 5.1 of the SI. The retrofit assumptions are also different in the three scenarios: in the slow adoption scenario, AM parts are only used in new aircraft. In the midrange adoption scenario, AM components are also substituted for existing components when they need to be replaced. In the rapid adoption scenario, old components are replaced with AM components ahead of schedule to save fuel. 
Table 9: Adoption scenarios

\begin{tabular}{lll}
\hline Scenario & $\begin{array}{l}\text { Years until 80\% AM adoption by } \\
\text { component producers }\end{array}$ & Incorporation of AM parts into fleet \\
\hline Slow adoption & 28 years [70] & new aircraft only \\
Mid-range adoption & 15 years [71] & $\begin{array}{l}\text { new aircraft and new parts in } \\
\text { existing aircraft }\end{array}$ \\
Rapid adoption & 5 years [69] & $\begin{array}{l}\text { new aircraft and new parts in } \\
\text { existing aircraft, with accelerated } \\
\text { replacement of non-AM parts }\end{array}$ \\
\hline
\end{tabular}

Figure 3 shows trajectories for how two representative AM components - one engine component and one furnishing and equipment systems component - are incorporated into the fleet in each of the three scenarios. Incorporation rates vary greatly between scenarios, with retrofits playing an increasingly important role in the more rapid adoption scenarios.
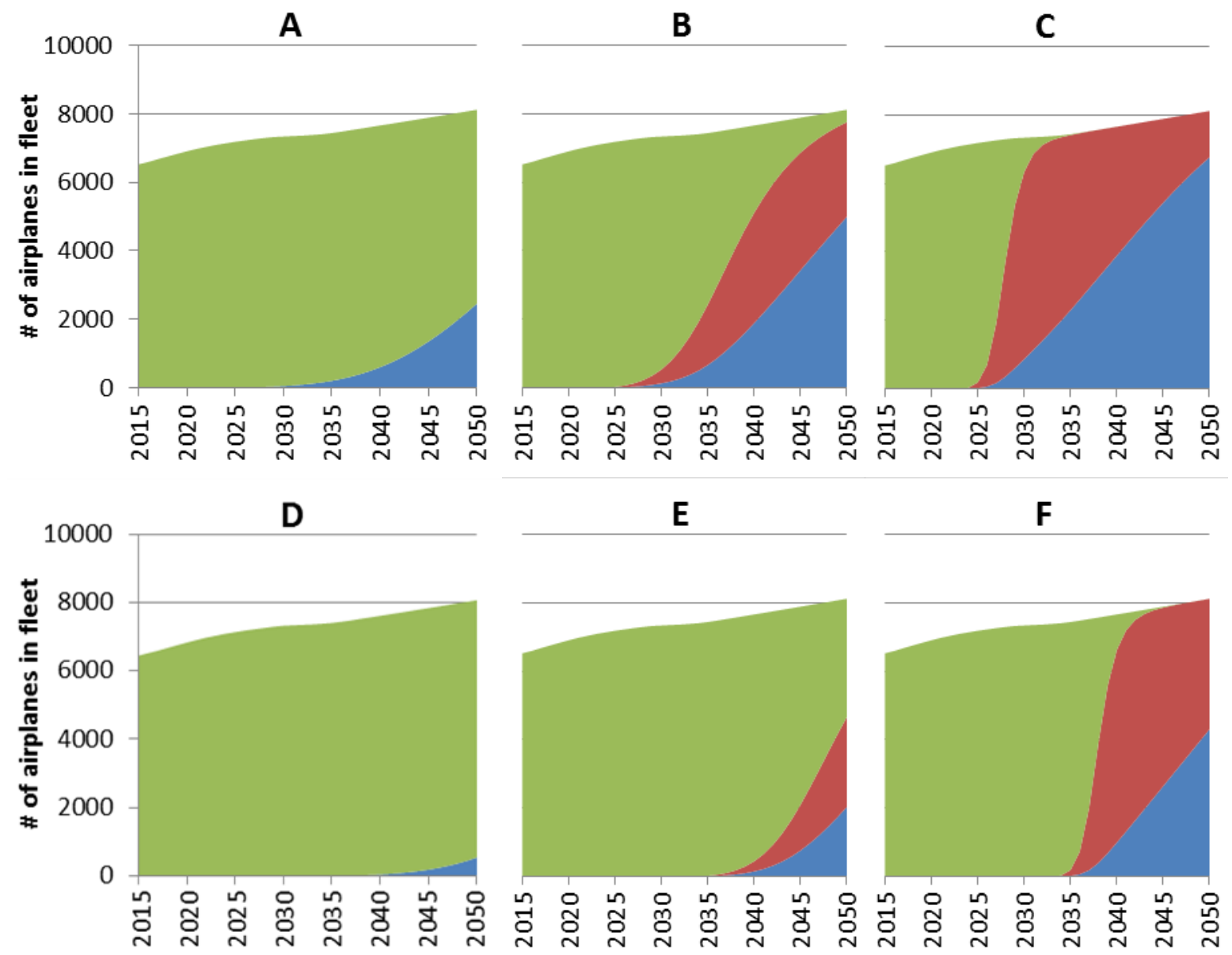

AM new production $\square$ AM retrofit $\square$ Non-AM

Figure 3: Incorporation of AM components into fleet of aircraft: (A) furnishings and equipment systems, slow adoption; (B) furnishings and equipment systems, mid-range adoption; (C) furnishings 

engine, rapid adoption.

\subsection{U.S. aircraft fleet fuel use modeling}

The adoption of lighter weight AM components in an aircraft will reduce its weight and therefore the amount of fuel used while operating the aircraft. Each $100 \mathrm{~kg}$ reduction in the weight of an aircraft is estimated to save 13.4-20.0 TJ of fuel over the course of a 30 year life of an airplane, or 0.45-0.67 TJ per year, based on the range of estimates in three sources[72-74]. This is equivalent to the fuel savings that would be achieved by 60-90 tons of vehicle lightweighting [73]. The life cycle energy savings and GHG emissions reduction associated with these fuel savings are based on estimates of well-to-wake energy use and carbon-equivalent emissions for jet fuel used in Argonne's GREET model [50]. These use-phase savings are applied to the active fleet of aircraft that have adopted AM parts.

\section{Results and discussion}

U.S. market-wide primary energy and GHG emissions savings trajectories for the three adoption scenarios are shown in Table 10. In each case, a range of outcomes is given, reflecting the uncertainty in our model assumptions. In the rapid adoption scenario, total primary energy savings potential reaches 70-173 million GJ/year by 2050, with cumulative primary energy savings of 1.2-2.8 billion GJ through 2050. The low and high ends of these ranges represent the combinations of low end and high end values for all model parameters that generate the lowest and highest possible savings. The greatest source of uncertainty is in the portion of each component system that is suitable for replacement with AM parts, followed by uncertainty in the amount of fuel that would be saved from a specified reduction in the mass of an aircraft.

Figure 4 shows the pattern of primary energy savings over time for the three adoption scenarios. The rapid adoption scenario shows two main waves of adoption, one which begins in 2024 and one which begins in 2034, reflecting our assumptions as to the temporal availability of the different AM components. These waves are not as evident in the slow and mid-range adoption scenarios because the different waves run together leading to a smoother overall curve.

The majority of the energy savings come from a reduction in airplane fuel consumption due to the lighter weight of the AM parts. In the mid-range adoption scenario, 95-98\% of the cumulative energy savings come from this reduction in use-phase fuel consumption, with the other $2-5 \%$ coming from cradle-to-gate manufacturing system savings. In the rapid adoption scenario, only 1-2\% of the energy savings are in the manufacturing system. Cradle-to-gate savings are lower in the rapid adoption scenario because of the increased production due to the accelerated replacement of parts, but this effect is more than offset by the increase in use-phase savings.

The largest share of use-phase savings come from weight reductions in furnishings and equipment system components. This is followed by engine components, with smaller shares coming from body systems, nacelle systems and propulsion systems. The breakdown for cradle-to-gate savings is different: the largest share of savings comes from engine components, which are made with energy-intensive 
metals such as titanium. Figure 5 shows the break-down of energy savings by component system in the use and production phases for the mid-range adoptions scenario, with high-end savings assumptions. A full breakdown for all scenarios is shown in section 5.2 of the SI.

Table 10: Energy saving and $\mathrm{CO}_{2} \mathrm{e}$ reduction ranges, by adoption scenario

\begin{tabular}{|c|c|c|c|c|c|c|}
\hline \multirow[b]{2}{*}{ Year } & \multicolumn{3}{|c|}{$\begin{array}{l}\text { Projected primary energy savings } \\
\text { (million GJ/year) }\end{array}$} & \multicolumn{3}{|c|}{$\begin{array}{l}\text { Projected } \mathrm{CO}_{2} \mathrm{e} \text { emissions reduction (million } \mathrm{t} \\
\mathrm{CO}_{2} \text {-equivalent/year) }\end{array}$} \\
\hline & $\begin{array}{l}\text { Slow } \\
\text { adoption }\end{array}$ & $\begin{array}{l}\text { Mid-range } \\
\text { adoption }\end{array}$ & $\begin{array}{l}\text { Rapid } \\
\text { adoption }\end{array}$ & Slow adoption & $\begin{array}{l}\text { Mid-range } \\
\text { adoption }\end{array}$ & $\begin{array}{l}\text { Rapid } \\
\text { adoption }\end{array}$ \\
\hline 2020 & $0.001-0.002$ & $0.005-0.015$ & $0.03-0.09$ & $0.0001-0.0002$ & 0.0004-0.0012 & $0.002-0.007$ \\
\hline 2025 & $0.03-0.07$ & $0.2-0.6$ & $2-5$ & $0.002-0.006$ & $0.02-0.04$ & $0.15-0.38$ \\
\hline 2030 & $0.3-0.7$ & $3-7$ & $32-65$ & $0.02-0.05$ & $0.2-0.5$ & $2.4-5.0$ \\
\hline 2035 & $1-3$ & $13-27$ & $38-78$ & $0.1-0.2$ & $1.0-2.1$ & $2.9-6.0$ \\
\hline 2040 & $4-8$ & $28-59$ & $60-145$ & $0.3-0.6$ & 2.1-4.6 & $4.6-11.2$ \\
\hline 2045 & $8-19$ & $43-97$ & $66-163$ & $0.6-1.4$ & $3.3-7.4$ & $5.1-12.6$ \\
\hline 2050 & $16-36$ & $56-134$ & $70-173$ & $1.2-2.8$ & $4.3-10.3$ & $5.4-13.3$ \\
\hline $\begin{array}{l}\text { Cumulative } \\
(2019-2050)^{a}\end{array}$ & $110-250$ & $598-1339$ & $\begin{array}{l}1195- \\
2789\end{array}$ & $8.5-19.3$ & $46.1-103.4$ & $92.1-215.0$ \\
\hline
\end{tabular}

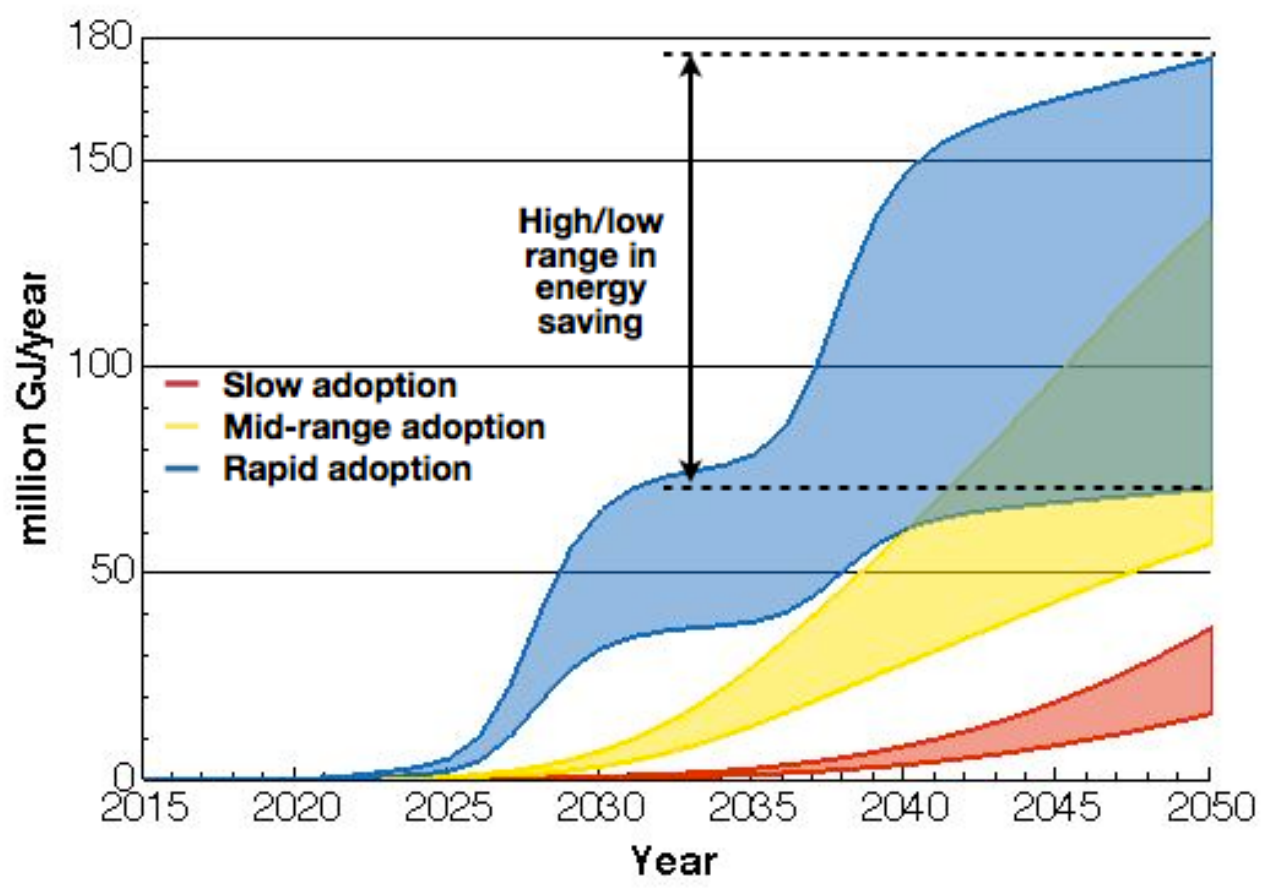

Figure 4: Fleet-wide primary energy use implications of AM Adoption 
- Furnishings and equipment, structure

- Furnishings and equipment, function

Engine, function

Engine, auxiliary

- Propulsion systems

- Body systems, auxiliary

Nacelle systems, auxiliary

Figure 5: Fleet-wide cumulative primary energy savings through 2050 - breakdowns by life cycle phase and by component for mid-range adoption scenario, high end of range

\section{Conclusions and future work}

The adoption of AM components in aircraft has the potential to provide significant energy savings, due to reduced material requirements needed for production and the fuel economy from lighter weight components. The weight reduction is particularly important for airplanes. If AM components evaluated in this study are used to their full potential, airplane fuel consumption could be reduced by as much as $6.4 \%$.

The $\mathrm{LCl}$ analysis of cradle-to-gate energy use also shows that producing AM components may use as little as $1 / 3$ to $1 / 2$ of the energy needed to produce $\mathrm{CM}$ components. In our study that evaluated only a few specific AM applications, we identified the potential to save 4050 tons/year Aluminum, 7600 tons/year Titanium and 8110 tons/year Nickel by 2050. Although the metal waste from CM can be recycled, the extra processing adds cost to the life cycle. For some applications, primary metals are required. Considering the potential for achieving significant reductions in metals consumption using AM technologies, useful future research could be directed to evaluating the impact of AM on demand for primary metals, exploring the possibility of using recycled metals for AM, and developing alternative technologies for producing AM metal feeds.

Based on our comprehensive review of the literature, we note a sparseness of LCl data on AM applications, which had the manifest effect of increasing the uncertainty (i.e., range between high and low values) in our energy and carbon savings estimates and forecasts. In our study, the uncertainties were not great enough to negate the estimated savings. However, for other applications where the usephase benefits are not as significant, the data uncertainties could alter the conclusions. Consequently, we highlight the need for and value of future $\mathrm{LCl}$ studies on $\mathrm{AM}$ applications. 
The scope of this study does not consider all possible energy and carbon savings from AM applications in the aircraft industry. First, it considers only passenger planes. Additional savings could be achieved by using AM parts in the engines of cargo aircraft, which currently make up about $12 \%$ of the total commercial airline fleet, and a larger share of fuel use due to the larger average size of cargo planes [75]. Still more savings could be achieved by using AM parts in military aircraft, which currently use about $19 \%$ of all aviation fuel in the USA[18]. Second, it is focused only on the U.S. aircraft fleet. Global energy savings potential would be much greater, and this potential would expand rapidly with projected growth in global airline travel.

Our calculations also do not include any secondary weight savings that are made possible in other parts of the aircraft due to the reduced weight of AM parts. Weight reductions in certain parts could generate substantial secondary weight savings - for example, a $1 \mathrm{~kg}$ reduction in the weight of fan blades could lead to a $1 \mathrm{~kg}$ reduction in the weight of the fan blade containment case, an $0.5 \mathrm{~kg}$ reduction in the weight of rotor and engine structures, and a $0.25 \mathrm{~kg}$ reduction in the weight of wing and fuselage structures[76]. However, to achieve these secondary savings would require new airplane designs, and therefore it would likely take longer for these savings to penetrate the fleet.

We only evaluated direct replacement of aircraft parts. In fact, AM technology offers the transformative potential to replace existing components with redesigned components, which are today impossible to manufacture. These redesigns might allow one component to replace multiple components, reducing the coupling hardware. Or AM could enable fundamentally different designs that perform the desired function with significantly higher energy efficiency, such as more efficient turbine blade and fuel injections.

The cumulative energy and carbon savings that can be achieved by 2050 from using AM parts in airplanes could be significantly greater given earlier adoption. However, technical challenges including machine productivity, geometric repeatability, residual stress, and high surface roughness need to be overcome to achieve earlier adoption. R\&D investment focused on developing solutions to these challenges could accelerate the use of AM parts in airplanes.

Beyond airplane components, AM also shows energy saving and economic potential in other areas, such as automotive, industry, tooling, medical and design. This study does not evaluate AM potential in any of these areas, but the results provide some indications as to where AM could lead to significant energy savings. Our results suggest that use-phase savings can be important, so one focus could be on identifying areas with the potential for use-phase savings from lightweight parts or other design improvements enabled by AM. However, even when these use-phase savings do not exist, our LCA results suggest that with wider AM adoption there could be significant material and energy savings in the cradle-to-gate phase - particularly in applications that have high scrap rates and use energy intensive materials such as titanium. In addition, the modular nature of AM could enable cost effective distributed manufacturing, which if adopted on a wide scale could lead to even greater impacts. 


\section{Acknowledgement}

The work was supported by the DOE Advanced Manufacturing Office. This document has been created by UChicago Argonne, LLC, Operator of Argonne National Laboratory (“Argonne"). Argonne, a U.S. Department of Energy Office of Science laboratory, is operated under Contract No. DE-AC02-06CH11357. The U.S. Government retains for itself, and others acting on its behalf, a paid-up, nonexclusive, irrevocable worldwide license in said article to reproduce, prepare derivative works, distribute copies to the public, and perform publicly and display publicly, by or on behalf of the Government. 


\section{References}

[1] ASTM International, "Standard Terminology for Additive Manufacturing Technologies," ed. West Conshohocken, PA: ASTM International, 2012.

[2] S. Huang, P. Liu, A. Mokasdar, and L. Hou, "Additive manufacturing and its societal impact: a literature review," The International Journal of Advanced Manufacturing Technology, vol. 67, pp. 1191-1203, 2013/07/01 2013.

[3] T. Wohlers. (2013, 09/01/2013). State of Additive manufacturing. Available:

https://http://www.google.com/url?sa=t\&rct=j\&q=\&esrc=s\&frm=1\&source=web\&cd=1\&ved=0C CwQFjAA\&url=https\%3A\%2F\%2Fregister.ornl.gov\%2F2013\%2FCOC_Workshop\%2Fpresentations $\% 2$ Fwohlers.pdf\&ei=M_UUsLyB8LOyAG3rYDYCA\&usg=AFQjCNEtBNJrqtq2noMqpiZDxjlUBgWd2Q\&bvm=bv.57155469,d. eWO\&cad=rja

[4] T. J. Horn and O. L. A. Harrysson, "Overview of current additive manufacturing technologies and selected applications," Science Progress, vol. 95, pp. 255-282, 2012.

[5] W. Frazier, "Metal Additive Manufacturing: A Review," Journal of Materials Engineering and Performance, vol. 23, pp. 1917-1928, 2014/06/01 2014.

[6] F. P. W. Melchels, M. A. N. Domingos, T. J. Klein, J. Malda, P. J. Bartolo, and D. W. Hutmacher, "Additive manufacturing of tissues and organs," Progress in Polymer Science, vol. 37, pp. 10791104, 2012.

[7] C. J. Tuck, R. J. Hague, M. Ruffo, M. Ransley, and P. Adams, "Rapid manufacturing facilitated customization," International Journal of Computer Integrated Manufacturing, vol. 21, pp. 245258, 2008.

[8] W. Morrow, H. Qi, I. Kim, J. Mazumder, and S. Skerlos, "Environmental aspects of laser-based and conventional tool and die manufacturing," Journal of Cleaner Production, vol. 15, pp. 932943, 2007.

[9] N. Serres, D. Tidu, S. Sankare, and F. Hlawka, "Environmental comparison of MESO-CLAD ${ }^{\circledR}$ process and conventional machining implementing life cycle assessment," Journal of Cleaner Production, vol. 19, pp. 1117-1124, 2011.

[10] J. Immarigeon, R. Holt, A. Koul, L. Zhao, W. Wallace, and J. Beddoes, "Lightweight materials for aircraft applications," Materials Characterization, vol. 35, pp. 41-67, 1995.

[11] Oak Ridge National Laboratory (ORNL), "Aerospace Workshop Planning Session Summary Report," DOE/ITP/ORNL, US2010.

[12] M. Munsch, E. Wycisk, J. Kranz, V. Seyda, and E. Claus. (2012, 09/01/2013). Functional products through laser additive manufacturing of TiAl6V4. Available: http://d12d0wzn4zozj6.cloudfront.net/pdf/LAM2012 Presentation 8.pdf

[13] D. Carrington. (2013, 09/02/2013). Jet engine makers get lift from 3-D printing technology. Available: http://www.cnn.com/2013/06/11/travel/leap-engine-3-d-printing

[14] IEA, "World Energy Outlook," IEA, France2010.

[15] C. E. Schlumberger, "Air Transport and Energy Efficiency," The World Bank, Washington, DC 68010, 2012/02/01 2012.

[16] C. Faganha, K. Blumberg, and J. Miller, "Global Transportation Energy and Climate Roadmap," ICCT, Washing DC, USA2012.

[17] J.-P. Rodrigue, C. Comtois, and B. Slack, The geography of transport systems: Routledge, 2009.

[18] Energy Information Administration(EIA), "Annual Energy Outlook 2014," EIA, US Department of Energy, Washington, DC, USA2014.

[19] D. Dornfeld. (2010, 12/15/2013). Green Manufacturing: Degrees of Perfection. Available: http://green-manufacturing.blogspot.com/2010/07/degrees-of-perfection.html 
[20] J. M. Allwood, M. F. Ashby, T. G. Gutowski, and E. Worrell, "Material efficiency: A white paper," Resources, Conservation and Recycling, vol. 55, pp. 362-381, 2011.

[21] M. Kaufmann, "Cost/Weight Optimization of Aircraft Structures," Licentiate of Technology, KTH, Stockholm, 2008.

[22] W. Cole. (2005, 09/03/2013). Boeing engineers and technologists are constantly developing better ways to design and make products. Available: http://www.boeing.com/news/frontiers/archive/2004/december/ts_sf03.html

[23] GE. (09/05/2013). GE Additive Manufacturing Lab. Available: http://www.ge.com/stories/additive-manufacturing

[24] J. E. Gausemeier, Niklas; Wall, Marina, "Thinking Ahead the Future of Additive Manufacturing Innovation Roadmapping of Required Advancements," DMRC, University of Paderborn, Paderborn, Germany2014.

[25] P. A. Kobryn, N. R. Ontko, L. P. Perkins, and J. S. Tiley, "Additive Manufacturing of Aerospace Alloys for Aircraft Structures," AFRL/MLSC Acquisition Systems Support Branch Materials and Manufacturing Directorate Air Force Research Laboratory, Wright-Patterson Air Force Base, Ohio2006.

[26] GE. (2013, 06/05/2014). Additive Manufacturing Redefining What's Possible. Available: http://www.americas.gecapital.com/GECA_Document/Additive_Manufacturing_Fall_2013.pdf

[27] Y. Luo, Z. Ji, M. C. Leu, and R. Caudill, "Environmental performance analysis of solid freedom fabrication processes," in Electronics and the Environment, 1999. ISEE-1999. Proceedings of the 1999 IEEE International Symposium on, 1999, pp. 1-6.

[28] P. Mognol, D. Lepicart, and N. Perry, "Rapid prototyping: energy and environment in the spotlight," Rapid prototyping journal, vol. 12, pp. 26-34, 2006.

[29] R. Sreenivasan and D. Bourell, "Sustainability Study in Selective Laser Sintering- An Energy Perspective," in 2009 Solid Freeform Fabrication Symposium, Austin, Texas, 2009.

[30] K. Kellens, W. Dewulf, W. Deprez, E. Yasa, and J. Duflou, "Environmental analysis of SLM and SLS manufacturing processes," in Proceedings of LCE2010 Conference, 2010, pp. 423-428.

[31] M. Baumers, C. Tuck, R. Hague, I. Ashcroft, and R. Wildman, "A comparative study of metallic additive manufacturing power consumption," in Proceedings of the 2010 Solid Freeform Fabrication Symposium, The University of Texas at Austin, Austin, TX, 9-11 August, 2010.

[32] M. Baumers, C. Tuck, D. Bourell, R. Sreenivasan, and R. Hague, "Sustainability of additive manufacturing: measuring the energy consumption of the laser sintering process," Proceedings of the Institution of Mechanical Engineers, Part B: Journal of Engineering Manufacture, vol. 225, pp. 2228-2239, 2011.

[33] M. Baumers, C. Tuck, R. Wildman, I. Ashcroft, and R. Hague, "Energy inputs to additive manufacturing: does capacity utilization matter?," EOS, vol. 1000, p. 270, 2011.

[34] M. Baumers, C. Tuck, R. Wildman, I. Ashcroft, E. Rosamond, and R. Hague, "Transparency Builtin," Journal of Industrial Ecology, vol. 17, p. 13, June 20132013.

[35] C. Telenko and S. Carolyn Conner, "A comparison of the energy efficiency of selective laser sintering and injection molding of nylon parts," Rapid Prototyping Journal, vol. 18, pp. 472-481, 2012.

[36] M. Kreiger and J. M. Pearce, "Environmental Impacts of Distributed Manufacturing from 3-D Printing of Polymer Components and Products," Mat. Res. Soc. Proceedings. Fall, 2012.

[37] J. M. Wilson, C. Piya, Y. C. Shin, F. Zhao, and K. Ramani, "Remanufacturing of turbine blades by laser direct deposition with its energy and environmental impact analysis," Journal of Cleaner Production, vol. 80, pp. 170-178, 2014.

[38] I. Kroo. (September 2013). Aricraft Design: Synthesis and Analysis. 
[39] GE. (1999, 09/15/2013). Defining Technology for the Next Millennium. Available: http://www.google.com/url?sa=t\&rct=j\&q=\&esrc=s\&frm=1\&source=web\&cd=1\&ved=0CCoQFjA A\&url=http\%3A\%2F\%2Fwww.southampton.ac.uk\%2F jps7\%2FAircraft Design Resources\%2FPowerplant\%2FGE slides on engine costs.ppt\&ei=6AKUUrSrDeaD2gWbOYCWBA\&usg=AFQjCNFfGsjxSJzhqVYWqeoZRVZ28knKzA

[40] M. Cervenka, "The rolls-royce trent engine," Lecture note at University of Cambridge, 2000.

[41] J. L. Cutler, Jeremy, Understanding Aircraft Structure, 4 ed.: Wiley, 2006.

[42] E. H. Biel, Gary; Ervin, Bruce, "Aviation Structural Mechanic (H\& S) 3 \& 2," U. S. Navy, Ed., ed. Washington, D.C.: Naval Education and training program management support activity, 1993.

[43] J. H. Mattingly, W; Pratt, D, Aircraft Engine Design, 2 ed.: AIAA, 2003.

[44] S. J. Schaich, "Design of Aircraft Interior," in Improved Fire- and Smoke-Resistant Materials for Commercial Aircraft Interiors Washington, D.C., 1995, pp. 203-212.

[45] AeroStrategy, "Commercial Aviation MRO (CAMRO)," 2009.

[46] G. Krailling and M. Novi. (2014, 06/10/2014). EOS and Airbus Group Innovations Team on Aerospace Sustainability Study for Industrial 3D Printing. Available: http://www.eos.info/eos_airbusgroupinnovationteam_aerospace_sustainability_study

[47] Airliners.net. (08/29/2013). Aircraft Technical Data and Specification. Available: http://www.airliners.net/aircraft-data/

[48] Bureau of Transportation Statistics (BTS). U.S. Air Carrier Traffic Statistics through May 2013 [Online]. Available: http://apps.bts.gov/xml/air_traffic/src/index.xml

[49] T. Norgate, S. Jahanshahi, and W. Rankin, "Assessing the environmental impact of metal production processes," Journal of Cleaner Production, vol. 15, pp. 838-848, 2007.

[50] Argonne National Laboratory (ANL), "The Greenhouse Gases, Regulated Emissions, and Energy Use in Transportation (GREET2_2012)," Argonne, IL2012.

[51] National Renewable Energy Laboratory (NREL). (2012, 11/19/2013). U.S. Life Cycle Inventory Database. Available: https://http://www.Icacommons.gov/nrel/search

[52] ecoinvent Centre. Ecoinvent data v3.1 [Online]. Available: http://www.ecoinvent.org

[53] S. F. Sibley, Overview of flow studies for recycling metal commodities in the United States: US Department of the Interior, US Geological Survey Reston, VA, 2011.

[54] M. F. Ashby, Materials and the environment: eco-informed material choice: Elsevier, 2012.

[55] N. Duque Ciceri, T. G. Gutowski, and M. Garetti, "A tool to estimate materials and manufacturing energy for a product," in Sustainable Systems and Technology (ISSST), 2010 IEEE International Symposium on, 2010, pp. 1-6.

[56] S. Kara and W. Li, "Unit process energy consumption models for material removal processes," CIRP Annals-Manufacturing Technology, vol. 60, pp. 37-40, 2011.

[57] J. Dahmus and T. Gutowski, "An environmental analysis of machining," in ASME International Mechanical Engineering Congress and RD\&D Exposition, Anaheim, California, USA, 2004.

[58] E. Ezugwu and Z. Wang, "Titanium alloys and their machinability-a review," Journal of Materials Processing Technology, vol. 68, pp. 262-274, 1997.

[59] Acram AB. (09/10/2013). EBM in Aerospace-Additive Manufacturing taken to unseen heights. Available: http://www.arcam.com/solutions/aerospace-ebm/

[60] T. Shinbara. (2013,03/12/2014). Additive Manufacturing: An expose on the Diversity of Industrial use. Available: http://www.naefrontiers.org/File.aspx?id=39131

[61] Oak Ridge National Laboratory (ORNL), "Case studies for additive manufacturing: Aerospace Brackets," 2013.

[62] The SAVING project. (2009, 09/15/2013). Innovation Results and R\&D Case Study: Redesigned airline buckle to save energy. Available: http://www.manufacturingthefuture.co.uk/casestudies/ 
[63] EOS. (09/12/2013). Case Study: Light-weight bracket. Available: http://www.eos.info/industries_markets/aerospace/interior

[64] M. Tomlin and J. Meyer, "Topology Optimization of an Additive Layer Manufactured (ALM) Aerospace Part," in The 7th Altair CAE Technology Conference, Gaydon, UK, 10th May, 2011.

[65] Boeing. (2013, 09/10/2013). Who's Building the 787 Dreamliner. Available: http://www.newairplane.com/787/whos_building/

[66] J. E. Gausemeier, Niklas; Kokoschka, Martin; Wall, Marina, "Thinking Ahead the Future of Additive Manufacturing - Future Applications," DMRC, University of Paderborn, Paderborn, Germany2014.

[67] F. M. Bass, "A NEW PRODUCT GROWTH FOR MODEL CONSUMER DURABLES," Management Science, vol. 15, pp. 215-227, 1969.

[68] D. Forsberg, "Aircraft Retirement Trends \& Outlook," Avolon2012.

[69] J. H. Pae and D. R. Lehmann, "Multigeneration innovation diffusion: The impact of intergeneration time," Journal of the Academy of Marketing Science, vol. 31, pp. 36-45, 2003.

[70] D. L. Greene, "Energy-efficiency improvement potential of commercial aircraft," Annual Review of Energy and the Environment, vol. 17, pp. 537-573, 1992.

[71] S. Das, D. Graziano, Upadhyayula V, E. Masanet, and M. Riddle, "Vehicle Lightweighting from a Life Cycle Energy and Emissions Perspective," 2013.

[72] Lufthansa Group. (2011, 09/05/2013). Fuel efficiency at theLufthansa Group - Cutting costs and protectign the environment. Available: http://www.lufthansagroup.com/fileadmin/downloads/en/LH-fuel-efficiency-0612.pdf

[73] H. Helms and U. Lambrecht, "The potential contribution of lightweighting to reduce transport energy consumption," The International Journal of Life Cycle Assessment, vol. 1, pp. 58-64, 2006.

[74] American Airlines. (2007, 09/20/2013). Commited to Preserving the Wonders of Our World. Available: http://www.aa.com/content/images/amrcorp/amrerr.pdf

[75] Federal Aviation Administration (FAA), "Aerospace Forecast: Fiscal Years 2013-2033," U.S. Department of Transportation, Washington DC2013.

[76] C. Red, "Aviation Outlook: Composites in commercial aircraft jet engines," High-Performance Composites, 2008. 
1

2

3

\section{The Energy and Emissions Saving Potential of Additive Manufacturing: The Case of Lightweight Aircraft Components}

\section{Supporting Information}

Runze Huang ${ }^{1}$, Matthew Riddle ${ }^{2}$, Diane Graziano ${ }^{3}$, Joshua Warren ${ }^{4}$, Sujit Das ${ }^{4}$, Sachin Nimbalkar ${ }^{4}$, Joe Cresko ${ }^{5}$, and Eric Masanet ${ }^{1 *}$

1. McCormick School of Engineering and Applied Science, Northwestern University, 2145 Sheridan Road, Evanston, Illinois, USA

2. Energy Systems Division, Argonne National Laboratory, 9700 South Cass Avenue, Argonne, Illinois, USA 60439

3. Global Security Sciences Division, Argonne National Laboratory, 9700 South Cass Avenue, Argonne, Illinois USA 60439

4. Oak Ridge National Laboratory, 1 Bethel Valley Road, Oak Ridge, Tennessee, 37831

5. Advanced Manufacturing Office, United States Department of Energy, 1000 Independence Avenue, SW, Washington, DC, USA 20585

*Corresponding author. Tel: +1 847467 2806; email: eric.masanet@northwestern.edu

\section{Number of Pages: 39 (including the cover page)}

Number of Figures: 2

Number of Tables: 31 


\section{Identification of major aircraft component systems}

A typical commercial passenger aircraft contains hundreds of thousands of components. It is therefore impractical to assess the potential for lightweight redesigns of each individual component. Rather, this study first identified the major component systems within an aircraft to select those systems that represent the most feasible application opportunities for lightweight AM components in the near term (i.e., within 5-20 years). Feasible applications were defined as those that met specific criteria for load profile, geometric complexity, geometric volume, materials, and other factors as described in Section 2.

This study adopted the major aircraft component system definitions and system weights developed by Kroo et al[1], which identified 17 major component systems within typical commercial passenger aircraft models and further provided total weight estimates for each system based on aircraft weight statements. These data are summarized in Table S1. Based on these data, an average mass fraction for each major component system across all aircraft types was calculated by dividing the average component system weight by the average empty aircraft weight. These mass fractions are shown in the last column of Table S1, and were assumed to be representative of the mass composition of the average aircraft in the U.S. commercial passenger aircraft fleet for the purposes of this study.

Several of the systems listed in Table S1 contain a wide variety of components that serve different purposes within their respective systems, not all of which are presently feasible for lightweight redesign using AM technologies. Therefore, these major component systems were further subdivided into three component categories as summarized in Table S2:

(1) Structural components, which refers to components whose primary purpose is to maintain aircraft geometries and bear major system loads; examples include skin, truss, rib, and stringer in the fuselage, wings and other systems.

(2) Functional components, which refers to components whose primary purpose is to provide flight functions such as seats, engine turbine, and air-conditioning.

(3) Auxiliary components, which refers to all non-structural and non-functional components (as defined above) that are also small geometric volume components; examples include small brackets, door hinges, joints and clips in different systems. 
Table S1. Aircraft component systems and weight contributions (in kg) [2]

\begin{tabular}{|c|c|c|c|c|c|c|c|c|c|c|}
\hline $\begin{array}{l}\text { Aircraft } \\
\text { component } \\
\text { system }\end{array}$ & $\begin{array}{l}727- \\
200\end{array}$ & $\begin{array}{l}707- \\
320\end{array}$ & DC-8-55 & DC-8-62 & $\begin{array}{l}\text { DC-10- } \\
10\end{array}$ & L-1011 & $\begin{array}{l}\text { DC-10- } \\
40\end{array}$ & 747 & $\begin{array}{l}\text { SCAT- } \\
15\end{array}$ & $\begin{array}{l}\text { Avg. } \\
\text { mass } \\
\text { fraction }\end{array}$ \\
\hline Wing system & 8,405 & 12,994 & 15,835 & 16,442 & 22,222 & 21,501 & 26,194 & 40,253 & 38,075 & 0.24 \\
\hline Tail system & 1,879 & 2,723 & 2,246 & 2,236 & 6,195 & 3,887 & 6,556 & 5,424 & 3,896 & 0.04 \\
\hline Body system & 10,167 & 10,115 & 10,091 & 10,752 & 20,317 & 22,422 & 21,102 & 31,050 & 24,646 & 0.19 \\
\hline $\begin{array}{l}\text { Alighting gear } \\
\text { system }\end{array}$ & 3,605 & 5,088 & 5,299 & 5,193 & 8,428 & 9,037 & 11,379 & 14,615 & 13,027 & 0.09 \\
\hline Nacelle system & 1,009 & 1,441 & 2,107 & 3,016 & 3,852 & 4,044 & 4,231 & 4,912 & 7,099 & 0.04 \\
\hline $\begin{array}{l}\text { Propulsion } \\
\text { system (less dry } \\
\text { engine) }\end{array}$ & 1,371 & 2,406 & 4,268 & 3,556 & 3,480 & 3,755 & 6,125 & 4,357 & 2,862 & 0.04 \\
\hline $\begin{array}{l}\text { Flight controls } \\
\text { system (less auto } \\
\text { pilot) }\end{array}$ & 1,354 & 970 & 923 & 952 & 2,322 & 2,299 & 2,353 & 3,123 & 4,888 & 0.02 \\
\hline $\begin{array}{l}\text { Auxiliary power } \\
\text { plant system }\end{array}$ & 385 & - & - & - & 721 & 545 & 722 & 815 & - & $<0.01$ \\
\hline $\begin{array}{l}\text { Instrument } \\
\text { system }\end{array}$ & 375 & 249 & 455 & 415 & 612 & 461 & 746 & 674 & 1,542 & 0.01 \\
\hline $\begin{array}{l}\text { Hydraulic and } \\
\text { pneumatic group }\end{array}$ & 520 & 706 & 1,021 & 791 & 1,882 & 1,996 & 1971 & 2,298 & 4,840 & 0.02 \\
\hline Electrical system & 1,290 & 1,789 & 2,456 & 1,248 & 2,434 & 2,490 & 2,401 & 2,406 & 2,723 & 0.02 \\
\hline $\begin{array}{l}\text { Avionics system } \\
\text { (incl. auto pilot) }\end{array}$ & 860 & 823 & 848 & 934 & 1,282 & 1,271 & 1,445 & 1,875 & 1,895 & 0.01 \\
\hline $\begin{array}{l}\text { Furnishings and } \\
\text { equipment } \\
\text { system }\end{array}$ & 6,669 & 7,655 & 7,205 & 6,958 & 17,269 & 14,891 & 15,021 & 21,776 & 9,351 & 0.13 \\
\hline $\begin{array}{l}\text { Air conditioning } \\
\text { system }\end{array}$ & 817 & 728 & 1,083 & 1,041 & 1,082 & 1,517 & 1,146 & 1,648 & 1,279 & 0.01 \\
\hline Anti-icing system & 302 & 284 & 360 & 305 & 189 & 134 & 252 & 187 & 95 & $<0.01$ \\
\hline $\begin{array}{l}\text { Load and } \\
\text { handling system }\end{array}$ & 9 & - & 25 & 24 & 28 & - & 28 & $\begin{array}{l}103- \\
406\end{array}$ & - & $<0.01$ \\
\hline $\begin{array}{l}\text { Empty weight } \\
\text { (less dry engine) }\end{array}$ & 39,017 & 47,971 & 52,860 & 53,865 & 92,317 & 90,252 & 101,674 & 135,112 & 116,214 & \\
\hline $\begin{array}{l}\text { Dry engine } \\
\text { weight }\end{array}$ & 4,390 & 8,809 & 7,682 & 7,855 & 10,537 & 13,629 & 11,606 & 16,194 & 20,421 & 0.12 \\
\hline Empty weight & 43,407 & 56,780 & 60,542 & 61,719 & 102,854 & 103,881 & 113,280 & 151,306 & 136,635 & 1 \\
\hline $\begin{array}{l}\text { Takeoff gross } \\
\text { weight }\end{array}$ & 79,380 & 141,523 & 147,420 & 151,956 & 195,048 & 195,048 & 256,284 & 351,540 & 286,217 & \\
\hline
\end{tabular}


Table S2. Mass fractions of categories within major component systems

\begin{tabular}{llll}
\hline Component system & \multicolumn{3}{l}{ Category mass fraction } \\
\hline Wing systems & Structural & Functional & Auxiliary \\
\hline Body systems & 0.95 & 0 & 0.05 \\
Furnishings and equipment systems & 0.95 & 0 & 0.05 \\
Engine & 0.36 & 0.57 & 0.07 \\
Alighting gear systems & 0.17 & 0.77 & 0.06 \\
Tail & 0.95 & 0 & 0.05 \\
\hline Propulsion & 0.95 & 0 & 0.05 \\
Nacelle Systems & 0 & 1 & 0 \\
\hline & 0.95 & 0 & 0.05 \\
\hline
\end{tabular}

These three component categories were defined to facilitate a more detailed and credible selection process for AM opportunities using the process discussed in Section 2. For each system listed in Table S2, the percent of the system mass that is attributable to each component category was estimated as follows:

- Furnishing and equipment systems: All mass fractions are based on an unpublished report from Boeing that contains the weights of furnishing and equipment components. Here, structural components include floor panels and fasteners, cabin panels, ceilings, stowage bins, partitions, air ducts, galley lavatories and windows; functional components include seat assemblies, passenger service units, and evacuation systems; and auxiliary components include the balance of mass from the Boeing data.

- Engine systems: All mass fractions are based on engine mass and material composition data from General Electric and Rolls-Royce, which are summarized in Table S3 [3, 4]. Here, structural components are limited to frames; functional components include the turbine, fan assembly, compressor, controls and accessories, and booster and combustor; and auxiliary components include the bearing, seals, and miscellaneous and assembly [3].

- Nacelle and fuselage systems: Given that the major purposes of the nacelle and fuselage (i.e., wing, tail, body, and alighting gear) systems are to provide structural support and bear loads, this study estimated that $95 \%$ of the mass in these component systems would be comprised of structural components[5]. The remaining $5 \%$ of the mass in these component systems was attributed to auxiliary components. 


\section{Selection and characterization of component systems for additive manufacturing}

The data in Section 1 describe the assumed mass fractions of each major component system within a typical commercial passenger aircraft, as well as the mass fractions attributable to structural, functional, and auxiliary components within each system. The next step in this study was to select and characterize the component systems that represent the most feasible opportunities in the near term for lightweight designs produced using AM technologies. The selection and characterization process was comprised of four key steps, which are described in Sections 2.1-2.4, respectively.

\subsection{Component system selection}

A recent review of $A M$ technologies suggests that the major factors that influence AM adoption for a given component are its load profile requirements, geometric complexity, geometric volume, and economic value [6]. In general, components with non-critical load profiles, complex geometries, small to medium geometric volumes, and high economic value represents the most attractive applications of current AM technologies [6, 7]. In the aircraft industry, the economic value of components is typically high given their use of advanced materials, engineering performance requirements, and high dimensional precision. Therefore, this study focused on assessing the load profile, geometric complexity, and geometric volume attributes of major aircraft component systems. Table S4 summarizes this study's assessment of these attributes. Each attribute was assigned a qualitative rating of low, medium, or high. Component systems that comprise less than $2 \%$ of the mass of the typical aircraft have been neglected for simplicity. 
Table S4. Attribute ratings for component system selection

\begin{tabular}{|c|c|c|c|c|c|c|}
\hline $\begin{array}{l}\text { Component systems } \\
\text { (component } \\
\text { category) }\end{array}$ & & Mass fraction & Load rating & $\begin{array}{l}\text { Shape } \\
\text { complexity } \\
\text { rating }\end{array}$ & $\begin{array}{l}\text { Geometric } \\
\text { volume rating }\end{array}$ & $\begin{array}{l}\text { Feasibility } \\
\text { Evaluation } \\
\text { score }\end{array}$ \\
\hline \multirow[t]{3}{*}{ Wing systems } & & 0.24 & & & & \\
\hline & Structural & 0.95 & High & Medium & High & 4 \\
\hline & Auxiliary & 0.05 & High & Low & Low & 5 \\
\hline \multirow[t]{3}{*}{ Body systems } & & 0.19 & & & & \\
\hline & Structural & 0.95 & High & Medium & High & 4 \\
\hline & Auxiliary & 0.05 & Medium & Low & Low & 6 \\
\hline \multirow{4}{*}{$\begin{array}{l}\text { Furnishings and } \\
\text { equipment systems }\end{array}$} & & 0.13 & & & & \\
\hline & Structural & 0.36 & Low-Medium & Medium & Low-Medium & 7 \\
\hline & Functional & 0.57 & Low & Medium & Medium & 7 \\
\hline & Auxiliary & 0.07 & Low & Low & Low & 7 \\
\hline \multirow[t]{4}{*}{ Engine } & & 0.12 & & & & \\
\hline & Structural & 0.17 & High & Medium & High & 4 \\
\hline & Functional & 0.77 & High & High & Medium-High & 5.5 \\
\hline & Auxiliary & 0.06 & Medium-High & Low & Low & 5.5 \\
\hline \multirow{3}{*}{$\begin{array}{l}\text { Alighting gear } \\
\text { systems }\end{array}$} & & 0.09 & & & & \\
\hline & Structural & 0.95 & High & Medium & High & 4 \\
\hline & Auxiliary & 0.05 & High & Low & Low & 5 \\
\hline \multirow[t]{3}{*}{ Tail systems } & & 0.04 & & & & \\
\hline & Structural & 0.95 & High & Medium & High & 4 \\
\hline & Auxiliary & 0.05 & High & Low & Low & 5 \\
\hline \multirow[t]{2}{*}{ Propulsion systems } & & 0.04 & & & & \\
\hline & Functional & 1.00 & High & High & Medium & 6 \\
\hline \multirow[t]{3}{*}{ Nacelle systems } & & 0.04 & & & & \\
\hline & Structure & 0.95 & High & Medium & High & 4 \\
\hline & Auxiliary & 0.05 & Low-Medium & Low & Low & 6.5 \\
\hline
\end{tabular}




\subsubsection{Load rating}

All structural components were assigned a medium or high load rating depending on the system, given that structural components are inherently load bearing. Structural components in wings, fuselage, tail, alighting gear and engine systems were assigned a high load rating, given the critical load-bearing nature of these systems, such as cyclic loading on wings and tails during flight and impact on the alighting gears during landing[8]. Structural components in furnishing and equipment were assigned low to medium load ratings because the loading caused by human behavior inside of the plane is relatively small compare to loading caused by lifting and landing the aircraft[9].

All functional components in the engine and propulsion systems were assigned a high load rating, since they provide the propulsive forces for the aircraft[10]. The functional components in furnishing systems were given a low load rating since the loading is relatively small compared to other aircraft loads[9]. Auxiliary components in the wings, tails, and alighting gear systems were assigned a high load rating, since they support or connect the structural components, which means they bear nearly the same loads as the structural components. Given the diversity of uses of auxiliary parts in the engine systems, medium to high load ratings were assigned to those components (for example, bearings for the fan assembles would see high loads, but fasteners used for the electrical wires would be bear much lower loads)[10]. Medium and low to medium load ratings were assigned to auxiliary components within the body and nacelle systems, respectively, given that such components (e.g., auxiliary components for doors) typically bear non-critical loads.

\subsubsection{Shape complexity rating}

A medium shape complexity rating was assigned to the structural components within all component systems, given that most structural components (e.g., ribs and trusses) use hollowed out designs for weight savings[8]. For furnishing systems, the major functional component is the seat, in which structural components are also hollowed out; therefore, functional components in furnishing systems were assigned a medium rating [11]. Functional components within engine and propulsion systems were all assigned a high shape complexity rating, given that these components are highly engineered for thermodynamic and fatigue performance and typically have complicated and/or precise geometries[10]. Auxiliary parts are all assigned a low shape complexity rating as these parts are typically small and simple parts.

\subsubsection{Geometric volume rating}

All structural components except those within furnishing systems were assigned a high geometric volume rating due their typically large sizes, especially for flight load-bearing components, which can be several meters in length, width, and/or depth[8]. Structural components in furnishing systems are typically smaller than those in other aircraft systems (e.g., fasteners, partitions and stowage bins) and were accordingly assigned a low to medium geometric volume rating [11]. For consistency with the above ratings, functional components in furnishing systems (majorly seats) were assigned a medium 

were assigned medium to high geometric volume ratings. All auxiliary components were assigned a low geometric volume rating based on the logic in Section 2.1.2.

\subsubsection{Feasibility scoring}

Table S5 summarizes the feasibility scoring scheme used to identify component system categories that are feasible near-term candidates for lightweighting using AM technologies. As described earlier, components with non-critical load profiles (i.e., low load ratings), complex geometries (i.e., high shape complexity ratings), and small to medium geometric volumes (i.e., low to medium geometric volume ratings) represent the most attractive applications of current $A M$ technologies. Based on this fundamental assumption, feasibility scores of 1, 2, and 3 were assigned to each rating in Table S5 to represent low, medium, and high feasibility of AM technology adoption. Feasibility scores were then summed across each component category with each component system to arrive at the final feasibility evaluation scores listed in Table S4. Component systems and categories with feasibility evaluation scores greater than 5 were selected as candidates for near-term lightweighting using AM technologies in this study. The selected component systems and categories are indicated in bold font in Table S4.

Table S5. Feasibility scoring scheme

\begin{tabular}{llll}
\hline Rating & Load & $\begin{array}{l}\text { Shape } \\
\text { Complexity }\end{array}$ & Volume \\
\hline High & 1 & 3 & 1 \\
Medium & 2 & 2 & 2 \\
Low & 3 & 1 & 3 \\
\hline
\end{tabular}

\subsection{Materials composition}

The next step in the selection and characterization process was to estimate the materials composition of each of selected component category within each selected component system. Establishing the materials composition was necessary to estimate the AM replacement potential within each component category and to identify the $\mathrm{CM}$ and $\mathrm{AM}$ process technologies applicable to manufacturing components within component category. Table S6 summarizes this study's assumptions for the average mass composition of each selected component category, expressed as the fraction of total component category mass that is comprised of polymers, aluminum alloys, titanium alloys, nickel alloys, steel alloys, and other materials (materials fractions sum to 1 ). The data in Table S6 for engine systems were estimated based on engine materials composition data for typical engines from GE (Table S2) and RollsRoyce [3]. No component-specific materials composition data could be found for body, propulsion, and nacelle systems; therefore, this study estimated that auxiliary components in body systems are made of aluminum alloys and that functional components in propulsion systems and auxiliary components in nacelle systems are made of titanium alloys based on more general system data [8]. The data in Table S6 for the remaining component categories were estimated based on the aforementioned unpublished aircraft materials composition data from Boeing. 
Table S6. Material composition assumptions for selected component categories

\begin{tabular}{|c|c|c|c|c|c|c|c|c|}
\hline \multirow{2}{*}{$\begin{array}{l}\text { Component } \\
\text { systems } \\
\text { (component } \\
\text { category) }\end{array}$} & \multirow[b]{2}{*}{$\begin{array}{l}\text { Mass } \\
\text { fraction }\end{array}$} & \multicolumn{6}{|c|}{ Material fraction (sums to 1.00 across materials) } & \multirow[b]{2}{*}{ Source(s) } \\
\hline & & Polymers & $\begin{array}{l}\text { Al } \\
\text { alloy }\end{array}$ & $\begin{array}{l}\text { Ti } \\
\text { alloy }\end{array}$ & $\begin{array}{l}\mathrm{Ni} \\
\text { alloy }\end{array}$ & Steel & Other & \\
\hline Body systems & 0.19 & & & & & & & \\
\hline Auxiliary & 0.05 & & 1.00 & & & & & Estimated \\
\hline $\begin{array}{l}\text { Furnishings and } \\
\text { equipment }\end{array}$ & 0.13 & & & & & & & Boeing data \\
\hline Structural & 0.36 & 0.92 & 0.07 & & & & 0.01 & \\
\hline Functional & 0.57 & 0.22 & 0.64 & & & & 0.14 & \\
\hline Auxiliary & 0.07 & 0.26 & & & & & 0.74 & \\
\hline Engine & 0.12 & & & & & & & {$[3,4,10]$} \\
\hline Functional & 0.77 & & & 0.37 & 0.50 & 0.05 & 0.08 & \\
\hline Auxiliary & 0.06 & & & 0.32 & 0.32 & 0.32 & 0.05 & \\
\hline Propulsion systems & 0.04 & & & & & & & \\
\hline Functional & 1.00 & & & 1.00 & & & & Estimated \\
\hline Nacelle Systems & 0.04 & & & & & & & \\
\hline Auxiliary & 0.05 & & & 1.00 & & & & Estimated \\
\hline
\end{tabular}

\subsection{Additive manufacturing applicability}

The third step in the selection and characterization process was to estimate the fraction of the materials mass within each selected component category that could realistically be replaced by components manufactured using AM technology (which this study defines as the replaceable fraction). Table S7 summarizes this study's estimates of the replaceable fraction of each material within each component category. This study focused only on opportunities for metal alloys as a matter of scope.

Table S7. Replaceable fraction of materials within selected component systems

\begin{tabular}{|c|c|c|c|c|c|c|c|c|}
\hline \multirow{2}{*}{$\begin{array}{l}\text { Component } \\
\text { systems } \\
\text { (component } \\
\text { category) }\end{array}$} & \multirow{2}{*}{$\begin{array}{l}\text { Mass } \\
\text { fraction }\end{array}$} & \multicolumn{6}{|c|}{ Fraction of material mass replaceable by AM technology } & \multirow[b]{2}{*}{ Source(s) } \\
\hline & & Polymer & Al alloy & Ti alloy & Ni alloy & Steel & Other & \\
\hline Body systems & 0.19 & & & & & & & \\
\hline Auxiliary & 0.05 & & $0.2-0.5$ & & & & & Estimated \\
\hline $\begin{array}{l}\text { Furnishings and } \\
\text { equipment } \\
\text { systems }\end{array}$ & 0.13 & & & & & & & $\begin{array}{l}\text { [12-14]and } \\
\text { Boeing data }\end{array}$ \\
\hline Structural & 0.36 & & $0.5-1.0$ & & & & & \\
\hline Functional & 0.57 & & $0.75-1.0$ & & & & & \\
\hline Auxiliary & 0.07 & & & & & & & \\
\hline Engine & 0.12 & & & & & & & {$[3,4,10,15]$} \\
\hline Functional & 0.77 & & & $0.5-1.0$ & $0.5-1.0$ & $0.5-1.0$ & & \\
\hline Auxiliary & 0.06 & & & $0.5-1.0$ & $0.5-1.0$ & $0.5-1.0$ & & \\
\hline $\begin{array}{l}\text { Propulsion } \\
\text { systems }\end{array}$ & 0.04 & & & & & & & \\
\hline Functional & 1 & & & $0.2-0.5$ & & & & Estimated \\
\hline Nacelle systems & 0.04 & & & & & & & \\
\hline Auxiliary & 0.05 & & & $0.2-0.5$ & & & & Estimated \\
\hline
\end{tabular}



of component information provided in the unpublished Boeing report and the engine component data from GE [3]. In furnishings systems, major metal alloy components were identified as, or within, floor fasteners, stowage bins, partitions, galleys, lavatories, and seats. In engine systems, major metal alloy components were identified as turbines, fans, combustors, boosters, compressors and their auxiliary parts. Potential applications of AM technologies for such components have appeared in the literature to date[12-15]. As such, this study assumed an upper bound on replacement fraction for these metal alloy components of $100 \%[16]$. However, how soon this replacement can occur is governed by this study's analysis of temporal feasibility (see Section 2.4). For functional components within furnishing systems, a lower bound of $75 \%$ was selected based on the assumption that only economy class seats would be subject to replacement. For functional titanium and nickel alloy components within engine systems, a lower bound replacement fraction of $50 \%$ was adopted based on GE's goal for weight reduction using AM technologies in future aircraft engines [15]. For the remaining metal alloy components in furnishing and engine systems, a lower bound of $50 \%$ replacement fraction was chosen as a conservative assumption, and in the absence of literature or empirical data. In the absence of detailed component and materials information for body systems, propulsion systems, and nacelle systems, a conservative replacement fraction range of $20-50 \%$ was assumed for components within these systems.

Table S8 summarizes estimates for the total mass of each material that is replaceable by components manufactured using AM technologies in the near term for the typical aircraft in this study. The estimates in Table 88 were calculated by multiplying the mass, materials, and replacement fractions in Tables S1, S6, and S7. These results were scaled to the average mass of an aircraft within the US commercial fleet, which was estimated to be $40,622 \mathrm{~kg}$. This estimate was derived by first constructing a linear relationship between operating empty mass and the number of passenger seats on a plane, and using that relationship to estimate the mass of a plane with an average number of seats. The average number of seats per plane, weighted by miles flown, was estimated to be 142 , based on data from the U.S. Bureau of Transportation Statistics on seat miles and aircraft miles flown from June 2012-May 2013[17]. The linear relationship, shown in Figure S1, was estimated by fitting data on operating empty mass and seating capacity for some of the most popular models of aircraft[18].

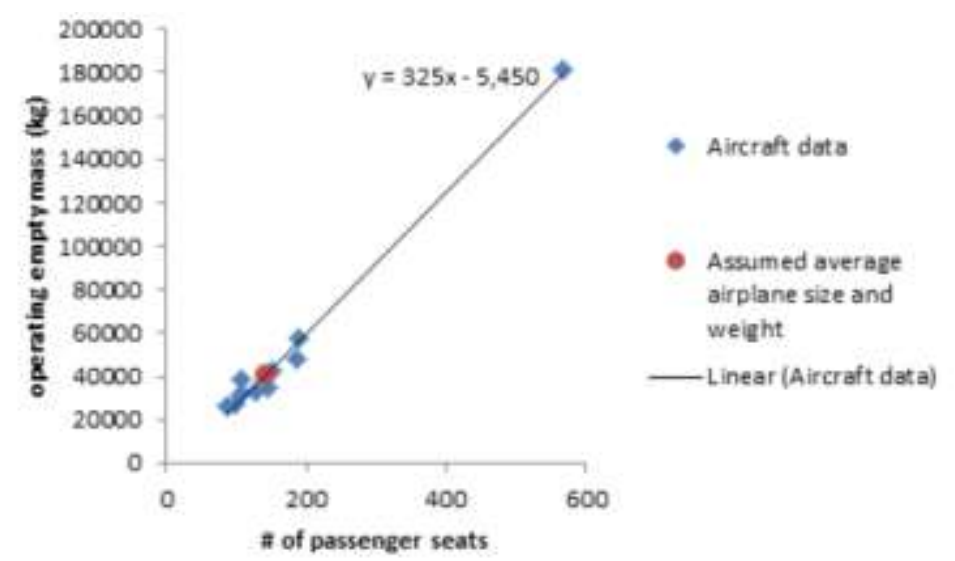

Figure S1. Relationship between empty mass and seating capacity for U.S. commercial aircraft 
In total, it was estimated that $9-17 \%$ of total typical aircraft mass may be replaceable by AM components in the near term, with $4-5 \%$ attributable to a replacement of aluminum alloy components, $2-5 \%$ attributable to replacement of nickel alloy components, 3-6\% attributable to replacement of titanium alloy components, and $0.4-1 \%$ attributable to steel alloy components. The replaceable aluminum alloy mass is associated with the furnishing and equipment component system, while the replace the replaceable nickel, steel, and titanium alloy mass is primarily associated with the engine component system.

Table S8. Replaceable mass by material type and component system

\begin{tabular}{llllll}
\hline & & \multicolumn{2}{l}{ Replaceable mass in average aircraft (kg) } & \\
\cline { 6 - 6 } Component system & Category & Al alloy & Ti alloy & Ni alloy & Steel \\
\hline Body systems & Auxiliary & $80-200$ & & & \\
Furnishings and equipment & Structural & $70-130$ & & & \\
& Functional & $1450-1930$ & & & \\
Engine & Functional & & $680-1350$ & $940-1880$ & $100-190$ \\
\hline & Auxiliary & & $50-90$ & $50-90$ & $50-90$ \\
\hline Propulsion systems & Functional & & $330-810$ & & \\
Nacelle Systems & Auxiliary & & $20-40$ & & $\mathbf{1 4 0 - 2 8 0}$ \\
\hline
\end{tabular}

\subsection{Temporal feasibility}

While AM technologies for metal alloys hold great potential, the adoption of metal alloy AM components is currently limited by constraints related to capacity, geometric repeatability, residual stress, and high surface roughness[7]. However it is likely that these obstacles will be overcome in the next 5-20 years. For example, higher capacity AM machines are currently under development [4], alternatives to powder (such as using wire) may increase production rates due to reduced sintering time [6], and mechanics theory and models are being developed to better understand and optimize the materials properties of finished AM parts [4]. Therefore, the final step in the selection and characterization process was to estimate the temporal availability of suitable AM components for each selected component system based on their characteristics.

Several published reports have provided projections on the pace of AM technology development. In particular, the Direct Manufacturing Research Center (a European research agency founded by Boeing, EOS, Evonik industries, SLM Solutions, and University Paderborn) has published a series of technical reports based on consultation with AM professionals, researchers, and engineers[19-23]. The projections in these reports suggest that the capacity and production rate of AM equipment could be highly improved by the early 2020s, and that the surface quality, mechanical properties and other thermal requirements of AM components could be improved by the mid 2020s[23]. 

component system are summarized in Table S9. For component categories with low geometric volume and low load requirements, it was conservatively assumed that suitable AM components would be available after five years. This estimate was based on evidence from Airbus, Boeing, Pratt and Whitney, GE, and Rolls-Royce, which are all adopting AM aircraft parts presently or within the next five years for non-critical applications. Examples include titanium brackets used in lavatories and galleys, door hinges, and air ducts[13, 15, 24-26]. Airbus has already replaced 120 different brackets in non-critical applications in the interior of its A350 [13], as well as crew seat panels in its A310 [14]. Other component categories with medium to high geometric volume but with low load requirements were assigned an adoption time of 10 years.

Considering the aircraft industry's strict reliability requirements and its long test cycles[27], the estimated adoption time for large geometric volume components was 10 years, and those with high mechanical strength and performance requirements were assigned an adoption time of 20 years. For engine and propulsion systems with high mechanical and thermal performance requirements, and with medium to high geometric volume, a 20 year adoption time was conservatively assumed.

Table S9. Temporal availability assumptions

\begin{tabular}{lll}
\hline Component system & Component category & Availability \\
\hline Body systems & Auxiliary & 10 years (2024) \\
Furnishings and equipment systems & Structural & 5 -10 years* (2019-2024) \\
Furnishings and equipment systems & Functional & 10 years (2024) \\
Engine & Functional & 20 years (2034) \\
Engine & Auxiliary & 10 years (2024) \\
Propulsion systems & Functional & 20 years (2034) \\
Nacelle systems & Auxiliary & 5 years (2019) \\
\hline
\end{tabular}

*5 years for galley and lavatory, 10 years for floor panel, fasteners and other

\section{Manufacturing energy and emissions analysis}

The data in Section 2 characterized the materials mass within different aircraft component systems that is plausible for replacement by metal alloy AM components over the next 5-20 years. The next step in this study was to construct and apply a "cradle to gate" energy and emissions analysis of manufactured components within the selected component systems to compare the energy and carbon dioxide $\left(\mathrm{CO}_{2}\right)$ emissions implications of replacing conventionally-manufactured (CM) components with AM components. The "cradle to gate" system boundary includes the following process steps as depicted in Figure 2 in the main paper: raw materials production, raw materials distribution, component manufacturing, and component distribution to the aircraft assembly plant.

The governing equation for cradle to gate primary energy use for a given component is as follows:

$$
\begin{aligned}
& E_{\text {total }}=E_{\text {materials }}+E_{\text {distribution I }}+E_{\text {manfuacturing }}+E_{\text {distribution II }} \\
& \quad=\epsilon_{\text {materials }} \cdot m_{\text {input }}+\epsilon_{\text {dis I }} \cdot m_{\text {input }}+\epsilon_{\text {mfg }} \cdot m_{\text {output }}+\epsilon_{\text {dis II }} \cdot m_{\text {output }}
\end{aligned}
$$


where $m$ represents mass into or out of a process step $(\mathrm{kg}), \epsilon$ represents the primary energy intensity of a process step $(\mathrm{MJ} / \mathrm{kg})$, and $E$ represents the primary energy use of a process step (MJ).

The governing equation for cradle to gate $\mathrm{CO}_{2}$ emissions for a given component is as follows:

$$
\begin{aligned}
& C_{\text {total }}=C_{\text {materials }}+C_{\text {distribution I }}+C_{\text {manfuacturing }}+C_{\text {distribution II }} \\
& \quad=\gamma_{\text {materials }} \cdot m_{\text {input }}+\gamma_{\text {dis I }} \cdot m_{\text {input }}+\gamma_{\text {mfg }} \cdot m_{\text {output }}+\gamma_{\text {dis II }} \cdot m_{\text {output }}
\end{aligned}
$$

where $\gamma$ represents the carbon dioxide equivalent $\left(\mathrm{CO}_{2} \mathrm{e}\right)$ emissions intensity of a process step $(\mathrm{kg}$ $\mathrm{CO}_{2} \mathrm{e} / \mathrm{kg}$ ), and $\mathrm{C}$ represents the $\mathrm{CO}_{2} \mathrm{e}$ emissions associated with a process step $\left(\mathrm{kg} \mathrm{CO} \mathrm{CO}_{2} \mathrm{e}\right.$.

In both equations above, mass inputs and mass outputs are related by the so-called "buy-to-fly" ratio. The buy-to-fly ratio, which is the mass ratio between the input raw material used make a component and the mass of the finished component itself, is widely used in the aircraft industry to represent the scrape rate or the waste generated during manufacturing, which is represented by $\alpha$ :

$$
m_{\text {input }}=\alpha \cdot m_{\text {output }}
$$

The analysis assumptions for each process step are presented below.

\subsection{Raw materials production}

As summarized in Table S8, this study focuses on replacement opportunities for existing components made of alloys of steel, aluminum, nickel, and titanium within selected component systems. Table S10 summarizes this study's estimates of the primary energy use and $\mathrm{CO}_{2} \mathrm{e}$ emissions associated with producing ingots, plates, and powders from each metal alloy, inclusive of ore mining, refining, metal production, and shape forming. For simplicity, and due to lack of data for many different alloy compositions, the estimates in Table S10 are based on ranges of best available literature values for the base material (e.g., titanium) of each alloy as referenced in the table.

Estimates for powder in Table S10 were derived by assuming ingots would be further subjected to powder metallurgy, thereby adding additional primary energy use and $\mathrm{CO}_{2}$ emissions beyond the values presented for ingots. This study assumed that powder metallurgy would require $2.1 \mathrm{kWh} / \mathrm{kg}, 1.9$ $\mathrm{kWh} / \mathrm{kg}, 2.8 \mathrm{kWh} / \mathrm{kg}$, and $1.9 \mathrm{kWh} / \mathrm{kg}$ for steel, aluminum, titanium, and nickel, respectively. The value for steel was based on literature sources [28]. The values for aluminum, titanium, and nickel were based on the following equation, which scales the value for steel to other metal alloys based on their heat capacities and melting points, which are documented in Table S11:

$$
\frac{\varepsilon_{\text {steel powder }}}{T_{\text {steel }} \cdot c_{\text {steel }}}=\frac{\varepsilon_{A l \text { powder }}}{T_{A l} \cdot c_{A l}}=\frac{\varepsilon_{T i \text { powder }}}{T_{T i} \cdot c_{T i}}=\frac{\varepsilon_{N i \text { powder }}}{T_{N i} \cdot c_{N i}}
$$

where $\varepsilon$ is the powder metallurgy electricity use intensity, $\mathrm{T}$ is the melting point and $\mathrm{c}$ is the heat capacity for the specific metal alloys. Kilowatt-hours for powder metallurgy were converted to primary energy using a conversion factor of $10.3 \mathrm{MJ} / \mathrm{KWh}$ and to $\mathrm{CO}_{2}$ e emissions using a conversion factor of 0.7 $\mathrm{kg} / \mathrm{KWh}$ based on the average U.S. grid mix[29]. 
Metal alloy scraps usually have high value in recycling without losing much quality in the final product, and the use of secondary metals can contribute significantly in the metal production supply. Open loop recycling is considered in the calculation of energy and emissions of metals use, which following the equations below:

$$
\epsilon_{\text {material }}=(1-\theta) \cdot \varepsilon_{\text {material,virgin }}+\theta \cdot \varepsilon_{\text {material,recycled }}
$$

where $\epsilon_{\text {material }}$ is the primary energy intensity value used for final calculation, the $\theta$ is the recycling rate of the metal in the supply, $\varepsilon_{\text {material,virgin }}$ is the primary energy intensity for the metal, while $\varepsilon_{\text {material,recycled }}$ is the primary energy intensity for recycling the metal. Similar methods are used for $\mathrm{CO}_{2} \mathrm{e}$ emissions. Based on the historical data for metal recycling rates in the United States[30], the value of $\theta$ is assumed as $45 \%$ for aluminum, titanium and nickel, and $55 \%$ for steel. The recycling energy intensity of different metals were collected from literature sources as documented in Table S10.

Table S10. Primary energy and $\mathrm{CO}_{2} \mathrm{e}$ intensity of metal production

\begin{tabular}{|c|c|c|c|c|}
\hline Material & Type & $\begin{array}{l}\text { Primary energy } \\
\varepsilon_{\text {material }}(\mathrm{MJ} / \mathrm{kg})\end{array}$ & $\begin{array}{l}\mathrm{CO}_{2} \text { e emissions } \\
\gamma_{\text {material }}(\mathrm{kg} / \mathrm{kg})\end{array}$ & Reference \\
\hline \multirow[t]{4}{*}{ Steel } & Ingot & $20-41$ & $2.1-4.9$ & {$[28,31-33]$} \\
\hline & Plate & $26-28$ & $2.6-3.0$ & {$[28,33]$} \\
\hline & Powder & $18-63$ & $2.2-5.0$ & [28] + powdering \\
\hline & Recycled & $10-27$ & $0.6-1.9$ & {$[34,35]$} \\
\hline \multirow[t]{3}{*}{ Stainless steel } & Ingot & $56-75$ & $5.0-6.8$ & [31-33] \\
\hline & Powder & $78-97$ & $5.1-6.9$ & {$[31,32]+$ powdering } \\
\hline & Recycled & $11-13$ & $0.7-0.8$ & [35] \\
\hline \multirow[t]{3}{*}{ Aluminum } & Ingot & $140-230$ & $9.2-22.4$ & {$[31,32,36]$} \\
\hline & Powder & $160-230$ & $9.3-22.5$ & {$[31,32]+$ powdering } \\
\hline & Recycled & $22-30$ & $1.9-2.3$ & {$[34,35]$} \\
\hline \multirow[t]{3}{*}{ Titanium } & Ingot & $317-361$ & $31-35.7$ & {$[31,36]$} \\
\hline & Powder & $346-390$ & $31.2-35.9$ & {$[31,36]+$ powdering } \\
\hline & Recycled & $78-96$ & $4.7-5.7$ & [35] \\
\hline \multirow[t]{3}{*}{ Nickel } & Ingot & $114-239$ & $11.4-16.1$ & {$[31,37-39]$} \\
\hline & Powder & $134-259$ & $11.5-16.2$ & [31, 37-39]+ powdering \\
\hline & Recycled & $34-38$ & $1.8-2.2$ & {$[34,35]$} \\
\hline
\end{tabular}

Table S11. Melting point and heat capacity of metals[40, 41]

\begin{tabular}{lll}
\hline Material & Melting point T (K) & Heat capacity c (J/g*K) \\
\hline Steel & 1510 & 0.45 \\
Aluminum & 660 & 0.91 \\
Titanium & 1670 & 0.54 \\
Nickel & 1375 & 0.45 \\
\hline
\end{tabular}




\subsection{Distribution I \& II}

This study included four different transportation modes associated with distribution of raw materials (distribution stage I) and distribution of finished parts and components for assembly (distribution II): (1) long-haul diesel trucks, (2) diesel engine railway, (3) air freight, and (4) residual fuel engine cargo ships. These four modes represent typical supply chain options for U.S. domestic and international freight. The fuel and emissions intensities of each mode were estimated from literature values on a metric ton ( $t$ ) per kilometer (km) shipped basis, as summarized in Table S12 [33].

Table S12. Fuel intensity and $\mathrm{CO}_{2} \mathrm{e}$ emissions factors for transport modes [33]

\begin{tabular}{llll}
\hline $\begin{array}{l}\text { Transportation } \\
\text { mode }\end{array}$ & Fuel & $\begin{array}{l}\text { Fuel intensity } \varepsilon_{i, j} \\
(\mathbf{M J} / \mathbf{t}-\mathbf{k m})\end{array}$ & $\begin{array}{l}\text { CO }{ }_{2} \text { e emissions } \\
\left.\text { intensity } \boldsymbol{\gamma}_{\boldsymbol{i}, \mathbf{j}} \mathbf{( g / t} \mathbf{\text { t}} \mathbf{k m}\right)\end{array}$ \\
\hline Cargo ship & Residual fuel & 0.19 & 14.4 \\
Rail & Diesel fuel & 0.25 & 18.9 \\
Road & Diesel fuel & 1.34 & 90 \\
Air & Jet fuel & 15.8 & 1050 \\
\hline
\end{tabular}

The total primary energy and $\mathrm{CO}_{2}$ emissions intensities of each distribution stage are calculated using the following relations based on distance shipped, values for which are presented in Section 3.4.

$$
\begin{array}{ll}
\epsilon_{d i s I}=\sum_{i} \varepsilon_{i} \cdot d_{i}, & \epsilon_{d i s ~ I I}=\sum_{j} \varepsilon_{j} \cdot d_{j} \\
\gamma_{d i s I}=\sum_{i} \gamma_{i} \cdot d_{i}, & \gamma_{d i s I I}=\sum_{j} \gamma_{j} \cdot d_{j}
\end{array}
$$

where:

$$
\begin{gathered}
d_{i}=\text { distance of transportation step } i \text { of distribution stage I } \\
d_{j}=\text { distance of transportation step } j \text { of distribution stage II }
\end{gathered}
$$

\subsection{Component manufacturing}

The component manufacturing process step includes all operations necessary for converting raw materials into final components for shipment to the aircraft assembly facility. This study considered both $\mathrm{CM}$ and $\mathrm{AM}$ processing pathways for producing components within the selected component systems.

Table S13 summarizes this study's estimates for the primary energy and $\mathrm{CO}_{2}$ emissions intensities of the $\mathrm{CM}$ processes that are currently used to produce existing components within the selected component systems. Forming processes include forging and casting; subtractive processes include turning, milling, and machining [40]. For forming processes, the energy intensity is stated in Table S13 based on the mass of the output product (e.g., a near net shape cast part). For subtractive processes, the energy intensity is based on the mass of material removed. 
The majority of the estimates in Table S13 were compiled directly from published values in the literature. Those estimates denoted by an asterisk were derived for subtractive processes for which data were only available for steel alloys in the literature. To estimate the CM direct energy use for other alloys, this study used the following relation, which scales the energy requirements for steel alloys to aluminum and titanium alloys based on strain energy required for metals deformation under linear plasticity [42]:

$$
\begin{gathered}
\frac{\varepsilon_{\text {steel subtractive }}}{\rho_{\text {steel }} U_{\text {steel }}}=\frac{\varepsilon_{A l \text { subtractive }}}{\rho_{A l} U_{A l}}=\frac{\varepsilon_{T i \text { subtractive }}}{\rho_{T i} U_{T i}}=\frac{\varepsilon_{N i \text { subtractive }}}{\rho_{N i} U_{N i}} \\
U=\int_{0}^{\varepsilon_{t}} \sigma d \epsilon=\frac{1}{2} \cdot \sigma_{y} \cdot \varepsilon_{y}+\frac{1}{2} \cdot\left(\sigma_{y}+\sigma_{t}\right) *\left(\varepsilon_{t}-\varepsilon_{y}\right) ; \\
\varepsilon_{\mathrm{y}}=\sigma_{\mathrm{y}} / E
\end{gathered}
$$

where: $\varepsilon$ is the manufacturing energy intensity, $\rho$ is the material density, $U$ is the strain energy, $\sigma_{y}, \varepsilon_{y}$ are the yield stress and yield strain, $\sigma_{t}, \varepsilon_{t}$ are the ultimate stress and ultimate strain, and $\mathrm{E}$ is the Young's modulus.

The materials property data used in the above relation for aluminum, titanium, and nickel are

\begin{tabular}{|c|c|c|c|c|}
\hline $\begin{array}{l}\text { CM } \\
\text { Process }\end{array}$ & Material & $\begin{array}{l}\text { Primary energy } \\
\text { intensity ( } \mathrm{MJ} / \mathrm{kg} \text { ) }\end{array}$ & $\begin{array}{l}\mathrm{CO}_{2} \mathrm{e} \text { emissions } \\
\text { intensity } \\
(\mathrm{kg} / \mathrm{kg})\end{array}$ & Reference(s) \\
\hline \multirow[t]{3}{*}{ Forging } & Steel & $13.7-33$ & $1.1-2.2$ & [43-45] \\
\hline & Aluminum & 16.6 & 1.1 & {$[46]$} \\
\hline & Titanium & $48.5-58.7$ & $3.3-4.0$ & [46] \\
\hline Turning & Steel & $0.88-27$ & 0.1 & {$[45,47]$} \\
\hline \multirow[t]{4}{*}{ Milling } & Steel & $1.9-8.3$ & $0.1-0.6$ & {$[28,44,47,48]$} \\
\hline & Aluminum* & $2.7-5.6$ & $0.2-0.4$ & {$[45,48]$} \\
\hline & Titanium* & $4.5-9.5$ & $0.3-0.6$ & [48] \\
\hline & Nickel* & $8.5-18.3$ & $0.6-1.2$ & {$[37,39,48]$} \\
\hline \multirow[t]{4}{*}{ Machining } & Steel & $22.2-66$ & $1.5-4.5$ & {$[43-45,48]$} \\
\hline & Aluminum* & 16.1-47.9 & $1.1-3.3$ & {$[45,48]$} \\
\hline & Titanium* & $27.4-81.5$ & $1.9-5.5$ & {$[48,49]$} \\
\hline & Nickel* & $52.4-155.8$ & $3.6-10.6$ & {$[37,39,50-52]$} \\
\hline $\begin{array}{l}\text { Iron } \\
\text { casting }\end{array}$ & Steel & $19-29$ & $1.3-2.0$ & {$[33,44]$} \\
\hline \multirow{3}{*}{$\begin{array}{l}\text { Die } \\
\text { casting }\end{array}$} & Steel & 14.9 & 1.0 & [44] \\
\hline & Aluminum & $33-44$ & $2.2-3.0$ & {$[33,43]$} \\
\hline & Titanium & $62-72$ & $4.2-4.9$ & {$[43,49]$} \\
\hline
\end{tabular}
summarized in Table S14.

Table S13. Primary energy and $\mathrm{CO}_{2} \mathrm{e}$ emissions intensities for $\mathrm{CM}$ processes 
Table S14. Material properties data $[40,51,52]$

\begin{tabular}{llllll}
\hline & Density $\boldsymbol{\rho}$ & $\begin{array}{l}\text { Young's } \\
\text { Modulus E }\end{array}$ & $\begin{array}{l}\text { Yield } \\
\text { stress } \boldsymbol{\sigma}_{\boldsymbol{y}}\end{array}$ & $\begin{array}{l}\text { Ultimate } \\
\text { stress } \boldsymbol{\sigma}_{\boldsymbol{t}}\end{array}$ & $\begin{array}{l}\text { Elongation } \\
\boldsymbol{\varepsilon}_{\boldsymbol{t}}\end{array}$ \\
\cline { 2 - 6 } Material & $10^{3} \mathrm{~kg} / \mathrm{m3}$ & $\mathrm{Gpa}$ & $\mathrm{Mpa}$ & $\mathrm{Mpa}$ & 1 \\
\hline Steel & 7.8 & 180 & 502 & 860 & 0.2 \\
Aluminum & 2.7 & 69 & 95 & 110 & 0.3 \\
Titanium & 4.5 & 110 & 825 & 895 & 0.1 \\
Nickel & 8.3 & 218 & 1062 & 1420 & 0.14 \\
\hline
\end{tabular}

The major AM processes currently used for metal alloys are selective laser melting (SLM), direct metal laser sintering (DMLS), and electron beam melting (EBM) [7, 53]. Primary energy intensity estimates for each AM process were derived from published literature values as summarized in Table S15 [54-57], and by converting direct electricity use to primary energy use using a conversion factor of $10.3 \mathrm{MJ} / \mathrm{kWh}$ [29]. The $\mathrm{CO}_{2} \mathrm{e}$ emissions intensity estimated in Table $\mathrm{S} 14$ were derived by converting direct electricity use to $\mathrm{CO}_{2} \mathrm{e}$ emissions using a conversion factor of $0.7 \mathrm{~kg} \mathrm{CO} 2 \mathrm{e} / \mathrm{kWh}[29]$. The intensity values in Table $\mathrm{S} 15$ are based on the output mass of the AM part.

Table S15. Primary energy and $\mathrm{CO}_{2} \mathrm{e}$ intensities for AM processes [56]

\begin{tabular}{lllll}
\hline $\begin{array}{l}\text { AM } \\
\text { Process }\end{array}$ & Platform & Material & $\begin{array}{l}\text { Primary energy } \\
\text { intensity (MJ/kg) }\end{array}$ & $\begin{array}{l}\mathrm{CO}_{2} \text { e emissions } \\
\text { intensity } \\
\mathbf{( k g / k g )}\end{array}$ \\
\hline SLM & MTT SLM 250 & Stainless steel & $83-106$ & $5.6-7.2$ \\
& M3 Linear & Stainless steel & $423-588$ & $28.8-40.0$ \\
DMLS & EOSINT M 270 & Stainless steel & $241-339$ & $16.4-23.1$ \\
EBM & Acram A 1 & Ti6Al4V & $61-177$ & $4.1-12.0$ \\
\hline
\end{tabular}

Available literature data are limited to processing of stainless steel and Grade 5 titanium alloy (Ti6Al4V). Therefore, this study estimated the energy intensities of AM processes for aluminum, nickel, and other titanium alloys based on their heat capacities and melting points using the following relation:

$$
\frac{\varepsilon_{\text {steel } A M}}{T_{\text {steel }} \cdot c_{\text {steel }}}=\frac{\varepsilon_{A l A M}}{T_{A l} \cdot c_{A l}}=\frac{\varepsilon_{T i A M}}{T_{T i} \cdot c_{T i}}=\frac{\varepsilon_{N i A M}}{T_{N i} \cdot c_{N i}}
$$

where $\varepsilon$ is the AM process electricity use intensity, $\mathrm{T}$ is the melting point and $\mathrm{c}$ is the heat capacity for the specific metal alloys. The above relation is based on the assumption that, since SLM, DMLS and EBM technologies are all powder bed fusion processes that melt power, the electricity consumption of AM processes for other metals could be scaled from that of stainless steel based on the materials' heat capacity and melting point. 
Table S16 summarizes the estimated primary energy and $\mathrm{CO}_{2} \mathrm{e}$ emissions intensities of other metal alloy AM technologies, based on the aforementioned approach.

Table S16. Primary energy and $\mathrm{CO}_{2} \mathrm{e}$ intensity estimates for aluminum, titanium, and nickel alloy AM processes

\begin{tabular}{lllll}
\hline $\begin{array}{l}\text { AM } \\
\text { Process }\end{array}$ & Platform & Material & $\begin{array}{l}\text { Primary energy } \\
\text { intensity }\end{array}$ (MJ/kg) & $\begin{array}{l}\mathrm{CO}_{2} \text { e emissions } \\
\text { intensity }(\mathrm{kg} / \mathrm{kg})\end{array}$ \\
\hline SLM & MTT SLM 250 & Al alloy & $73-94$ & $5.0-6.4$ \\
& & Ti Alloy & $110-141$ & $7.5-9.6$ \\
& \multirow{2}{*}{ M3 Linear } & Al alloy & $374-520$ & $25.4-35.4$ \\
& & Ti Alloy & $561-780$ & $38.2-53.1$ \\
DMLS & \multirow{2}{*}{ EOSINT M 270 } & Al alloy & $213-300$ & $14.5-20.4$ \\
& & Ti Alloy & $320-450$ & $21.8-30.6$ \\
EBM & Acram A 1 & Nickel alloy & $42-122$ & $2.9-8.3$ \\
\hline
\end{tabular}

Using the estimates in Tables S13, S15, and S16, the total primary energy and $\mathrm{CO}_{2}$ emissions intensities of different $\mathrm{CM}$ and $\mathrm{AM}$ pathways were calculated using the following relations:

$$
\begin{gathered}
\epsilon_{A M}=\varepsilon_{A M} ; \\
\epsilon_{\text {subtractive }}=\varepsilon_{\text {machining }} *(\alpha-1) ; \\
\epsilon_{\text {casting }}=\varepsilon_{\text {casting }} * \alpha_{\text {machining }}+\varepsilon_{\text {machining }} *\left(\alpha_{\text {machining }}-1\right) \\
\gamma_{\text {subtractive }}=\gamma_{\text {machining }} *(\alpha-1) ; \\
\gamma_{\text {casting }}=\gamma_{\text {casting }} * \alpha_{\text {machining }}+\gamma_{\text {machining }} *\left(\alpha_{\text {machining }}-1\right), \text { in which } \alpha \\
=\alpha_{\text {casting }} * \alpha_{\text {nachining }}
\end{gathered}
$$

The buy-to-fly ratios for different manufacturing pathways used in this study were estimated as follows:

- The average buy-to-fly ratio of aircraft components using subtractive CM pathways is 8 to 12 , and can sometimes be as high as 30[58-60]. Given the aircraft industry's strong economic incentives for reducing buy-to-fly ration, and that these ratios can vary greatly by component, material, and subtractive CM process pathway, this study adopts a conservative average buyto-fly ratio of 8 for all subtractive $\mathrm{CM}$ components.

- For components manufactured primarily through forming CM pathways such as casting or forging, buy-to-fly ratios are typically lower than for subtractive CM pathways. Based on data in the literature, this study assumed a buy-fly ratio of 4.5 for final formed components[61], which includes a rough forming process with buy-to-fly ratio of 2 and an additional buy-to-fly ration of 2.25 for the subtractive finishing operations that follow.

- Given that AM processes build up components in layer by layer fashion, and internally recycle unused powder at each layer, in theory AM processes should lead to negligible materials waste [7]. In current practice, however, AM processes exhibit powder loss and AM components typically require finishing to improve surface quality, which leads to subtractive 

of 1.5 for all AM processes.

\subsection{Comparisons of $\mathrm{CM}$ and $\mathrm{AM}$ pathways}

The final step in the manufacturing energy and emissions analysis was to estimate the net differences in "cradle to gate" primary energy use and $\mathrm{CO}_{2}$ emissions associated with replacing $\mathrm{CM}$ components with AM components within the selected component systems. Given the wide variety of components within the selected component systems, and the lack of information on engineering specifications for all such components, it was not practical to estimate net differences on a component-by-component basis. Rather, this study took the following estimation approach:

1. A literature review was conducted to identify credible, quantitative energy and mass analysis case studies of AM replacements within the selected component systems. In particular, case studies describing the geometric design, material use, component mass, AM technologies, and CM processes replaced were identified[12, 26, 61, 64-66].

2. From the available case studies, a representative component was chosen for each component system to serve as a proxy for all replaceable components within that component system.

3. For each representative component, transportation distances and modes were estimated for distribution of raw materials and finished parts based on representative distances for aircraft component supply chains.

4. "Cradle to gate" energy and emissions analyses were conducted for the AM replacement component and the existing CM component that was replaced in each case study, using the framework and data summarized in Sections 3.1-3.3.

5. The net differences between the "cradle to gate" primary energy use and $\mathrm{CO}_{2}$ emissions of the AM replacement component and existing $\mathrm{CM}$ component were calculated and expressed as percent reductions in primary energy use, $\mathrm{CO}_{2}$ emissions, and final component mass on a percomponent basis.

6. The net differences calculated for the representative components were applied to the total mass of replaceable components within each selected component system to estimate the aircraftlevel effects of switching from CM pathways to AM pathways.

Table S17 summarizes the representative AM replacement component chosen for each component system, as well as key data obtained from the published case studies on the material, original CM pathway, AM technology, and achieved mass reductions.

Table S17. Representative component analysis data $[12,26,61,64-66]$

\begin{tabular}{|c|c|c|c|c|c|c|c|c|}
\hline $\begin{array}{l}\text { Component } \\
\text { system }\end{array}$ & $\begin{array}{l}\text { Component } \\
\text { category }\end{array}$ & $\begin{array}{l}\text { Representative } \\
\text { component }\end{array}$ & Material & $\begin{array}{l}\text { Original } \\
\text { CM } \\
\text { pathway }\end{array}$ & $\begin{array}{l}\text { AM } \\
\text { technology }\end{array}$ & $\begin{array}{l}\text { Original } \\
\mathrm{CM} \\
\text { component } \\
\text { mass (kg) }\end{array}$ & $\begin{array}{l}\text { Replacement } \\
\text { AM } \\
\text { component } \\
\text { mass (kg) }\end{array}$ & $\begin{array}{l}\text { Mass } \\
\text { reduction } \\
\text { (CM- } \\
\mathrm{AM}) / \mathrm{CM}\end{array}$ \\
\hline $\begin{array}{l}\text { Furnishing } \\
\&\end{array}$ & Structural & Bracket & Ti alloy & Machining & EBM & 1.09 & 0.38 & $65 \%$ \\
\hline
\end{tabular}


Table S18 summarizes this study's estimates of transportation modes and distances for the distribution of raw materials and finished components associated with the original $\mathrm{CM}$ components. This study assumes that $\mathrm{CM}$ processes will be replaced by $\mathrm{AM}$ processes at the component manufacturing plant; therefore, the transportation distances and modes are identical for the original $\mathrm{CM}$ parts and the replacement AM parts in this study. The data in Table S17 are based on Boeing direct supply chain partner data[67], and assume finished component shipment to the U.S. state of Washington for aircraft assembly[68]. Raw material suppliers were assumed to be those companies with the largest raw materials production capacity nearest to the manufacturer[69-74]. The transportation mode for raw materials was assumed to be railway in China and Russia, diesel truck in other countries, and barge if international transportation is involved. For transportation of the final components to assembly, the airplane mode is assumed for large components or if international travel is needed[75]. For inland transportation of small parts, diesel trucking is assumed. All distances were estimated using Google Maps[76]. These data were used to estimate the primary energy use and $\mathrm{CO}_{2}$ emissions intensities of both distribution steps as discussed in Section 3.2.

Table S18. Distribution system location, mode, and distance estimates [67, 69-74]

\begin{tabular}{|c|c|c|c|c|c|c|c|}
\hline \multirow{2}{*}{$\begin{array}{l}\begin{array}{l}\text { Representative } \\
\text { component }\end{array} \\
\text { Raw material } \\
\text { Supplier }\end{array}$} & \multirow{2}{*}{$\begin{array}{l}\text { Fork fitting } \\
\text { RUSAL }\end{array}$} & \multicolumn{2}{|l|}{ Bracket } & \multirow{2}{*}{$\begin{array}{l}\text { Engine door } \\
\text { cover } \\
\text { TIMET }\end{array}$} & \multirow{2}{*}{$\begin{array}{l}\text { Seat buckle } \\
\text { ALCOA }\end{array}$} & \multicolumn{2}{|c|}{ Bionic bracket } \\
\hline & & KOBELCO & CHALCO & & & ATI & TIMET \\
\hline Location & $\begin{array}{l}\text { Bogoslovsk, } \\
\text { Russia }\end{array}$ & $\begin{array}{l}\text { Moka, } \\
\text { Japan }\end{array}$ & $\begin{array}{l}\text { Henan, } \\
\text { China }\end{array}$ & $\begin{array}{l}\text { Monroe, NC, } \\
\text { US }\end{array}$ & $\begin{array}{l}\text { Wenatchee, } \\
\text { WA, US }\end{array}$ & $\begin{array}{l}\text { Pittsburgh, } \\
\text { PA, US }\end{array}$ & $\begin{array}{l}\text { Monroe, } \\
\text { NC, US }\end{array}$ \\
\hline $\begin{array}{l}\text { Transport } \\
\text { distance } d_{i}\end{array}$ & $\begin{array}{l}\text { Rail: } 2300 \mathrm{~km} \text {; } \\
\text { Barge: } 824 \mathrm{~km} \text {; } \\
\text { Road: } 42 \mathrm{~km}\end{array}$ & $\begin{array}{l}\text { Road: } \\
151 \mathrm{~km}\end{array}$ & $\begin{array}{l}\text { Rail:700km; } \\
\text { Barge: } \\
\text { 2090km; } \\
\text { Road: 30km }\end{array}$ & $\begin{array}{l}\text { Road: } \\
\text { 1907km }\end{array}$ & $\begin{array}{l}\text { Road: } \\
1857 \mathrm{~km}\end{array}$ & $\begin{array}{l}\text { Road: } \\
451 \mathrm{~km}\end{array}$ & $\begin{array}{l}\text { Road: } \\
818 \mathrm{~km}\end{array}$ \\
\hline $\begin{array}{l}\text { Component } \\
\text { manufacturer }\end{array}$ & $\begin{array}{l}\text { Saab } \\
\text { Aerostructures }\end{array}$ & Jamco & Jamco & $\begin{array}{l}\text { Spirit } \\
\text { AeroSystems } \\
\text { Holdings }\end{array}$ & Ipeco & $\begin{array}{l}\text { General } \\
\text { Electric }\end{array}$ & $\begin{array}{l}\text { General } \\
\text { Electric }\end{array}$ \\
\hline Location & $\begin{array}{l}\text { Linköping, } \\
\text { Sweden }\end{array}$ & $\begin{array}{l}\text { Osawa, } \\
\text { Mitaka } \\
\text { Tokyo, } \\
\text { Japan }\end{array}$ & $\begin{array}{l}\text { Osawa, } \\
\text { Mitaka } \\
\text { Tokyo, Japan }\end{array}$ & $\begin{array}{l}\text { Wichita, } \\
\text { Kansas, US }\end{array}$ & $\begin{array}{l}\text { Torrance, CA, } \\
\text { US }\end{array}$ & $\begin{array}{l}\text { Cincinnati, } \\
\mathrm{OH}, \text { US }\end{array}$ & $\begin{array}{l}\text { Cincinnati, } \\
\mathrm{OH}, \mathrm{US}\end{array}$ \\
\hline
\end{tabular}


For each representative component, Tables S19 and S20 summarize this study's estimates for the "cradle to gate" primary energy use and $\mathrm{CO}_{2}$ emissions associated with the original $\mathrm{CM}$ component and the AM replacement component, using the equations and high and low data values summarized in the preceding sections. Importantly, the low difference values are calculated by subtracting the high $\mathrm{AM}$ values from the low $\mathrm{CM}$ values, and the high difference values are calculated by subtracting the low AM values from the high CM values. The final column in Tables S19 and S20 expresses the "cradle to gate" results per kg of finished component, which allows for scaling results to different production quantities based on the following relations:

$$
\begin{gathered}
\frac{E_{c_{\_} t o_{-} g}}{m_{\text {output }}}=\frac{\epsilon_{\text {materials }} \cdot m_{\text {input }}+\epsilon_{\text {dis I }} \cdot m_{\text {input }}+\epsilon_{\text {manufacturing }} \cdot m_{\text {output }}+\epsilon_{\text {dis II }} \cdot m_{\text {output }}}{m_{\text {output }}} \\
=\epsilon_{\text {materials }} \cdot \alpha+\epsilon_{\text {dis I }} \cdot \alpha+\epsilon_{\text {manufacturing }}+\epsilon_{\text {dis II }} \\
\frac{C_{c_{-} \text {to_g }}}{m_{\text {output }}}=\frac{\gamma_{\text {materials }} \cdot m_{\text {input }}+\gamma_{\text {dis I }} \cdot m_{\text {input }}+\gamma_{\text {manufacturing }} \cdot m_{\text {output }}+\gamma_{\text {dis II }} \cdot m_{\text {output }}}{m_{\text {output }}} \\
=\gamma_{\text {materials }} \cdot \alpha+\gamma_{\text {dis I }} \cdot \alpha+\gamma_{\text {manufacturing }}+\gamma_{\text {dis II }}
\end{gathered}
$$


Table S19. "Cradle to gate" primary energy intensities of representative components

\begin{tabular}{|c|c|c|c|c|c|c|c|c|c|c|c|c|}
\hline \multirow{3}{*}{$\begin{array}{l}\text { Representative } \\
\text { component }\end{array}$} & \multirow{3}{*}{$\begin{array}{l}\text { Manufacturing } \\
\text { process }\end{array}$} & \multirow{3}{*}{$\begin{array}{l}\text { Component } \\
\text { mass (kg) }\end{array}$} & \multicolumn{8}{|c|}{ Primary energy consumption (MJ) } & \multirow{2}{*}{\multicolumn{2}{|c|}{\begin{tabular}{|l}
$\begin{array}{l}\text { Cradle to gate primary } \\
\text { energy intensity }\end{array}$ \\
(GJ/kg)
\end{tabular}}} \\
\hline & & & \multicolumn{2}{|c|}{\begin{tabular}{|l|} 
Raw material \\
production
\end{tabular}} & \multirow[t]{2}{*}{ Distribution I } & \multicolumn{2}{|c|}{ Manufacturing } & \multirow[t]{2}{*}{ Distribution II } & \multicolumn{2}{|l|}{ Total } & & \\
\hline & & & Low & High & & Low & High & & Low & High & Low & High \\
\hline \multirow[t]{3}{*}{ Bracket } & Machining & 1.09 & 1820 & 2110 & 1.8 & 210 & 620 & 134 & 2170 & 2870 & 2.0 & 2.6 \\
\hline & EBM & 0.38 & 136 & 154 & 0.1 & 23.2 & 67.3 & 46.7 & 206 & 268 & 0.5 & 0.7 \\
\hline & $\begin{array}{l}\text { Difference (\% } \\
\text { change) }\end{array}$ & $\begin{array}{l}0.71 \\
(-65 \%)\end{array}$ & $\begin{array}{l}1670 \\
(-92 \%)\end{array}$ & $\begin{array}{l}1970(- \\
94 \%)\end{array}$ & $\begin{array}{l}1.7 \\
(-94 \%)\end{array}$ & $\begin{array}{l}142 \\
(-68 \%)\end{array}$ & $\begin{array}{l}599 \\
(-96 \%)\end{array}$ & $87.3(-65 \%)$ & $\begin{array}{l}1910(- \\
88 \%)\end{array}$ & $\begin{array}{l}2660 \\
(-93 \%)\end{array}$ & $\begin{array}{l}1.3 \\
(-65 \%)\end{array}$ & $\begin{array}{l}2.1 \\
(-79 \%)\end{array}$ \\
\hline \multirow[t]{3}{*}{ Bionic bracket } & Machining & 0.06 & 100 & 116 & 1.1 & 11.5 & 34.2 & 0.2 & 113 & 1534 & 1.9 & 2.5 \\
\hline & EBM & 0.04 & 13.9 & 15.8 & 0.1 & 2.4 & 6.9 & 0.1 & 16.6 & 22.9 & 0.4 & 0.6 \\
\hline & $\begin{array}{l}\text { Difference (\% } \\
\text { change) }\end{array}$ & $\begin{array}{l}0.02 \\
(-35 \%)\end{array}$ & $\begin{array}{l}85 \\
(-84 \%)\end{array}$ & $\begin{array}{l}102 \\
(-88 \%)\end{array}$ & $\begin{array}{l}1.0 \\
(-91 \%)\end{array}$ & $\begin{array}{l}4.6 \\
(-40 \%)\end{array}$ & $\begin{array}{l}31.9 \\
(-93 \%)\end{array}$ & $0.1(-35 \%)$ & $\begin{array}{l}91 \\
(-80 \%)\end{array}$ & $\begin{array}{l}136 \\
(-89 \%)\end{array}$ & $\begin{array}{l}1.3 \\
(-70 \%)\end{array}$ & $\begin{array}{l}2.1 \\
(-84 \%)\end{array}$ \\
\hline \multirow{3}{*}{$\begin{array}{l}\text { Engine cover } \\
\text { door hinge }\end{array}$} & Casting & 0.92 & 570 & 1000 & 1.9 & 160 & 242 & 45.7 & 1080 & 1290 & 1.2 & 1.4 \\
\hline & DMLS & 0.33 & 116 & 132 & 0.2 & 104 & 147 & 16.2 & 237 & 296 & 0.7 & 0.9 \\
\hline & $\begin{array}{l}\text { Difference (\% } \\
\text { change) }\end{array}$ & \begin{tabular}{|l|}
0.59 \\
$(-65 \%)$
\end{tabular} & $\begin{array}{l}730 \\
(-85 \%)\end{array}$ & $\begin{array}{l}880(- \\
88 \%)\end{array}$ & $\begin{array}{l}1.7 \\
(-89 \%)\end{array}$ & $\begin{array}{l}12.8 \\
(-8 \%)\end{array}$ & $\begin{array}{l}138 \\
(-57 \%)\end{array}$ & $29.5(-65 \%)$ & $\begin{array}{l}780(- \\
72 \%)\end{array}$ & $\begin{array}{l}1050 \\
(-82 \%)\end{array}$ & $\begin{array}{l}0.3 \\
(-23 \%)\end{array}$ & $\begin{array}{l}0.7 \\
(-49 \%)\end{array}$ \\
\hline \multirow[t]{3}{*}{ Seat buckle } & Forging & 0.16 & 61 & 97 & 3.1 & 14.6 & 24.6 & 0.4 & 79 & 126 & 0.5 & 0.8 \\
\hline & SLM & 0.07 & 11 & 17 & 0.1 & 5.1 & 36.4 & 0.2 & 16.6 & 53.6 & 0.2 & 0.8 \\
\hline & $\begin{array}{l}\text { Difference (\% } \\
\text { change) }\end{array}$ & \begin{tabular}{|l|}
0.09 \\
$(-55 \%)$
\end{tabular} & \begin{tabular}{|l|}
44 \\
$(-72 \%)$
\end{tabular} & $\begin{array}{l}86 \\
(-88 \%)\end{array}$ & $\begin{array}{l}3.0 \\
(-97 \%)\end{array}$ & $\begin{array}{l}-21.8 \\
(149 \%)\end{array}$ & $\begin{array}{l}19.5 \\
(-79 \%)\end{array}$ & $0.2(-55 \%)$ & $\begin{array}{l}25 \\
(-32 \%)\end{array}$ & $\begin{array}{l}110 \\
(-87 \%)\end{array}$ & \begin{tabular}{|l|}
-0.3 \\
$(55 \%)$
\end{tabular} & $\begin{array}{l}0.6 \\
(-70 \%)\end{array}$ \\
\hline \multirow[t]{3}{*}{ Fork fitting } & Casting & 0.80 & 313 & 504 & 2.8 & 75.5 & 127 & 97.3 & 490 & 740 & 0.6 & 0.9 \\
\hline & SLM & 0.40 & 64 & 97 & 0.5 & 29.3 & 208 & 48.6 & 142 & 354 & 0.4 & 1.0 \\
\hline & $\begin{array}{l}\text { Difference (\% } \\
\text { change) }\end{array}$ & $\begin{array}{l}0.40 \\
(-50 \%)\end{array}$ & $\begin{array}{l}216 \\
(-69 \%)\end{array}$ & $\begin{array}{l}440 \\
(-87 \%)\end{array}$ & $\begin{array}{l}2.3 \\
(-82 \%)\end{array}$ & $\begin{array}{l}-132 \\
(175 \%)\end{array}$ & $\begin{array}{l}97.8 \\
(-77 \%)\end{array}$ & $48.7(-50 \%)$ & $\begin{array}{l}135 \\
(-28 \%)\end{array}$ & $\begin{array}{l}594 \\
(-81 \%)\end{array}$ & $\begin{array}{l}-0.3 \\
(45 \%)\end{array}$ & $\begin{array}{l}0.6 \\
(-61 \%)\end{array}$ \\
\hline
\end{tabular}


Table S20. "Cradle to gate" $\mathrm{CO}_{2} \mathrm{e}$ emissions intensities of representative parts

\begin{tabular}{|c|c|c|c|c|c|c|c|c|c|c|c|c|}
\hline \multirow{3}{*}{$\begin{array}{l}\text { Representative } \\
\text { component }\end{array}$} & \multirow{3}{*}{$\begin{array}{l}\text { Manufacturing } \\
\text { process }\end{array}$} & \multirow{3}{*}{$\begin{array}{l}\text { Component } \\
\text { mass (kg) }\end{array}$} & \multicolumn{8}{|c|}{$\mathrm{CO}_{2} \mathrm{e}$ emissions $(\mathrm{kg})$} & \multirow{2}{*}{\multicolumn{2}{|c|}{\begin{tabular}{|l|} 
Cradle to gate primary \\
$\mathrm{CO}_{2} \mathrm{e}$ emissions \\
intensity
\end{tabular}}} \\
\hline & & & \multicolumn{2}{|c|}{\begin{tabular}{|l|} 
Raw material \\
production
\end{tabular}} & \multirow[t]{2}{*}{ Distribution I } & \multicolumn{2}{|c|}{ Manufacturing } & \multirow[t]{2}{*}{ Distribution II } & \multicolumn{2}{|l|}{ Total } & & \\
\hline & & & Low & High & & Low & High & & Low & High & Low & High \\
\hline \multirow[t]{3}{*}{ Bracket } & Machining & 1.09 & 167 & 193 & 0.1 & 14.2 & 42.3 & 8.9 & 191 & 245 & 175 & 225 \\
\hline & EBM & 0.38 & 11.0 & 12.8 & 0 & 1.6 & 4.6 & 3.1 & 15.7 & 20.4 & 41.4 & 53.7 \\
\hline & $\begin{array}{l}\text { Difference (\% } \\
\text { change) }\end{array}$ & $\begin{array}{l}0.71 \\
(-65 \%)\end{array}$ & $\begin{array}{l}154(- \\
92 \%)\end{array}$ & $\begin{array}{l}182(- \\
94 \%)\end{array}$ & $0.1(-93 \%)$ & $9.6(-68 \%)$ & $\begin{array}{l}40.7(- \\
96 \%)\end{array}$ & $5.8(-65 \%)$ & $\begin{array}{l}170(- \\
89 \%)\end{array}$ & $\begin{array}{l}230(- \\
94 \%)\end{array}$ & $122(-69 \%)$ & $184(-82 \%)$ \\
\hline \multirow[t]{3}{*}{ Bionic bracket } & Machining & 0.06 & 9.2 & 10.6 & 0.1 & 0.8 & 2.3 & 0 & 10.1 & 13.1 & 169 & 219 \\
\hline & EBM & 0.04 & 1.1 & 1.3 & 0 & 0.2 & 0.5 & 0 & 1.3 & 1.8 & 32.9 & 45.3 \\
\hline & $\begin{array}{l}\text { Difference (\% } \\
\text { change) }\end{array}$ & $\begin{array}{l}0.02 \\
(-35 \%)\end{array}$ & $\begin{array}{l}7.9(- \\
86 \%)\end{array}$ & $\begin{array}{l}9.5(- \\
89 \%)\end{array}$ & $0.1(-91 \%)$ & $0.3(-40 \%)$ & $\begin{array}{l}2.2(- \\
93 \%)\end{array}$ & $0.0(-35 \%)$ & $\begin{array}{l}8.3(- \\
82 \%)\end{array}$ & $\begin{array}{l}11.8(- \\
90 \%)\end{array}$ & $123(-73 \%)$ & $186(-85 \%)$ \\
\hline \multirow{3}{*}{$\begin{array}{l}\text { Engine cover } \\
\text { door hinge }\end{array}$} & Casting & 0.92 & 79 & 92 & 0.1 & 10.9 & 16.5 & 3 & 93 & 111 & 101 & 121 \\
\hline & DMLS & 0.33 & 9.5 & 11.0 & 0 & 7.1 & 10 & 1.1 & 17.7 & 22.0 & 53.6 & 66.6 \\
\hline & $\begin{array}{l}\text { Difference (\% } \\
\text { change) }\end{array}$ & $\begin{array}{l}0.59 \\
(-65 \%)\end{array}$ & $\begin{array}{l}68(- \\
86 \%)\end{array}$ & $\begin{array}{l}83(- \\
90 \%)\end{array}$ & $0.1(-88 \%)$ & $0.9(-8 \%)$ & $\begin{array}{l}9.4(- \\
57 \%)\end{array}$ & $1.9(-65 \%)$ & $\begin{array}{l}71(- \\
76 \%)\end{array}$ & $\begin{array}{l}93(- \\
84 \%)\end{array}$ & $34.6(-34 \%)$ & $67.1(-56 \%)$ \\
\hline \multirow[t]{3}{*}{ Seat buckle } & Forging & 0.16 & 4.1 & 9.3 & 0.2 & 1 & 1.7 & 0 & 5.3 & 11.2 & 33.2 & 70.0 \\
\hline & SLM & 0.07 & 0.6 & 1.4 & 0 & 0.3 & 2.5 & 0 & 0.9 & 3.9 & 13.5 & 56.2 \\
\hline & $\begin{array}{l}\text { Difference (\% } \\
\text { change) }\end{array}$ & $\begin{array}{l}0.09 \\
(-55 \%)\end{array}$ & $\begin{array}{l}2.7(- \\
65 \%)\end{array}$ & $\begin{array}{l}8.7(- \\
93 \%)\end{array}$ & $0.2(-98 \%)$ & $\begin{array}{l}-1.5 \\
(149 \%)\end{array}$ & $\begin{array}{l}1.3(- \\
79 \%)\end{array}$ & $0.0(-55 \%)$ & $\begin{array}{l}1.4(- \\
26 \%)\end{array}$ & $\begin{array}{l}10.3(- \\
92 \%)\end{array}$ & $-23.0(69 \%)$ & $56.5(-81 \%)$ \\
\hline \multirow[t]{3}{*}{ Fork fitting } & Casting & 0.80 & 21.3 & 48.1 & 0.2 & 5.1 & 8.6 & 6.5 & 33 & 64 & 41.5 & 79.3 \\
\hline & SLM & 0.40 & 3.6 & 8.1 & 0 & 2 & 14.1 & 3.2 & 8.8 & 25.5 & 22.1 & 63.7 \\
\hline & $\begin{array}{l}\text { Difference (\% } \\
\text { change) }\end{array}$ & $\begin{array}{l}0.40 \\
(-50 \%)\end{array}$ & $\begin{array}{l}19.6(- \\
59 \%)\end{array}$ & $\begin{array}{l}75.1(- \\
93 \%)\end{array}$ & $0.2(-83 \%)$ & $\begin{array}{l}-9.0 \\
(175 \%)\end{array}$ & $\begin{array}{l}6.7(- \\
77 \%)\end{array}$ & $3.3(-50 \%)$ & $\begin{array}{l}7.7(- \\
23 \%)\end{array}$ & $\begin{array}{l}54.6(- \\
86 \%)\end{array}$ & $-22.2(54 \%)$ & $57.3(-72 \%)$ \\
\hline
\end{tabular}




\section{Aircraft-level estimates}

The results in Tables S19 and S20 estimate the mass reduction potential associated with replacing CM pathways with AM pathways for the representative components, as well as corresponding potential reductions in "cradle to gate" primary energy use and $\mathrm{CO}_{2} \mathrm{e}$ emissions associated with component manufacturing. In Table S21, mass reduction potentials are scaled up to estimate the total mass reduction for each selected aircraft component system that would occur if the full AM replacement potential were realized (as estimated in Section 2.3 and summarized in Table S8). Specifically, the results in Table S21 were generated by applying the mass reduction potentials for each representative component (Table S17) to the total replaceable mass ranges for each component system (Table S8). First, a representative component was assigned to each component system and component category in Table S8 on the basis of similar function. Second, the mass reduction potential associated with the representative component was multiplied by the replaceable mass ranges for all materials within that same component system and component category. Implicit in this approach is that the mass reductions documented in the case study data for each representative component could be replicated across all replaceable mass within the same component system and category. Table S22 expresses the data in Table S21 as percent reductions of total aircraft mass.

Table S21. Estimated mass reductions (in $\mathrm{kg}$ ) by material and component system through AM replacement

\begin{tabular}{|c|c|c|c|c|c|c|c|}
\hline \multirow[b]{2}{*}{$\begin{array}{l}\text { Component } \\
\text { system }\end{array}$} & \multirow[b]{2}{*}{ Category } & \multirow[b]{2}{*}{$\begin{array}{l}\text { Representative } \\
\text { component }\end{array}$} & \multicolumn{5}{|c|}{ Mass reduction in average aircraft (kg) } \\
\hline & & & Al alloy & Ti alloy & Ni alloy & Steel & Total \\
\hline Body systems & Auxiliary & Fork fitting & $40-100$ & & & & $40-100$ \\
\hline \multirow{2}{*}{$\begin{array}{l}\text { Furnishings and } \\
\text { equipment }\end{array}$} & Structural & Bracket & $50-90$ & & & & $50-90$ \\
\hline & Functional & Seat buckle & $790-1060$ & & & & $790-1060$ \\
\hline \multirow[t]{2}{*}{ Engine } & Functional & Bionic bracket & & $240-470$ & $330-660$ & $30-70$ & $600-1200$ \\
\hline & Auxiliary & Bionic bracket & & $20-30$ & $20-30$ & $20-30$ & $50-90$ \\
\hline $\begin{array}{l}\text { Propulsion } \\
\text { systems }\end{array}$ & Functional & Bionic bracket & & $110-290$ & & & $110-290$ \\
\hline \multirow[t]{2}{*}{ Nacelle Systems } & Auxiliary & $\begin{array}{l}\text { Engine cover } \\
\text { door hinge }\end{array}$ & & $10-30$ & & & $10-30$ \\
\hline & Total & & $880-1240$ & $380-820$ & $340-690$ & $50-100$ & $1650-2840$ \\
\hline
\end{tabular}


Table S22. Estimated mass reductions (\% of total aircraft mass) by material and component system through AM replacement

\begin{tabular}{|c|c|c|c|c|c|c|c|}
\hline \multirow[b]{2}{*}{$\begin{array}{l}\text { Component } \\
\text { system }\end{array}$} & \multirow[b]{2}{*}{ Category } & \multirow[b]{2}{*}{$\begin{array}{l}\text { Representative } \\
\text { component }\end{array}$} & \multicolumn{5}{|c|}{ Mass reduction in average aircraft (\%) } \\
\hline & & & Al alloy & Ti alloy & Ni alloy & Steel & Total \\
\hline Body systems & Auxiliary & Fork fitting & $\begin{array}{l}0.10- \\
0.24 \%\end{array}$ & & & & $0.1-0.2 \%$ \\
\hline \multirow[t]{2}{*}{$\begin{array}{l}\text { Furnishings and } \\
\text { equipment }\end{array}$} & Structural & Bracket & $\begin{array}{l}0.11- \\
0.21 \%\end{array}$ & & & & $0.1-0.2 \%$ \\
\hline & Functional & Seat buckle & $\begin{array}{l}1.94- \\
2.58 \%\end{array}$ & & & & $1.9-2.6 \%$ \\
\hline \multirow[t]{2}{*}{ Engine } & Functional & Bionic bracket & & $\begin{array}{l}0.61- \\
1.21 \%\end{array}$ & $\begin{array}{l}0.82- \\
1.64 \%\end{array}$ & $\begin{array}{l}0.08- \\
0.16 \%\end{array}$ & $1.5-3.0 \%$ \\
\hline & Auxiliary & Bionic bracket & & $\begin{array}{l}0.06- \\
0.12 \%\end{array}$ & $\begin{array}{l}0.06- \\
0.12 \%\end{array}$ & $\begin{array}{l}0.06- \\
0.12 \%\end{array}$ & $0.2-0.4 \%$ \\
\hline $\begin{array}{l}\text { Propulsion } \\
\text { systems }\end{array}$ & Functional & Bionic bracket & & $\begin{array}{l}0.27- \\
0.68 \%\end{array}$ & & & $0.3-0.7 \%$ \\
\hline \multirow[t]{2}{*}{ Nacelle Systems } & Auxiliary & $\begin{array}{l}\text { Engine cover } \\
\text { door hinge }\end{array}$ & & $\begin{array}{l}0.02- \\
0.06 \%\end{array}$ & & & $\begin{array}{l}0.02- \\
0.06 \%\end{array}$ \\
\hline & Total & & $2.1-3.0 \%$ & $1.0-2.1 \%$ & $0.9-1.8 \%$ & $0.1-0.3 \%$ & $4.1-7.1 \%$ \\
\hline
\end{tabular}

Tables S23 and S24 summarize the estimated "cradle to gate" reductions in primary energy use and $\mathrm{CO}_{2} \mathrm{e}$ emissions, respectively, associated with the replacement of $\mathrm{CM}$ components by AM components when achieving the mass reductions summarized in Table S21. To generate the estimates in Table S24, this study first estimated the "cradle to gate" primary energy use of CM components by multiplying the replaceable mass data in Table $\mathrm{S} 8$ by the corresponding "cradle to gate" CM primary energy intensities in described in Section 3 for each component category and material. Second, the mass of the replacement AM components was calculated by subtracting the mass reductions in Table S21 from the replaceable mass in Table $\mathrm{S} 8$ for each component category and material. Third, the "cradle to gate" primary energy use of AM components was estimated by multiplying the estimated mass of AM replacements by the "cradle to gate" AM primary energy intensities described in Section 3. Finally, this study estimated "cradle to gate" reductions in primary energy use by subtracting the values obtained in the third step from the values obtained in the first step. An identical approach was taken to generate the estimates in Table S24 for "cradle to gate" $\mathrm{CO}_{2}$ e emissions reductions. The data in Tables S23 and S24 are expressed as total "cradle to gate" reductions per average aircraft. To obtain estimates of total reductions per kg of empty aircraft, one may divide the values in Tables S23 and S24 by the empty weight of the average aircraft assumed in this study (i.e., 40,622 kg) 
Table S23. Aircraft level "cradle to gate" primary energy use reductions

\begin{tabular}{|c|c|c|c|c|c|c|}
\hline \multirow[b]{2}{*}{$\begin{array}{l}\text { Component } \\
\text { system }\end{array}$} & \multirow[b]{2}{*}{ Category } & \multicolumn{5}{|c|}{ Primary energy use reductions (GJ/aircraft) } \\
\hline & & Al alloy & Ti alloy & Ni alloy & Steel & Total \\
\hline Body systems & Auxiliary & $10-130$ & & & & $10-130$ \\
\hline \multirow{2}{*}{$\begin{array}{l}\text { Furnishings and } \\
\text { equipment }\end{array}$} & Structural & $20-190$ & & & & $20-190$ \\
\hline & Functional & $210-1340$ & & & & $210-1340$ \\
\hline \multirow[t]{2}{*}{ Engine } & Functional & & $1020-3050$ & $720-4090$ & $1-50$ & $1740-7180$ \\
\hline & Auxiliary & & $70-200$ & $40-190$ & $0-60$ & $110-450$ \\
\hline $\begin{array}{l}\text { Propulsion } \\
\text { systems }\end{array}$ & Functional & & $490-1830$ & & & $490-1830$ \\
\hline \multirow[t]{2}{*}{ Nacelle Systems } & Auxiliary & & $10-50$ & & & $10-50$ \\
\hline & Total & $240-1660$ & $1590-5120$ & $760-4280$ & $2-110$ & $2560-11170$ \\
\hline
\end{tabular}

Table S24. Aircraft level "cradle to gate" reductions in $\mathrm{CO}_{2} \mathrm{e}$ emissions

\begin{tabular}{|c|c|c|c|c|c|c|}
\hline \multirow[b]{2}{*}{$\begin{array}{l}\text { Component } \\
\text { system }\end{array}$} & \multirow[b]{2}{*}{ Category } & \multicolumn{5}{|c|}{$\mathrm{CO}_{2} \mathrm{e}$ emissions reductions (metric ton/aircraft) } \\
\hline & & Al alloy & Ti alloy & Ni alloy & Steel & Total \\
\hline Body systems & Auxiliary & $0-12$ & & & & 0-12 \\
\hline \multirow{2}{*}{$\begin{array}{l}\text { Furnishings and } \\
\text { equipment }\end{array}$} & Structural & $2-17$ & & & & 2-17 \\
\hline & Functional & $12-130$ & & & & $12-130$ \\
\hline \multirow[t]{2}{*}{ Engine } & Functional & & $90-270$ & $60-270$ & $1-4$ & $160-540$ \\
\hline & Auxiliary & & $7-17$ & 3-13 & $0-5$ & $10-35$ \\
\hline $\begin{array}{l}\text { Propulsion } \\
\text { systems }\end{array}$ & Functional & & $45-160$ & & & $45-160$ \\
\hline \multirow[t]{2}{*}{ Nacelle Systems } & Auxiliary & & $2-6$ & & & 2-6 \\
\hline & Total & $14-160$ & $150-450$ & $70-290$ & $1-10$ & $230-900$ \\
\hline
\end{tabular}

\section{U.S. aircraft fleet adoption and fuel use modeling}

\subsection{Fleet adoption}

To determine the U.S. national primary energy and GHG emissions implications of using lightweight AM parts in passenger aircraft, the use-phase and cradle-to-gate energy and GHG savings found for each aircraft are applied to the US fleet of passenger aircraft. Three possible trajectories for US energy and GHG savings through 2050 are generated based on different assumptions about the rate of new technology adoption and part replacement.

Forecasts for the size of the US fleet are based on the US Department of Energy's Annual Energy Outlook (AEO) 2014 forecasts for active aircraft fleet in the US [77]. The AEO forecasts, which go through 2040, 
are extended to 2050 by assuming the average forecasted growth rate from 2035 to 2040 continues through 2050.

The average size and the number of miles traveled per year by aircraft in the fleet are assumed to be constant over time. This assumption is consistent with AEO forecasts, which predict similar annual growth rates for seat miles demanded $(0.9 \%)$ as for fleet size $(0.8 \%)$. An alternative forecast made by the US Federal Aviation Administration (FAA) projects a more rapid increase in seat miles demanded due to an increase in average airplane seating capacity over time[27]. This would increase airplane fuel use relative to the AEO forecasts and also the potential for operational fuel savings from the use of AM parts, as there is greater weight reduction potential in larger aircraft. If actual trends follow the FAA forecasts, energy savings potential from the use of AM parts could be greater than indicated in this paper.

The penetration of AM components into the airplane fleet depends on three factors: the time it takes to work out technological and economic barriers to the use of AM components, the diffusion curve for adoption of new AM technologies by component manufacturers once these barriers are removed, and the turnover rate for conventionally produced parts, either through the retirement of old aircraft or through replacement of parts in existing aircraft. The year in which it becomes technically feasible to substitute AM components for conventional components depends on the type of component. There are three waves of AM component adoption, with adoption beginning either in 2019, 2024 or 2034. These waves correspond to the 5-year, 10-year and 20-year time frames for adoption shown in Table S9. The basis for selecting these adoption time frames is discussed in more detail in the supplemental materials. Once it becomes technically feasible, a Bass diffusion curve determines how fast AM technologies are adopted in new component production[78]. These components are then used in new aircraft, which penetrate the fleet gradually as old aircraft are retired, and may also replace old components in existing aircraft.

Three scenarios are considered for the adoption of AM parts in aircraft, which are summarized in Table S25. They differ both in the diffusion parameters that are used, and in the conditions under which retrofits are performed. A wide range of technology diffusion rates have been observed for different aircraft technologies and time periods. Adoption rates for piston and turbine technologies in the 1940s, 50s and 60s were very slow [79], while successive waves of new generations of aircraft took over rapidly from previous models in the 1960s, 70s and 80s [80]. The average of the diffusion parameters for piston and turbine technologies [79]are used in our slow adoption scenario, and the parameters for our rapid adoption scenario are chosen to reach $80 \%$ adoption in 5 years, as was observed for $5^{\text {th }}$ generation aircraft [80]. For the mid-range scenario, intermediate values for the diffusion parameters are used that lead to $80 \%$ adoption in 15 years. These values are taken from a study of vehicle adoption of lightweight materials[81].

Three different possibilities for the rate at which AM parts penetrate the fleet of aircraft are also considered. In the slow adoption scenario, AM parts are only used in new aircraft. In the mid-range adoption scenario, AM components are also substituted for existing components when they need to be replaced. In the rapid adoption scenario, old components are replaced with AM components ahead of schedule to save fuel. 
Table S25. Adoption scenarios

\begin{tabular}{lll}
\hline Scenario & $\begin{array}{l}\text { Years until 80\% AM adoption by } \\
\text { component producers }\end{array}$ & Incorporation of AM parts into fleet \\
\hline Slow adoption & 28 years & new aircraft only \\
Mid-range adoption & 15 years & $\begin{array}{l}\text { new aircraft and new parts in } \\
\text { existing aircraft }\end{array}$ \\
Rapid adoption & 5 years & $\begin{array}{l}\text { new aircraft and new parts in } \\
\text { existing aircraft, with accelerated } \\
\text { replacement of non-AM parts }\end{array}$ \\
\hline
\end{tabular}

AM components are incorporated into the fleet of aircraft through a combination of new airplane production $\left(P^{A M}\right)$, and retrofits, which can be further broken down into baseline retrofits $\left(R B^{A M}\right)$ and accelerated retrofits $\left(R A^{A M}\right)$. Airplanes in the fleet are also periodically retired at a rate, $\rho_{a}$, that depends on the age $a$ of the aircraft. The number of aircraft, $F^{A M}$, of age $a$ in the fleet in year $t$, that have adopted AM component $c$ is calculated as follows:

$$
\begin{gathered}
F^{A M}{ }_{c, a, 2010}=0 \\
F^{A M}{ }_{c, 0, t}=P^{A M}{ }_{c, t} \\
F_{c, a, t}^{A M}=F_{c, a-1, t-1}^{A M} \cdot\left(1-\rho_{a}\right)+R B_{c, a, t}^{A M}+R A^{A M}{ }_{c, a, t}
\end{gathered}
$$

The retirement rate at each age, $\rho_{a}$, is set based on a piece-wise linear approximation $\left(N R_{a}\right)$ of the storage-adjusted retirement age distribution from Forsberg (2012)[82].

$$
\begin{gathered}
N R_{a}= \begin{cases}5 & \text { if } 1<a \leq 10 \\
5+(450-5) \cdot \frac{a-10}{24-10} & \text { if } 10<a \leq 24 \\
450+(5-450) \cdot \frac{a-24}{44-24} & \text { if } 24<a \leq 44 \\
5 & \text { if } 44<a \leq 48\end{cases} \\
\rho_{a}=\frac{N R_{a}}{\sum_{b \geq a} N R_{b}}
\end{gathered}
$$

The number of new aircraft produced with AM components, $P^{A M}{ }_{c, t}$, depends on the total production of new aircraft, $P_{t}$, and on the adoption level for AM technologies, $a^{A M}{ }_{c, t}$, following:

$$
\begin{aligned}
& P_{c, t}^{A M}=P_{t} \cdot a^{A M}{ }_{c, t} \\
& a^{A M}{ }_{c, t}=F\left(t-t_{c}^{0}\right)
\end{aligned}
$$

where $a^{A M}$ is set by the Bass curve $F(t)$ defined by $\frac{F^{\prime}(t)}{1-F(t)}=p+q F(t)$. The innovation and imitation parameters $p$ and $q$ vary by adoption scenario as shown in Table S26. $P_{t}$ is set to be enough to match 
retirements plus the increase in fleet size, which in turn is taken from AEO $2014 \mathrm{~b}$ [77]. $t_{c}^{0}$ is the first year that component $c$ becomes available, as specified in Table 59 .

The level of adoption of AM components through retrofits depends on the scenario and on the type of component. Engine and interior parts are replaced periodically throughout an airplane's life. Engine parts have limits on the number of cycles (takeoffs and landings) they can go through before they must be replaced. Interiors are refurbished periodically to remove signs of wear and improve passenger experiences. It is assumed that under normal conditions, one tenth of all engine parts and one seventh of all interior parts are replaced each year, based on estimates of the average life of rotating engine parts and on the frequency of interior refurbishment programs $[83,84]$. Body, nacelle and propulsion system components are not replaced until the aircraft is retired. In the mid-range adoption scenario, AM components are adopted with the same frequency in retrofits as they are in new production, following the formula:

$$
R B_{c, a, t}^{A M}=a_{c, t} \cdot \bar{r}_{c} \cdot\left(F_{a-1, t-1}-F_{c, a-1, t-1}^{A M}\right) \cdot\left(1-\rho_{a}\right)
$$

Where $\bar{r}_{c}$ is the baseline retrofit rate for component $c$, and $F_{a-1, t-1}$ is the total fleet size of age $a-1$ in the previous period. The age distribution of fleet is calculated based on retirement rates and new production, along with an initial age distribution in 2010 shown in Figure S2. This distribution was estimated using a backwards extrapolation of production numbers along with the same retirement rates as used for the forecasts.

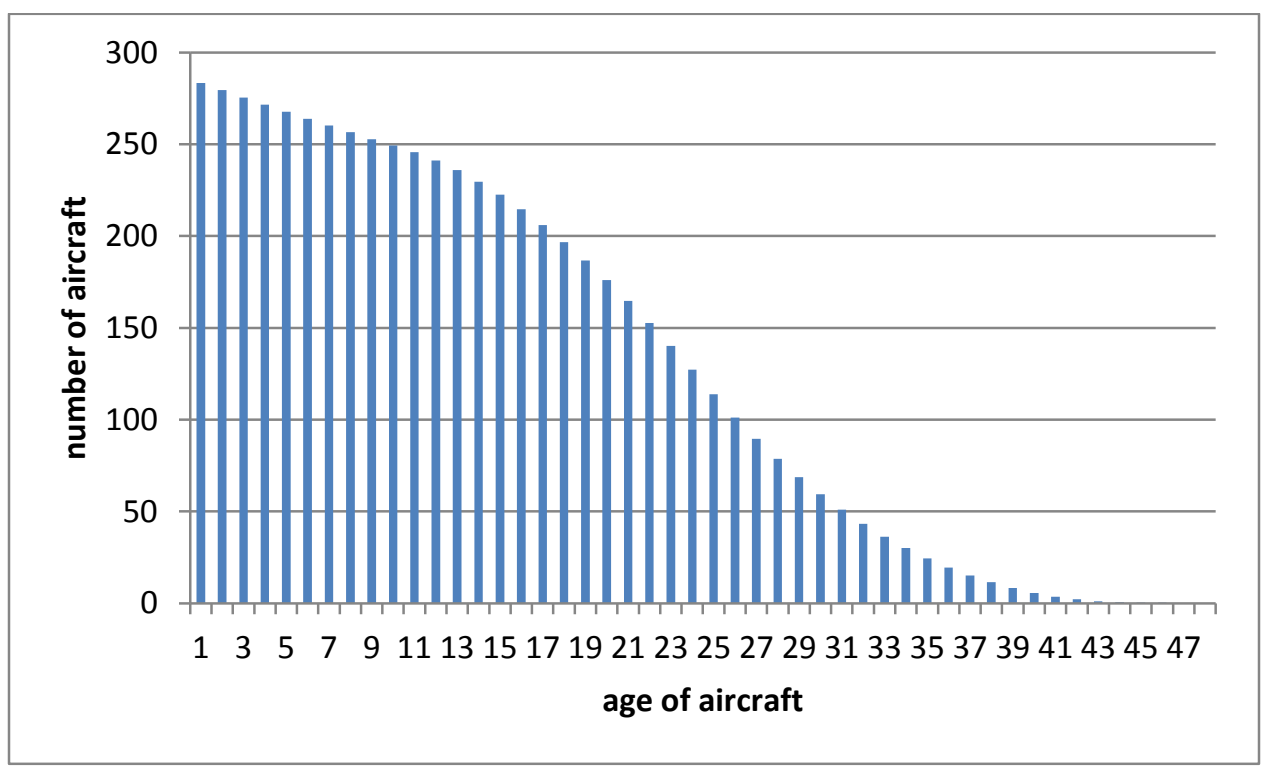

Figure S2. Distribution of aircraft ages in 2010

In the rapid adoption scenario, replacement rates for non-AM parts accelerate from the usual rate to $50 \%$ per year as the share of new construction that uses AM parts approaches $100 \%$. It is assumed that all accelerated retrofits use AM parts.

$$
R A_{c, a, t}^{A M}=a_{c, t} \cdot\left(r_{c}^{\max }-\bar{r}_{c}\right) \cdot\left(F_{a-1, t-1}-F A M_{c, a-1, t-1}\right) \cdot\left(1-\rho_{a}\right)
$$


Table S26. Scenario parameters

\begin{tabular}{llccccc}
\hline Scenario & $\mathrm{p}$ & $\mathrm{q}$ & $\begin{array}{l}\overline{\boldsymbol{r}}_{\boldsymbol{c}} \\
\text { (engine) }\end{array}$ & $\begin{array}{l}\overline{\boldsymbol{r}}_{\boldsymbol{c}} \\
\text { (furnishings and } \\
\text { equipment) }\end{array}$ & $\begin{array}{l}\boldsymbol{r}_{\boldsymbol{c}}^{\text {max }} \\
\text { (engine) }\end{array}$ & $\begin{array}{l}\boldsymbol{r}_{\boldsymbol{c}}^{\max } \\
\text { (furnishings and } \\
\text { equipment) }\end{array}$ \\
\hline $\begin{array}{l}\text { Slow } \\
\text { adoption }\end{array}$ & 0.0045 & 0.18 & 0 & 0 & 0 & 0 \\
$\begin{array}{l}\text { Mid-range } \\
\text { adoption }\end{array}$ & 0.0074 & 0.34 & $\frac{1}{10}$ & $\frac{1}{7}$ & $\frac{1}{10}$ & $\frac{1}{7}$ \\
$\begin{array}{l}\text { Rapid } \\
\text { adoption }\end{array}$ & 0.0074 & 1.32 & $\frac{1}{10}$ & $\frac{1}{7}$ & $\frac{1}{2}$ & $\frac{1}{2}$ \\
\hline
\end{tabular}

The turnover of each airplane component depends on when it becomes available, the adoption scenario, and the retrofit rate. Table S27 shows how two representative AM components are incorporated into the fleet: one engine component that becomes available in 2024, and one furnishings and equipment system component that becomes available in 2034. Incorporation rates vary greatly between scenarios, with retrofits playing an increasingly important role in the more rapid adoption scenarios.

Table S27. Incorporation of AM components into fleet of aircraft

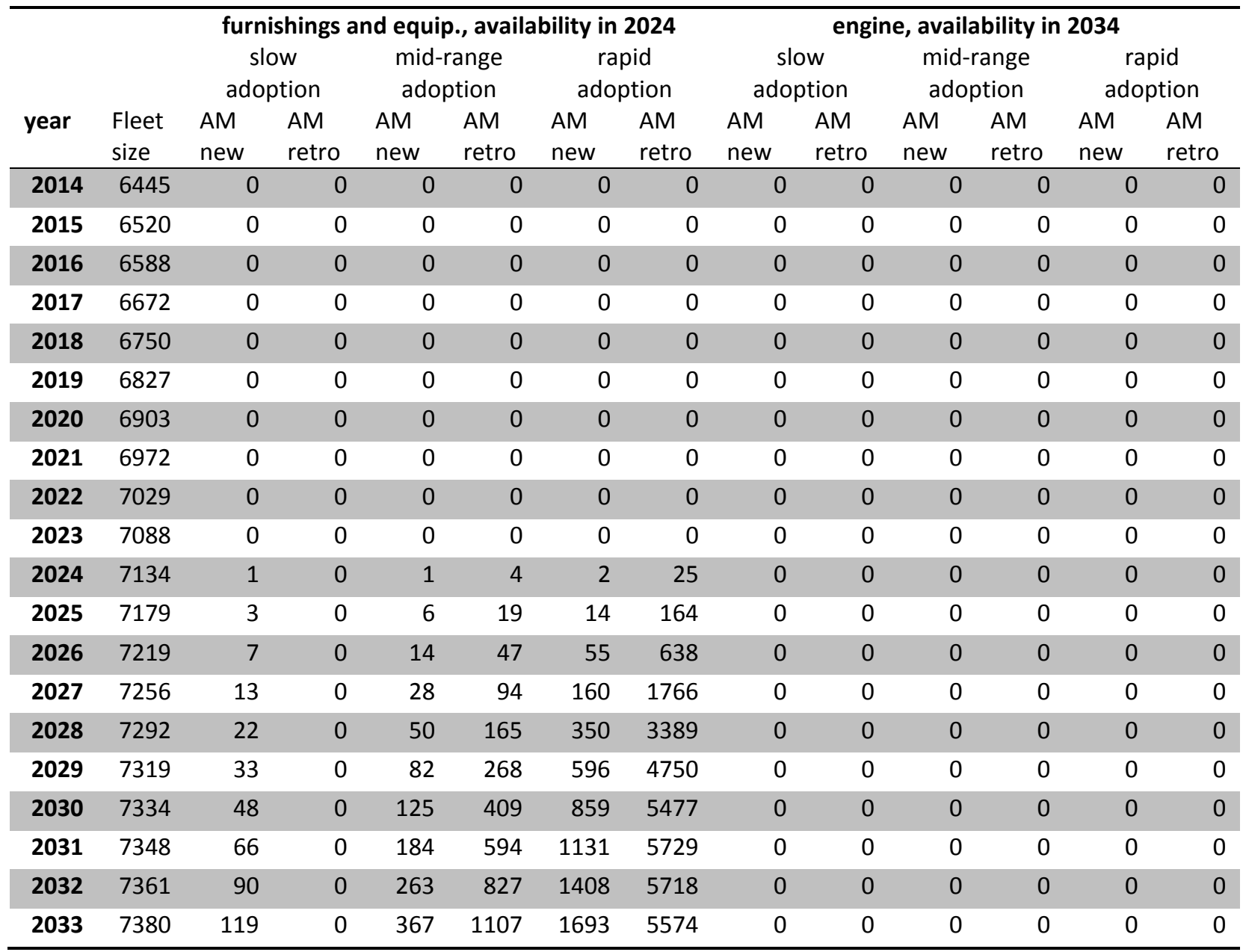




\begin{tabular}{rrrrrrrrrrrrrrr}
\hline $\mathbf{2 0 3 4}$ & 7403 & 155 & 0 & 498 & 1425 & 1984 & 5364 & 1 & 0 & 1 & 3 & 2 & 26 \\
$\mathbf{2 0 3 5}$ & 7437 & 201 & 0 & 663 & 1769 & 2290 & 5121 & 3 & 0 & 6 & 14 & 15 & 170 \\
$\mathbf{2 0 3 6}$ & 7478 & 257 & 0 & 860 & 2120 & 2604 & 4861 & 8 & 0 & 15 & 34 & 59 & 659 \\
$\mathbf{2 0 3 7}$ & 7524 & 324 & 0 & 1087 & 2457 & 2925 & 4593 & 14 & 0 & 31 & 68 & 178 & 1823 \\
$\mathbf{2 0 3 8}$ & 7566 & 402 & 0 & 1334 & 2763 & 3244 & 4319 & 24 & 0 & 56 & 120 & 389 & 3496 \\
$\mathbf{2 0 3 9}$ & 7612 & 493 & 0 & 1603 & 3021 & 3567 & 4044 & 37 & 0 & 92 & 194 & 673 & 4894 \\
$\mathbf{2 0 4 0}$ & 7657 & 598 & 0 & 1888 & 3226 & 3888 & 3769 & 55 & 0 & 144 & 297 & 988 & 5635 \\
$\mathbf{2 0 4 1}$ & 7702 & 718 & 0 & 2184 & 3372 & 4207 & 3495 & 77 & 0 & 214 & 434 & 1313 & 5884 \\
$\mathbf{2 0 4 2}$ & 7747 & 852 & 0 & 2490 & 3461 & 4522 & 3225 & 104 & 0 & 308 & 609 & 1643 & 5861 \\
\hline $\mathbf{2 0 4 3}$ & 7793 & 1002 & 0 & 2801 & 3497 & 4833 & 2959 & 138 & 0 & 429 & 822 & 1974 & 5702 \\
\hline $\mathbf{2 0 4 4}$ & 7838 & 1168 & 0 & 3117 & 3486 & 5138 & 2700 & 180 & 0 & 579 & 1069 & 2306 & 5476 \\
\hline $\mathbf{2 0 4 5}$ & 7884 & 1348 & 0 & 3434 & 3433 & 5435 & 2449 & 230 & 0 & 759 & 1343 & 2639 & 5219 \\
$\mathbf{2 0 4 6}$ & 7930 & 1544 & 0 & 3752 & 3345 & 5724 & 2206 & 289 & 0 & 967 & 1630 & 2972 & 4946 \\
\hline $\mathbf{2 0 4 7}$ & 7977 & 1753 & 0 & 4068 & 3229 & 6002 & 1975 & 359 & 0 & 1203 & 1915 & 3306 & 4665 \\
\hline $\mathbf{2 0 4 8}$ & 8023 & 1976 & 0 & 4382 & 3089 & 6269 & 1754 & 440 & 0 & 1461 & 2185 & 3639 & 4382 \\
\hline $\mathbf{2 0 4 9}$ & 8070 & 2210 & 0 & 4692 & 2932 & 6523 & 1547 & 535 & 0 & 1739 & 2428 & 3971 & 4098 \\
\hline $\mathbf{2 0 5 0}$ & 8118 & 2455 & 0 & 4996 & 2761 & 6764 & 1354 & 643 & 0 & 2032 & 2633 & 4302 & 3816 \\
\hline
\end{tabular}

\subsection{Fuel use modeling and fleet-wide results}

The adoption of lighter weight AM components in an aircraft will reduce its mass and therefore the amount of fuel used while operating the aircraft. Fuel savings, in TJ, from a $100 \mathrm{~kg}$ reduction in the mass of an aircraft, $\frac{\Delta F}{\Delta m}$, is estimated to be 13.4-20.0 TJ of fuel over the course of a 30 year life of an airplane, or 0.45-0.67 TJ per year, based on the range of estimates in three sources [85-87]. The primary energy savings $\left(\epsilon_{\text {jet fuel }}\right)$ and $\mathrm{CO}_{2}$ e emissions reduction $\left(\gamma_{\text {jet fuel }}\right)$ per $\mathrm{GJ}$ of jet fuel saved are $1.2 \mathrm{GJ}$ primary energy and $92 \mathrm{~kg} \mathrm{CO} 2$ e respectively, based on estimates of well-to-wake energy use and carbonequivalent emissions from jet fuel used in Argonne's GREET model [32].

The primary energy and $\mathrm{CO}_{2}$ savings trajectories for the US passenger fleet are built from use-phase savings from reduced fuel use and from cradle-to-gate manufacturing system savings from the LCA. Usephase savings for an average aircraft are applied to the active fleet of aircraft that have adopted AM parts, and manufacturing system savings are applied to all AM parts produced for new aircraft as well as for retrofits of parts that would have been replaced anyway. In the accelerated retrofit scenario, parts that are replaced ahead of schedule incur an energy penalty due the additional part production that is necessary in this scenario.

Cradle-to-gate and use-phase (fuel) energy savings ( $\Delta E_{c_{-} t t_{-} g, c, t}$ and $\Delta E_{f u e l, c, t}$ respectively) and $\mathrm{CO}_{2} \mathrm{e}$ savings ( $\Delta C_{c_{-} t t_{-} g, c, t}$ and $\Delta C_{f u e l, c, t}$ respectively) are calculated for each type of component using the following formulas:

$$
\Delta E_{\text {fuel }, c, t}=\epsilon_{\text {jet fuel }} \cdot \frac{\Delta F}{\Delta m} \cdot \frac{\Delta m_{c}}{\text { airplane }} \cdot \sum_{a=0}^{A} F_{c, a, t}^{A M}
$$




$$
\begin{aligned}
& \Delta E_{c_{-} t o \_g, c, t}=\frac{E^{C M}{ }_{c_{-} t t_{-} g, c}}{\text { airplane }} \cdot\left(P^{A M}{ }_{c, t}+\sum_{a=1}^{A} R B^{A M}{ }_{c, a, t}\right)-
\end{aligned}
$$

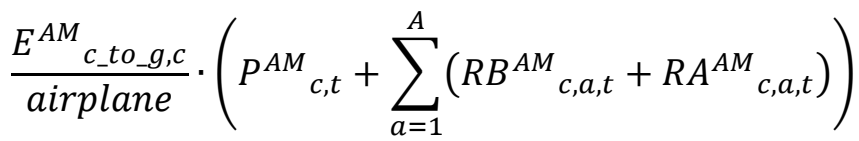

$$
\begin{aligned}
& \Delta C_{\text {fuel,c,t }}=\gamma_{\text {jet fuel }} \cdot \frac{\Delta F}{\Delta m} \cdot \frac{\Delta m_{c}}{\text { airplane }} \cdot \sum_{a=0}^{A} F_{c, a, t}^{A M} \\
& \Delta C_{c_{-} t o \_g, c, t}=\frac{C^{C M}{ }_{{ }_{-} \text {to_g }, c}}{\text { airplane }} \cdot\left(P^{A M}{ }_{c, t}+\sum_{a=1}^{A} R B^{A M}{ }_{c, a, t}\right)- \\
& \frac{C_{{ }^{A-} t_{-} g, c}}{\text { airplane }} \cdot\left(P_{c, t}^{A M}+\sum_{a=1}^{A}\left(R B^{A M}{ }_{c, a, t}+R A_{c, a, t}^{A M}\right)\right)
\end{aligned}
$$

$\frac{E^{C M}{ }_{c_{-} t o_{-}, c}}{\text { airplane }}$ and $\frac{E^{A M}{ }_{c_{-} t o_{-}, c}}{\text { airplane }}$ give the cradle-to-gate primary energy use per airplane from producing component $c$ with conventional manufacturing and additive manufacturing, respectively, as calculated in section 4. $\frac{C^{C M}{ }_{c_{-} t t_{-}, c} \text { airplane }}{\text { and }} \frac{C^{A M}{ }_{c_{-} \text {to g, }, c}}{\text { airplane }}$ give the equivalent numbers for carbon emissions. $\frac{\Delta m_{c}}{\text { airplane }}$ is the mass reductions per airplane associated with each component, shown in Table S21.

The results of these calculations, aggregated across components, are shown in Tables S28-S29. Tables $\mathrm{S} 30-\mathrm{S} 31$ show the share of cumulative use phase and production phase energy and $\mathrm{CO}_{2} \mathrm{e}$ savings in each scenario that are attributed to each component system. 
Table S28. Energy savings from AM adoption (million GJ/year)

\begin{tabular}{|c|c|c|c|c|c|c|c|c|c|c|}
\hline \multirow{2}{*}{\multicolumn{2}{|c|}{ year }} & \multicolumn{3}{|c|}{ slow adoption } & \multicolumn{3}{|c|}{ mid-range adoption } & \multicolumn{3}{|c|}{ rapid adoption } \\
\hline & & $\begin{array}{l}\text { cradle-to- } \\
\text { gate }\end{array}$ & use-phase & total & $\begin{array}{l}\text { cradle-to- } \\
\text { gate }\end{array}$ & use-phase & total & $\begin{array}{l}\text { cradle-to- } \\
\text { gate }\end{array}$ & use-phase & total \\
\hline & 2014 & $0.0-0.0$ & $0.0-0.0$ & $0.0-0.0$ & $0.0-0.0$ & $0.0-0.0$ & $0.0-0.0$ & $0.0-0.0$ & $0.0-0.0$ & $0.0-0.0$ \\
\hline & 2015 & $0.0-0.0$ & $0.0-0.0$ & $0.0-0.0$ & $0.0-0.0$ & $0.0-0.0$ & $0.0-0.0$ & $0.0-0.0$ & $0.0-0.0$ & $0.0-0.0$ \\
\hline & 2016 & $0.0-0.0$ & $0.0-0.0$ & $0.0-0.0$ & $0.0-0.0$ & $0.0-0.0$ & $0.0-0.0$ & $0.0-0.0$ & $0.0-0.0$ & $0.0-0.0$ \\
\hline & 2017 & $0.0-0.0$ & $0.0-0.0$ & $0.0-0.0$ & $0.0-0.0$ & $0.0-0.0$ & $0.0-0.0$ & $0.0-0.0$ & $0.0-0.0$ & $0.0-0.0$ \\
\hline & 2018 & $0.0-0.0$ & $0.0-0.0$ & $0.0-0.0$ & $0.0-0.0$ & $0.0-0.0$ & $0.0-0.0$ & $0.0-0.0$ & $0.0-0.0$ & $0.0-0.0$ \\
\hline & 2019 & $0.0-0.0$ & $0.0-0.0$ & $0.0-0.0$ & $0.0-0.0$ & $0.0-0.0$ & $0.0-0.0$ & $0.0-0.0$ & $0.0-0.0$ & $0.0-0.0$ \\
\hline & 2020 & $0.0-0.0$ & $0.0-0.0$ & $0.0-0.0$ & $0.0-0.0$ & $0.0-0.0$ & $0.0-0.0$ & $0.0-0.0$ & $0.0-0.1$ & $0.0-0.1$ \\
\hline & 2021 & $0.0-0.0$ & $0.0-0.0$ & $0.0-0.0$ & $0.0-0.0$ & $0.0-0.0$ & $0.0-0.0$ & $0.0-0.0$ & $0.1-0.3$ & $0.1-0.3$ \\
\hline & 2022 & $0.0-0.0$ & $0.0-0.0$ & $0.0-0.0$ & $0.0-0.0$ & $0.0-0.1$ & $0.0-0.1$ & $0.0-0.1$ & $0.3-0.9$ & $0.3-1.0$ \\
\hline & 2023 & $0.0-0.0$ & $0.0-0.0$ & $0.0-0.0$ & $0.0-0.0$ & $0.0-0.1$ & $0.0-0.1$ & $0.0-0.1$ & $0.7-1.8$ & $0.7-1.8$ \\
\hline & 2024 & $0.0-0.0$ & $0.0-0.0$ & $0.0-0.0$ & $0.0-0.0$ & $0.1-0.2$ & $0.1-0.3$ & 0.0-0.1 & $1.1-2.8$ & $1.1-2.9$ \\
\hline & 2025 & $0.0-0.0$ & 0.0-0.1 & $0.0-0.1$ & $0.0-0.1$ & $0.2-0.5$ & $0.2-0.6$ & $0.0-0.1$ & $2.0-4.7$ & $2.0-4.9$ \\
\hline & 2026 & $0.0-0.0$ & 0.1-0.1 & $0.1-0.1$ & $0.0-0.1$ & $0.4-1.0$ & $0.5-1.1$ & $-0.1-0.3$ & $4.6-9.9$ & $4.4-10.2$ \\
\hline & 2027 & $0.0-0.0$ & $0.1-0.2$ & $0.1-0.2$ & $0.0-0.2$ & $0.8-1.7$ & $0.8-1.9$ & $-0.3-0.6$ & $10.5-21.7$ & $10.2-22.4$ \\
\hline & 2028 & $0.0-0.0$ & $0.1-0.3$ & $0.1-0.3$ & $0.0-0.2$ & $1.3-2.8$ & $1.3-3.0$ & $-0.5-0.9$ & $19.3-39.0$ & $18.8-40.0$ \\
\hline & 2029 & $0.0-0.0$ & $0.2-0.4$ & $0.2-0.5$ & $0.1-0.3$ & $2.0-4.3$ & $2.1-4.6$ & $-0.4-1.0$ & $27.0-54.4$ & $26.6-55.4$ \\
\hline & 2030 & $0.0-0.0$ & $0.3-0.6$ & $0.3-0.7$ & $0.1-0.4$ & $3.0-6.3$ & $3.1-6.7$ & $-0.2-0.8$ & $31.8-64.0$ & $31.6-64.8$ \\
\hline & 2031 & $0.0-0.0$ & $0.4-0.8$ & $0.4-0.9$ & $0.1-0.6$ & $4.3-8.8$ & $4.4-9.4$ & $-0.1-0.7$ & $34.4-69.2$ & $34.3-69.9$ \\
\hline & 2032 & $0.0-0.1$ & 0.5-1.1 & $0.5-1.2$ & $0.1-0.7$ & $5.9-12.1$ & $6.0-12.8$ & $0.0-0.7$ & $35.7-71.9$ & $35.7-72.6$ \\
\hline & 2033 & 0.0-0.1 & $0.7-1.5$ & $0.7-1.5$ & $0.1-0.8$ & $7.8-16.0$ & 7.9-16.8 & $0.1-0.7$ & $36.4-73.5$ & $36.5-74.2$ \\
\hline & 2034 & $0.0-0.1$ & 0.9-1.9 & $0.9-2.0$ & $0.2-1.0$ & 10.1-20.6 & $10.2-21.6$ & $0.1-0.7$ & $37.0-74.9$ & $37.1-75.5$ \\
\hline & 2035 & 0.0-0.1 & $1.1-2.4$ & $1.2-2.6$ & $0.2-1.2$ & $12.6-25.8$ & $12.9-27.1$ & 0.1-0.9 & $37.9-77.2$ & $38.0-78.1$ \\
\hline & 2036 & $0.0-0.2$ & 1.5-3.1 & $1.5-3.3$ & $0.3-1.5$ & $15.5-31.6$ & $15.7-33.1$ & $0.2-1.5$ & $39.8-82.9$ & $40.0-84.4$ \\
\hline & 2037 & $0.0-0.2$ & $1.8-4.0$ & $1.9-4.2$ & $0.3-1.7$ & $18.4-37.7$ & $18.7-39.4$ & $0.3-2.8$ & $44.1-95.5$ & $44.4-98.2$ \\
\hline & 2038 & $0.1-0.3$ & $2.3-5.0$ & $2.4-5.3$ & $0.4-1.9$ & $21.4-44.0$ & $21.8-45.9$ & $0.4-4.1$ & $50.2-113.6$ & 50.6-117.6 \\
\hline & 2039 & $0.1-0.3$ & $2.8-6.2$ & $2.9-6.5$ & $0.4-2.2$ & $24.4-50.4$ & $24.8-52.6$ & $0.6-4.6$ & $55.7-130.0$ & 56.4-134.6 \\
\hline & 2040 & $0.1-0.4$ & $3.5-7.6$ & $3.6-7.9$ & $0.5-2.5$ & $27.3-56.9$ & $27.9-59.5$ & $0.7-4.3$ & 59.4-141.0 & $60.2-145.3$ \\
\hline & 2041 & $0.1-0.5$ & 4.2-9.1 & 4.3-9.6 & $0.6-2.9$ & $30.2-63.5$ & $30.9-66.4$ & $0.8-4.0$ & 61.6-147.6 & 62.4-151.6 \\
\hline & 2042 & $0.1-0.6$ & $5.0-11.0$ & 5.1-11.5 & $0.7-3.4$ & $33.1-70.2$ & $33.8-73.6$ & $0.8-3.9$ & 63.1-151.8 & 63.9-155.7 \\
\hline & 2043 & $0.1-0.6$ & 5.9-13.0 & 6.1-13.6 & $0.9-3.9$ & $35.9-77.1$ & $36.8-81.0$ & $0.9-3.8$ & 64.1-154.8 & 64.9-158.6 \\
\hline & 2044 & $0.2-0.7$ & $7.0-15.3$ & 7.1-16.0 & $1.0-4.4$ & $38.8-84.3$ & $39.8-88.7$ & 0.9-3.7 & 64.9-157.3 & $65.8-161.0$ \\
\hline & 2045 & $0.2-0.9$ & 8.1-17.9 & 8.3-18.7 & $1.1-4.9$ & $41.6-91.6$ & $42.8-96.5$ & $0.9-3.7$ & $65.6-159.4$ & $66.5-163.2$ \\
\hline & 2046 & $0.2-1.0$ & $9.3-20.7$ & $9.5-21.6$ & $1.2-5.3$ & $44.5-99.1$ & $45.7-104.4$ & $0.9-3.7$ & 66.3-161.5 & $67.2-165.2$ \\
\hline & 2047 & $0.2-1.1$ & $10.7-23.8$ & $10.9-24.9$ & $1.3-5.6$ & $47.2-106.6$ & $48.6-112.2$ & 0.9-3.7 & $67.0-163.4$ & $67.8-167.1$ \\
\hline & 2048 & $0.3-1.2$ & $12.1-27.1$ & $12.4-28.3$ & $1.4-5.8$ & 49.9-113.9 & 51.3-119.7 & $0.9-3.7$ & $67.6-165.3$ & $68.5-169.0$ \\
\hline & 2049 & $0.3-1.4$ & $13.7-30.7$ & $14.0-32.1$ & $1.4-5.8$ & $52.5-121.0$ & $53.9-126.8$ & $0.9-3.7$ & $68.3-167.2$ & 69.1-170.9 \\
\hline & 2050 & $0.3-1.5$ & $15.4-34.6$ & $15.7-36.1$ & $1.4-5.8$ & $54.9-127.7$ & $56.3-133.5$ & $0.9-3.8$ & $68.9-169.0$ & $69.8-172.8$ \\
\hline $\begin{array}{l}\text { Cumul } \\
2014-\end{array}$ & $\begin{array}{l}\text { lative } \\
-2050\end{array}$ & $\begin{array}{l}2.4- \\
11.4\end{array}$ & $\begin{array}{l}107.7- \\
238.5\end{array}$ & $\begin{array}{l}110.1- \\
249.9\end{array}$ & $\begin{array}{l}13.9- \\
63.4\end{array}$ & $\begin{array}{l}584.2- \\
1275.9\end{array}$ & $\begin{array}{l}\text { 598.1- } \\
1339.3\end{array}$ & $\begin{array}{l}9.4- \\
62.9\end{array}$ & $\begin{array}{l}1185.4- \\
2726.5\end{array}$ & $\begin{array}{l}1194.8- \\
2789.4\end{array}$ \\
\hline
\end{tabular}




\begin{tabular}{|c|c|c|c|c|c|c|c|c|c|}
\hline \multirow[b]{2}{*}{ year } & \multicolumn{3}{|c|}{ slow adoption } & \multicolumn{3}{|c|}{ mid-range adoption } & \multicolumn{3}{|c|}{ rapid adoption } \\
\hline & $\begin{array}{l}\text { cradle-to- } \\
\text { gate }\end{array}$ & use-phase & total & $\begin{array}{l}\text { cradle-to- } \\
\text { gate }\end{array}$ & use-phase & total & $\begin{array}{l}\text { cradle-to- } \\
\text { gate }\end{array}$ & use-phase & total \\
\hline 2014 & $0.0-0.0$ & $0.0-0.0$ & $0.0-0.0$ & $0.0-0.0$ & $0.0-0.0$ & $0.0-0.0$ & $0.0-0.0$ & $0.0-0.0$ & $0.0-0.0$ \\
\hline 2015 & $0.0-0.0$ & $0.0-0.0$ & $0.0-0.0$ & $0.0-0.0$ & $0.0-0.0$ & $0.0-0.0$ & $0.0-0.0$ & $0.0-0.0$ & $0.0-0.0$ \\
\hline 2016 & $0.0-0.0$ & $0.0-0.0$ & $0.0-0.0$ & $0.0-0.0$ & $0.0-0.0$ & $0.0-0.0$ & $0.0-0.0$ & $0.0-0.0$ & $0.0-0.0$ \\
\hline 2017 & $0.0-0.0$ & $0.0-0.0$ & $0.0-0.0$ & $0.0-0.0$ & $0.0-0.0$ & $0.0-0.0$ & $0.0-0.0$ & $0.0-0.0$ & $0.0-0.0$ \\
\hline 2018 & $0.0-0.0$ & $0.0-0.0$ & $0.0-0.0$ & $0.0-0.0$ & $0.0-0.0$ & $0.0-0.0$ & $0.0-0.0$ & $0.0-0.0$ & $0.0-0.0$ \\
\hline 2019 & $0.0-0.0$ & $0.0-0.0$ & $0.0-0.0$ & $0.0-0.0$ & $0.0-0.0$ & $0.0-0.0$ & $0.0-0.0$ & $0.0-0.0$ & $0.0-0.0$ \\
\hline 2020 & $0.0-0.0$ & $0.0-0.0$ & $0.0-0.0$ & $0.0-0.0$ & $0.0-0.0$ & $0.0-0.0$ & $0.0-0.0$ & $0.0-0.0$ & $0.0-0.0$ \\
\hline 2021 & $0.0-0.0$ & $0.0-0.0$ & $0.0-0.0$ & $0.0-0.0$ & $0.0-0.0$ & $0.0-0.0$ & $0.0-0.0$ & $0.0-0.0$ & $0.0-0.0$ \\
\hline 2022 & $0.0-0.0$ & $0.0-0.0$ & $0.0-0.0$ & $0.0-0.0$ & $0.0-0.0$ & $0.0-0.0$ & $0.0-0.0$ & $0.0-0.1$ & $0.0-0.1$ \\
\hline 2023 & $0.0-0.0$ & $0.0-0.0$ & $0.0-0.0$ & $0.0-0.0$ & $0.0-0.0$ & $0.0-0.0$ & $0.0-0.0$ & $0.1-0.1$ & $0.1-0.1$ \\
\hline 2024 & $0.0-0.0$ & $0.0-0.0$ & $0.0-0.0$ & $0.0-0.0$ & $0.0-0.0$ & $0.0-0.0$ & $0.0-0.0$ & $0.1-0.2$ & $0.1-0.2$ \\
\hline 2025 & $0.0-0.0$ & $0.0-0.0$ & $0.0-0.0$ & $0.0-0.0$ & $0.0-0.0$ & $0.0-0.0$ & $0.0-0.0$ & $0.2-0.4$ & $0.2-0.4$ \\
\hline 2026 & $0.0-0.0$ & $0.0-0.0$ & $0.0-0.0$ & $0.0-0.0$ & $0.0-0.1$ & $0.0-0.1$ & $0.0-0.0$ & $0.4-0.8$ & $0.3-0.8$ \\
\hline 2027 & $0.0-0.0$ & $0.0-0.0$ & $0.0-0.0$ & $0.0-0.0$ & $0.1-0.1$ & $0.1-0.1$ & $0.0-0.1$ & $0.8-1.7$ & $0.8-1.7$ \\
\hline 2028 & $0.0-0.0$ & $0.0-0.0$ & $0.0-0.0$ & $0.0-0.0$ & $0.1-0.2$ & $0.1-0.2$ & $0.0-0.1$ & $1.5-3.0$ & 1.4-3.1 \\
\hline 2029 & $0.0-0.0$ & $0.0-0.0$ & $0.0-0.0$ & $0.0-0.0$ & $0.2-0.3$ & $0.2-0.4$ & $0.0-0.1$ & $2.1-4.2$ & $2.0-4.3$ \\
\hline 2030 & $0.0-0.0$ & $0.0-0.0$ & $0.0-0.1$ & $0.0-0.0$ & $0.2-0.5$ & $0.2-0.5$ & $0.0-0.1$ & $2.4-4.9$ & $2.4-5.0$ \\
\hline 2031 & $0.0-0.0$ & $0.0-0.1$ & $0.0-0.1$ & $0.0-0.0$ & $0.3-0.7$ & $0.3-0.7$ & $0.0-0.1$ & $2.6-5.3$ & $2.6-5.4$ \\
\hline 2032 & $0.0-0.0$ & $0.0-0.1$ & $0.0-0.1$ & $0.0-0.1$ & $0.5-0.9$ & $0.5-1.0$ & $0.0-0.1$ & $2.7-5.5$ & $2.7-5.6$ \\
\hline 2033 & $0.0-0.0$ & $0.1-0.1$ & $0.1-0.1$ & $0.0-0.1$ & $0.6-1.2$ & $0.6-1.3$ & $0.0-0.1$ & $2.8-5.7$ & $2.8-5.7$ \\
\hline 2034 & $0.0-0.0$ & $0.1-0.1$ & $0.1-0.2$ & $0.0-0.1$ & $0.8-1.6$ & $0.8-1.7$ & $0.0-0.1$ & $2.8-5.8$ & $2.9-5.8$ \\
\hline 2035 & $0.0-0.0$ & $0.1-0.2$ & $0.1-0.2$ & $0.0-0.1$ & $1.0-2.0$ & $1.0-2.1$ & $0.0-0.1$ & $2.9-5.9$ & $2.9-6.0$ \\
\hline 2036 & $0.0-0.0$ & $0.1-0.2$ & $0.1-0.3$ & $0.0-0.1$ & $1.2-2.4$ & $1.2-2.6$ & $0.0-0.1$ & $3.1-6.4$ & $3.1-6.5$ \\
\hline 2037 & $0.0-0.0$ & $0.1-0.3$ & $0.1-0.3$ & $0.0-0.1$ & $1.4-2.9$ & 1.4-3.1 & $0.0-0.2$ & $3.4-7.3$ & $3.4-7.6$ \\
\hline 2038 & $0.0-0.0$ & $0.2-0.4$ & $0.2-0.4$ & $0.0-0.2$ & $1.6-3.4$ & $1.7-3.6$ & $0.1-0.3$ & $3.9-8.7$ & 3.9-9.1 \\
\hline 2039 & $0.0-0.0$ & $0.2-0.5$ & $0.2-0.5$ & $0.0-0.2$ & 1.9-3.9 & $1.9-4.1$ & $0.1-0.4$ & 4.3-10.0 & 4.4-10.4 \\
\hline 2040 & $0.0-0.0$ & 0.3-0.6 & $0.3-0.6$ & $0.0-0.2$ & 2.1-4.4 & $2.1-4.6$ & $0.1-0.3$ & 4.6-10.9 & $4.6-11.2$ \\
\hline 2041 & $0.0-0.0$ & $0.3-0.7$ & $0.3-0.7$ & $0.1-0.2$ & $2.3-4.9$ & $2.4-5.1$ & $0.1-0.3$ & 4.7-11.4 & $4.8-11.7$ \\
\hline 2042 & $0.0-0.0$ & $0.4-0.8$ & $0.4-0.9$ & $0.1-0.3$ & $2.5-5.4$ & $2.6-5.7$ & $0.1-0.3$ & $4.9-11.7$ & $4.9-12.0$ \\
\hline 2043 & $0.0-0.1$ & $0.5-1.0$ & $0.5-1.1$ & $0.1-0.3$ & $2.8-5.9$ & $2.8-6.3$ & $0.1-0.3$ & 4.9-11.9 & $5.0-12.2$ \\
\hline 2044 & $0.0-0.1$ & $0.5-1.2$ & $0.5-1.2$ & $0.1-0.4$ & $3.0-6.5$ & $3.1-6.8$ & $0.1-0.3$ & $5.0-12.1$ & $5.1-12.4$ \\
\hline 2045 & $0.0-0.1$ & $0.6-1.4$ & $0.6-1.4$ & $0.1-0.4$ & $3.2-7.1$ & 3.3-7.4 & $0.1-0.3$ & $5.1-12.3$ & $5.1-12.6$ \\
\hline 2046 & $0.0-0.1$ & $0.7-1.6$ & $0.7-1.7$ & $0.1-0.4$ & $3.4-7.6$ & $3.5-8.0$ & $0.1-0.3$ & $5.1-12.4$ & $5.2-12.7$ \\
\hline 2047 & $0.0-0.1$ & $0.8-1.8$ & 0.8-1.9 & $0.1-0.4$ & $3.6-8.2$ & $3.8-8.6$ & $0.1-0.3$ & $5.2-12.6$ & $5.2-12.9$ \\
\hline 2048 & $0.0-0.1$ & $0.9-2.1$ & $1.0-2.2$ & $0.1-0.5$ & $3.8-8.8$ & $4.0-9.2$ & $0.1-0.3$ & $5.2-12.7$ & $5.3-13.0$ \\
\hline 2049 & $0.0-0.1$ & $1.1-2.4$ & $1.1-2.5$ & $0.1-0.5$ & $4.0-9.3$ & $4.2-9.8$ & $0.1-0.3$ & 5.3-12.9 & 5.3-13.2 \\
\hline 2050 & $0.0-0.1$ & $1.2-2.7$ & $1.2-2.8$ & $0.1-0.5$ & $4.2-9.8$ & $4.3-10.3$ & $0.1-0.3$ & 5.3-13.0 & 5.4-13.3 \\
\hline $\begin{array}{l}\text { Cumulative } \\
2014-2050\end{array}$ & $0.2-1.0$ & 8.3-18.4 & 8.5-19.3 & $1.2-5.2$ & $45.0-98.2$ & 46.1-103.4 & 0.9-5.1 & 91.2-209.9 & $92.1-215.0$ \\
\hline
\end{tabular}

Table S29. $\mathrm{CO}_{2} \mathrm{e}$ savings from $\mathrm{AM}$ adoption (million tons $\mathrm{CO}_{2} \mathrm{e} /$ year) 
Table S30. Cumulative primary energy savings from AM adoption, 2014-2050, in million GJ

\begin{tabular}{|c|c|c|c|c|c|c|c|c|c|c|}
\hline \multirow[t]{2}{*}{ Component system } & \multirow{2}{*}{$\begin{array}{l}\text { Component } \\
\text { category }\end{array}$} & \multicolumn{3}{|c|}{ slow adoption } & \multicolumn{3}{|c|}{ mid-range adoption } & \multicolumn{3}{|c|}{ rapid adoption } \\
\hline & & $\begin{array}{l}\text { cradle-to- } \\
\text { gate }\end{array}$ & use-phase & total & $\begin{array}{l}\text { cradle-to- } \\
\text { gate }\end{array}$ & use-phase & total & $\begin{array}{l}\text { cradle-to- } \\
\text { gate }\end{array}$ & use-phase & total \\
\hline Body systems & Auxiliary & $0-0$ & $4-14$ & $4-14$ & $0-1$ & $9-34$ & $9-35$ & $0-1$ & $17-63$ & $17-64$ \\
\hline $\begin{array}{l}\text { Furnishing and } \\
\text { equipment systems }\end{array}$ & Structural & $0-1$ & $7-19$ & $7-20$ & $0-2$ & $32-84$ & $33-86$ & $0-2$ & $52-134$ & $52-136$ \\
\hline $\begin{array}{l}\text { Furnishing and } \\
\text { equipment systems }\end{array}$ & Functional & $1-3$ & $79-150$ & $79-154$ & $2-14$ & $432-825$ & $434-839$ & $-1-11$ & $756-1442$ & $755-1453$ \\
\hline Engine & Functional & $1-5$ & $9-28$ & $11-33$ & $9-38$ & $78-231$ & $87-269$ & $7-37$ & $292-869$ & $299-906$ \\
\hline Engine & Auxiliary & $0-1$ & $5-13$ & $5-14$ & $1-4$ & $23-64$ & $24-68$ & $1-4$ & $45-125$ & $45-129$ \\
\hline Propulsion systems & Functional & $0-1$ & $2-7$ & $2-8$ & $1-4$ & $6-23$ & $7-26$ & $2-8$ & $18-69$ & $21-77$ \\
\hline Nacelle systems & Auxiliary & $0-0$ & $2-7$ & $2-7$ & $0-0$ & $4-15$ & 4-15 & $0-0$ & $7-24$ & $7-25$ \\
\hline
\end{tabular}

Table S31. Cumulative $\mathrm{CO}_{2}$ e savings from AM adoption, 2014-2050, in million tons $\mathrm{CO}_{2} \mathrm{e}$

\begin{tabular}{|c|c|c|c|c|c|c|c|c|c|c|}
\hline \multirow[t]{2}{*}{ Component system } & \multirow{2}{*}{$\begin{array}{l}\text { Component } \\
\text { category }\end{array}$} & \multicolumn{3}{|c|}{ slow adoption } & \multicolumn{3}{|c|}{ mid-range adoption } & \multicolumn{3}{|c|}{ rapid adoption } \\
\hline & & $\begin{array}{l}\text { cradle-to- } \\
\text { gate }\end{array}$ & use-phase & total & $\begin{array}{l}\text { cradle-to- } \\
\text { gate }\end{array}$ & use-phase & total & $\begin{array}{l}\text { cradle-to- } \\
\text { gate }\end{array}$ & use-phase & total \\
\hline Body systems & Auxiliary & $0.0-0.0$ & 0.3-1.1 & $0.3-1.1$ & $0.0-0.1$ & $0.7-2.7$ & $0.7-2.7$ & $0.0-0.1$ & $1.3-4.9$ & $1.3-4.9$ \\
\hline $\begin{array}{l}\text { Furnishing and } \\
\text { equipment systems }\end{array}$ & Structural & $0.0-0.1$ & $0.6-1.5$ & $0.6-1.5$ & $0.0-0.2$ & $2.5-6.5$ & $2.5-6.7$ & $0.0-0.2$ & $4.0-10.3$ & $4.0-10.5$ \\
\hline $\begin{array}{l}\text { Furnishing and } \\
\text { equipment systems }\end{array}$ & Functional & $0.0-0.3$ & 6.1-11.6 & 6.1-11.9 & $0.1-1.4$ & $33.3-63.5$ & $33.4-64.8$ & $-0.1-1.1$ & $58.2-111.0$ & 58.1-112.1 \\
\hline Engine & Functional & $0.1-0.3$ & $0.7-2.2$ & $0.8-2.5$ & $0.8-2.8$ & $6.0-17.8$ & $6.8-20.6$ & $0.7-2.8$ & $22.4-66.9$ & 23.1-69.7 \\
\hline Engine & Auxiliary & $0.0-0.1$ & $0.4-1.0$ & $0.4-1.1$ & $0.1-0.3$ & $1.8-4.9$ & $1.9-5.3$ & $0.1-0.3$ & $3.5-9.6$ & $3.5-9.9$ \\
\hline Propulsion systems & Functional & $0.0-0.1$ & $0.1-0.5$ & $0.2-0.6$ & $0.1-0.3$ & $0.5-1.7$ & $0.6-2.1$ & $0.2-0.7$ & $1.4-5.3$ & $1.6-6.0$ \\
\hline Nacelle systems & Auxiliary & $0.0-0.0$ & $0.1-0.5$ & $0.1-0.5$ & $0.0-0.0$ & $0.3-1.1$ & $0.3-1.2$ & $0.0-0.0$ & $0.5-1.9$ & $0.5-1.9$ \\
\hline
\end{tabular}




\section{References}

[1] I. Kroo. (September 2013). Aricraft Design: Synthesis and Analysis.

[2] I. Kroo and J. Alonso. (09/10/2013). Aircraft Weight Estimation. Available: http://adg.stanford.edu/aa241/structures/weights.html

[3] GE. (1999, 09/15/2013). Defining Technology for the Next Millennium. Available: http://www.google.com/url?sa=t\&rct=i\&q=\&esrc=s\&frm=1\&source=web\&cd=1\&ved=0CCoQFiA A\&url=http\%3A\%2F\%2Fwww.southampton.ac.uk\%2F jps7\%2FAircraft Design Resources\%2FPowerplant\%2FGE slides on engine costs.ppt\&ei=6AKUUrSrDeaD2gWbOYCwBA\&usg=AFQjCNFfGsjxSJzhqVYWqeoZRVZ28knKzA

[4] M. Cervenka, "The rolls-royce trent engine," Lecture note at University of Cambridge, 2000.

[5] E. H. Biel, Gary; Ervin, Bruce, "Aviation Structural Mechanic (H\& S) 3 \& 2," U. S. Navy, Ed., ed. Washington, D.C.: Naval Education and training program management support activity, 1993.

[6] T. Wohlers. (2013, 09/01/2013). State of Additive manufacturing. Available: https://http://www.google.com/url?sa=t\&rct=i\&q=\&esrc=s\&frm=1\&source=web\&cd=1\&ved=0C CwQFjAA\&url=https\%3A\%2F\%2Fregister.ornl.gov\%2F2013\%2FCOC Workshop\%2Fpresentations \%2Fwohlers.pdf\&ei=M UUsLyB8LOyAG3rYDYCA\&usg=AFQjCNEtBNJrqta2noMqpiZDxjlUBgWd2Q\&bvm=bv.57155469,d.e W0\&cad=rja

[7] S. Huang, P. Liu, A. Mokasdar, and L. Hou, "Additive manufacturing and its societal impact: a literature review," The International Journal of Advanced Manufacturing Technology, vol. 67, pp. 1191-1203, 2013/07/01 2013.

[8] J. L. Cutler, Jeremy, Understanding Aircraft Structure, 4 ed.: Wiley, 2006.

[9] S. J. Schaich, "Design of Aircraft Interior," in Improved Fire- and Smoke- Resistant Materials for Commercial Aircraft Interiors Washington, D.C., 1995, pp. 203-212.

[10] J. H. Mattingly, W; Pratt, D, Aircraft Engine Design, 2 ed.: AIAA, 2003.

[11] C. Telenko and S. Carolyn Conner, "A comparison of the energy efficiency of selective laser sintering and injection molding of nylon parts," Rapid Prototyping Journal, vol. 18, pp. 472-481, 2012.

[12] EOS. (09/12/2013). Case Study: Light-weight bracket. Available: http://www.eos.info/industries markets/aerospace/interior

[13] Airbus. (2011, 09/15/2013). Bringing new dimensions to Airbus production through Additive Layer Manufacturing. Available: http://www.airbus.com/newsevents/news-eventssingle/detail/bringing-new-dimensions-to-airbus-production-through-additive-layermanufacturing/

[14] Airbus. (2014, 07/05/2014). Printing the future: Airbus expands its applications of the revolutionary additive layer manufacturing process. Available:

http://www.airbus.com/presscentre/pressreleases/press-release-detail/detail/printing-thefuture-airbus-expands-its-applications-of-the-revolutionary-additive-layer-manufacturi/

[15] GE. (09/05/2013). GE Additive Manufacturing Lab. Available: http://www.ge.com/stories/additive-manufacturing

[16] C. Holshouser, C. Newell, S. Palas, C. Duty, L. Love, V. Kunc, et al., "Out of Bounds Additive Manufacturing," Advanced Materials \& Processes, vol. 171, pp. 15-16, March 2013.

[17] Bureau of Transportation Statistics (BTS). U.S. Air Carrier Traffic Statistics through May 2013 [Online]. Available: http://apps.bts.gov/xml/air traffic/src/index.xml

[18] Airliners.net. (08/29/2013). Aircraft Technical Data and Specification. Available: http://www.airliners.net/aircraft-data/ 
[19] DMRC, "Direct Manufacturing Research Center Annual Report 2012," DMRC, University of Paderborn, Paderborn, Gemany2012.

[20] DMRC, "Direct Manufacturing Research Center Annual Report 2013," DMRC, University of Paderborn, Paderborn, Gemany2013.

[21] J. E. Gausemeier, Niklas; Kokoschka, Martin; Wall, Marina, "Thinking Ahead the Future of Additive Manufacturing - Future Applications," DMRC, University of Paderborn, Paderborn, Germany2014.

[22] J. E. Gausemeier, Niklas; Kokoschka, Martin; Wall, Marina, "Thinking Ahead the Future of Additive Manufacturing - Analysis of Promising Industries," DMRC, University of Paderborn, Paderborn, Germany2014.

[23] J. E. Gausemeier, Niklas; Wall, Marina, "Thinking Ahead the Future of Additive Manufacturing Innovation Roadmapping of Required Advancements," DMRC, University of Paderborn, Paderborn, Germany2014.

[24] W. Cole. (2005, 09/03/2013). Boeing engineers and technologists are constantly developing better ways to design and make products. Available: http://www.boeing.com/news/frontiers/archive/2004/december/ts sf03.html

[25] Airsight. (2013, November). Additive Manufacturing. Available: http://airinsight.com/2013/10/07/additive-manufacturing/

[26] 3Dsystems. (2013, Septmeber). CRDM make a model Rolls Royce engine for Paris Air Show. Available: http://crdm.co.uk/3d-model-rolls-royce-engine-additive-manufacturing/

[27] Federal Aviation Administration (FAA), "Aerospace Forecast: Fiscal Years 2013-2033," U.S. Department of Transportation, Washington DC2013.

[28] W. Morrow, H. Qi, I. Kim, J. Mazumder, and S. Skerlos, "Environmental aspects of laser-based and conventional tool and die manufacturing," Journal of Cleaner Production, vol. 15, pp. 932-943, 2007.

[29] US Environmental Protection Agency (EPA). eGRID 2012 Version 1.0 [Online]. Available: http://www.epa.gov/cleanenergy/energy-resources/egrid/index.html

[30] S. F. Sibley, Overview of flow studies for recycling metal commodities in the United States: US Department of the Interior, US Geological Survey Reston, VA, 2011.

[31] T. Norgate, S. Jahanshahi, and W. Rankin, "Assessing the environmental impact of metal production processes," Journal of Cleaner Production, vol. 15, pp. 838-848, 2007.

[32] A. N. Laboratory(ANL), "The Greenhouse Gases, Regulated Emissions, and Energy Use in Transportation (GREET2_2012)," Argonne, IL2012.

[33] National Renewable Energy Laboratory (NREL). (2012, 11/19/2013). U.S. Life Cycle Inventory Database. Available: https://http://www.lcacommons.gov/nrel/search

[34] Argonne National Laboratory (ANL), "The Greenhouse Gases, Regulated Emissions, and Energy Use in Transportation (GREET2_2012)," Argonne, IL2012.

[35] M. F. Ashby, Materials and the environment: eco-informed material choice: Elsevier, 2012.

[36] J. M. Allwood, M. F. Ashby, T. G. Gutowski, and E. Worrell, "Material efficiency: A white paper," Resources, Conservation and Recycling, vol. 55, pp. 362-381, 2011.

[37] Granta Mateiral Inspiration. CES EDUPACK Nickel-chromium alloy, NICHROME V, annealed [Online]. Available: http://simulatentoast.files.wordpress.com/2013/03/nichrome.pdf

[38] J. Papp, "2010 Minerals Yearbook Chromium," USGS, Washington, D.C.2012.

[39] Nickel Development Institute. (12/10/2013). Machining nickel alloys. Available: http://www.nickelinstitute.org/ /Media/Files/TechnicalLiterature/MachiningNickelAlloys 11008 .pdf

[40] M. P. Groover, Fundamentals of modern manufacturing: materials processes, and systems: Wiley. com, 2007. 
[41] L. E. Murr, E. Martinez, X. M. Pan, S. M. Gaytan, J. A. Castro, C. A. Terrazas, et al., "Microstructures of Rene 142 nickel-based superalloy fabricated by electron beam melting," Acta Materialia, vol. 61, pp. 4289-4296, 2013.

[42] R. D. S. G. Campilho, M. F. S. F. de Moura, and J. J. M. S. Domingues, "Using a cohesive damage model to predict the tensile behaviour of CFRP single-strap repairs," International Journal of Solids and Structures, vol. 45, pp. 1497-1512, 2008.

[43] V. Kruzhanov and V. Arnhold, "Energy consumption in powder metallurgical manufacturing," Powder Metallurgy, vol. 55, pp. 14-21, 2012.

[44] N. Duque Ciceri, T. G. Gutowski, and M. Garetti, "A tool to estimate materials and manufacturing energy for a product," in Sustainable Systems and Technology (ISSST), 2010 IEEE International Symposium on, 2010, pp. 1-6.

[45] ecoinvent Centre. Ecoinvent data v3.1 [Online]. Available: http://www.ecoinvent.org

[46] L. N. Senyana, "Environmental impact comparison of distributed and centralized manufacturing scenarios," Rochester Institute of Technology, 2011.

[47] S. Kara and W. Li, "Unit process energy consumption models for material removal processes," CIRP Annals-Manufacturing Technology, vol. 60, pp. 37-40, 2011.

[48] J. Dahmus and T. Gutowski, "An environmental analysis of machining," in ASME International Mechanical Engineering Congress and RD\&D Exposition, Anaheim, California, USA, 2004.

[49] E. Ezugwu and Z. Wang, "Titanium alloys and their machinability-a review," Journal of Materials Processing Technology, vol. 68, pp. 262-274, 1997.

[50] D. Zhu, X. Zhang, and H. Ding, "Tool wear characteristics in machining of nickel-based superalloys," International Journal of Machine Tools and Manufacture, vol. 64, pp. 60-77, 2013.

[51] T. M. Pollock and S. Tin, "Nickel-based superalloys for advanced turbine engines: chemistry, microstructure and properties," Journal of propulsion and power, vol. 22, pp. 361-374, 2006.

[52] J. Benes. (2008). Tips for Machining Super Alloys. Available: http://americanmachinist.com/cutting-tools/tips-machining-super-alloys

[53] I. Gibson, D. W. Rosen, and B. Stucker, Additive manufacturing technologies: rapid prototyping to direct digital manufacturing: Springer, 2010.

[54] M. Baumers, C. Tuck, D. Bourell, R. Sreenivasan, and R. Hague, "Sustainability of additive manufacturing: measuring the energy consumption of the laser sintering process," Proceedings of the Institution of Mechanical Engineers, Part B: Journal of Engineering Manufacture, vol. 225, pp. 2228-2239, 2011.

[55] M. Baumers, C. Tuck, R. Hague, I. Ashcroft, and R. Wildman, "A comparative study of metallic additive manufacturing power consumption," in Proceedings of the 2010 Solid Freeform Fabrication Symposium, The University of Texas at Austin, Austin, TX, 9-11 August, 2010.

[56] M. Baumers, C. Tuck, R. Wildman, I. Ashcroft, and R. Hague, "Energy inputs to additive manufacturing: does capacity utilization matter?," EOS, vol. 1000, p. 270, 2011.

[57] M. Baumers, C. Tuck, R. Wildman, I. Ashcroft, E. Rosamond, and R. Hague, "Transparency Builtin," Journal of Industrial Ecology, vol. 17, p. 13, June 20132013.

[58] Oak Ridge National Laboratory (ORNL), "Aerospace Workshop Planning Session Summary Report," DOE/ITP/ORNL, US2010.

[59] D. Dornfeld. (2010, 12/15/2013). Green Manufacturing: Degrees of Perfection. Available: http://green-manufacturing.blogspot.com/2010/07/degrees-of-perfection.html

[60] Acram AB. (09/10/2013). EBM in Aerospace-Additive Manufacturing taken to unseen heights. Available: http://www.arcam.com/solutions/aerospace-ebm/

[61] G. Krailling and M. Novi. (2014, 06/10/2014). EOS and Airbus Group Innovations Team on Aerospace Sustainability Study for Industrial 3D Printing. Available: http://www.eos.info/eos airbusgroupinnovationteam aerospace sustainability study 
[62] T. Shinbara. (2013, 03/12/2014). Additive Manufacturing: An expose on the Diversity of Industrial use. Available: http://www.naefrontiers.org/File.aspx?id=39131

[63] Oak Ridge National Laboratory (ORNL), "Case studies for additive manufacturing: Aerospace Brackets," 2013.

[64] M. Munsch, E. Wycisk, J. Kranz, V. Seyda, and E. Claus. (2012, 09/01/2013). Functional products through laser additive manufacturing of TiAl6V4. Available: http://d12d0wzn4zozj6.cloudfront.net/pdf/LAM2012 Presentation 8.pdf

[65] The SAVING project. (2009, 09/15/2013). Innovation Results and R\&D Case Study: Redesigned airline buckle to save energy. Available: http://www.manufacturingthefuture.co.uk/case-studies/

[66] M. Tomlin and J. Meyer, "Topology Optimization of an Additive Layer Manufactured (ALM) Aerospace Part," in The 7th Altair CAE Technology Conference, Gaydon, UK, 10th May, 2011.

[67] Boeing. (2013, 09/10/2013). Who's Building the 787 Dreamliner. Available: http://www.newairplane.com/787/whos building/

[68] Boeing. History of Boeing and the Everett site. Available: http://www.boeing.com/boeing/commercial/facilities/index.page

[69] Mundi index. (09/05/2013). Primary Annual Aluminum Production Capacity In The United States, By Company. Available: http://www.indexmundi.com/en/commodities/minerals/aluminum/aluminum t2.html

[70] Mundi index. (2011, 09/05/2013). U.S. Titanium Metal Production Capacity in 2010. Available: http://www.indexmundi.com/en/commodities/minerals/titanium/titanium t2.html

[71] RUSAL. (09/10/2013). RUSAL company webstie. Available: http://www.rusal.ru/en/about/

[72] KEOBELCO. (09/06/2013). Top Titanium Manufacturer-KOBELCO. Available: http://www.kobelco.co.jp/english/titan/kobelco/index.html

[73] Wikipedia. (09/13/2013). Aluminum Corporation of China Limited. Available: http://en.wikipedia.org/wiki/Aluminum Corporation of China Limited

[74] B. Robert. (2012, 04/10/2014). ATI, GE Aviation in New Lont-Term Supply Agreement. Available: http://forgingmagazine.com/materialsmro/ati-ge-aviation-new-long-term-supply-agreement

[75] Y. Leach. (05/12/2014). Boeing 7E7 will Use Air Transport for Component Delivery. Available: http://boeing.mediaroom.com/2003-10-13-Boeing-7E7-Will-Use-Air-Transport-for-ComponentDelivery

[76] I. Google. (09/10/2013). Googel Map. Available: https://http://www.google.com/maps

[77] DOE, "Annual Energy Outlook 2014," Energy Information Administration(EIA), US Department of Energy, Washington, DC, USA2014.

[78] F. M. Bass, "A NEW PRODUCT GROWTH FOR MODEL CONSUMER DURABLES," Management Science, vol. 15, pp. 215-227, 1969.

[79] J. H. Pae and D. R. Lehmann, "Multigeneration innovation diffusion: The impact of intergeneration time," Journal of the Academy of Marketing Science, vol. 31, pp. 36-45, 2003.

[80] D. L. Greene, "Energy-efficiency improvement potential of commercial aircraft," Annual Review of Energy and the Environment, vol. 17, pp. 537-573, 1992.

[81] S. Das, D. Graziano, Upadhyayula V, E. Masanet, and M. Riddle, "Vehicle Lightweighting from a Life Cycle Energy and Emissions Perspective," 2013.

[82] D. Forsberg, "Aircraft Retirement Trends \& Outlook," Avolon2012.

[83] M. F. Niţă and D. Scholz, "Business opportunities in aircraft cabin conversion and refurbishing," Journal of Aerospace Operations, vol. 1, pp. 129-153, 2011.

[84] S. Ackert. (2012, 09/12/2013). Basics of Aircraft Maintenance Reserve Development and Management-A Lessor's Perspective of Maintenance Reserve Theory and Best Practices. Available: http://www.iata.org/whatwedo/workgroups/Documents/Paperless Supply Chain/Basics-AC-MR.pdf 
[85] H. Helms and U. Lambrecht, "The potential contribution of lightweighting to reduce transport energy consumption," The International Journal of Life Cycle Assessment, vol. 1, pp. 58-64, 2006.

[86] American Airlines. (2007, 09/20/2013). Commited to Preserving the Wonders of Our World. Available: http://www.aa.com/content/images/amrcorp/amrerr.pdf

[87] Lufthansa Group. (2011, 09/05/2013). Fuel efficiency at theLufthansa Group - Cutting costs and protectign the environment. Available:

http://www.lufthansagroup.com/fileadmin/downloads/en/LH-fuel-efficiency-0612.pdf 